\title{
André Dornfeld Vilela
}

\author{
De Câmbio Fixo a Metas para a \\ Inflação \\ Mudança Estrutural de Política Monetária \\ em um Modelo DSGE Estimado para a \\ Economia Brasileira
}

\section{DISSERTAÇÃO DE MESTRADO}

DEPARTAMENTO DE ECONOMIA

Programa de Pós-graduação em Economia 


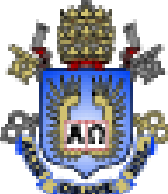

André Dornfeld Vilela

De Câmbio Fixo a Metas para a Inflação

Mudança Estrutural de Política Monetária em um Modelo DSGE Estimado para a Economia Brasileira

Dissertação de Mestrado

Dissertação apresentada como requisito parcial para obtenção do grau de Mestre pelo Programa de Pós-graduação em Economia do Departamento de Economia da PUC-Rio

Orientador: Prof. Carlos Viana de Carvalho 
André Dornfeld Vilela

\title{
De Câmbio Fixo a Metas para a Inflação \\ Mudança Estrutural de Política Monetária em um Modelo DSGE Estimado para a Economia Brasileira
}

\begin{abstract}
Dissertação apresentada como requisito parcial para obtenção do grau de Mestre pelo Programa de Pós-graduação em Economia do Departamento de Economia do Centro de Ciências Sociais da PUC-Rio. Aprovada pela Comissão Examinadora abaixo assinada.
\end{abstract}

\author{
Carlos Viana de Carvalho \\ Orientador \\ Departamento de Economia - PUC-Rio \\ Tiago Berriel \\ Departamento de Economia - PUC-Rio
}

Diogo Abry Guillén

Gávea Investimentos

Monica Herz

Coordenadora Setorial do Centro de Ciências Sociais - PUC-Rio 
Todos os direitos reservados. É proibida a reprodução total ou parcial do trabalho sem autorização da universidade, do autor e do orientador.

\section{André Dornfeld Vilela}

Banco Central do Brasil. Graduou-se em Administração de Empresas na EAESP-FGV (São Paulo, Brasil).

Vilela, André Dornfeld

De Câmbio Fixo a Metas para a Inflação:Mudança Estrutural de Política Monetária em um Modelo DSGE Estimado para a Economia Brasileira / André Dornfeld Vilela; orientador: Carlos Viana de Carvalho. - Rio de Janeiro: PUC-Rio, Departamento de Economia, 2014.

v., 92 f: il. ; $29,7 \mathrm{~cm}$

1. Dissertação (mestrado) - Pontifícia Universidade Católica do Rio de Janeiro, Departamento de Economia.

Inclui referências bibliográficas.

1. Economia - Tese. 2. Política Monetária. 3. Modelo DSGE. 4. Quebra Estrutural. 5. Estimação Bayesiana. 6. Câmbio Fixo. 7. Metas para a inflação. I. Viana de Carvalho, Carlos. II. Pontifícia Universidade Católica do Rio de Janeiro. Departamento de Economia. III. Título. 


\section{Agradecimentos}

A meus pais e irmãos, Lauro, Marisa, Flavio e Henrique.

A todos os colegas e amigos que fiz na Puc-Rio ao longo do curso de mestrado, entre os quais faço questão de mencionar os estimados Napoleão Silva, Ricardo Masini, Thiago Machado, Michele Bandarra e Murilo Ramos.

Ao Banco Central do Brasil, instituição à qual pertenço e financiadora deste período de estudos,

Ao meu orientador, o professor Carlos Viana de Carvalho, pelo excelente convívio e inestimável ajuda para a conclusão deste trabalho.

Aos membros da banca examinadora pelos comentários e contribuições.

A todos integrantes do Departamento de Economia, professores e funcionários, que fizeram parte desta importante etapa de minha trajetória profissional. 


\section{Resumo}

Vilela, André Dornfeld; Viana de Carvalho, Carlos. De Câmbio Fixo a Metas para a Inflação:Mudança Estrutural de Política Monetária em um Modelo DSGE Estimado para a Economia Brasileira. Rio de Janeiro, 2014. 92p. Dissertação de Mestrado - Departamento de Economia, Pontifícia Universidade Católica do Rio de Janeiro.

Estimamos um modelo DSGE para a economia brasileira abrangendo a transição do regime de bandas cambiais para o regime de metas para a inflação ocorrida em 1999. Utilizamos um modelo novo keynesiano de pequena economia aberta no qual o Banco Central segue uma regra de política monetária estruturalmente distinta em cada regime. Encontramos diferenças significativas na dinâmica macroeconômica e nos mecanismos de transmissão dos choques estruturais, com destaque àqueles relacionados ao setor externo da economia. Realizamos experimentos contrafactuais onde simulamos o impacto de cenários alternativos para a transição de regime na trajetória das variáveis econômicas brasileiras. Entre outros resultados, as simulações sugerem que a manutenção do sistema de bandas cambiais seria insustentável enquanto a antecipação da implementação do regime de metas para a inflação para antes da crise da Rússia de 1998 poderia deixar a economia brasileira em situação mais favorável. Por fim, mostramos que um teste de quebra estrutural aplicado sobre todo o período amostral detecta com precisão a ocorrência da mudança de regime em 1999.

\section{Palavras-chave}

Política Monetária; Modelo DSGE; Quebra Estrutural; Estimação Bayesiana; Câmbio Fixo; Metas para a inflação; 


\section{Abstract}

Vilela, André Dornfeld; Viana de Carvalho, Carlos. From Fixed Exchange Rate to Inflation Targeting: Structural Monetary Policy Change in a Estimated DSGE Model of the Brazilian Economy. Rio de Janeiro, 2014. 92p. MSc. Dissertation - Departamento de Economia, Pontifícia Universidade Católica do Rio de Janeiro.

We estimate a DSGE model of the brazilian economy taking into account the transition from the exchange rate band system to inflation targeting occurred in 1999. We use a new Keynesian small open economy model where the Central Bank follows structurally different monetary policy rules in each regime. By comparing the transmission channels of exogenous shocks we find significant differences across the regimes, specially on those shocks related to the foreign sector of the economy. We then perform counterfactual experiments where we simulate the response of key macro variables under alternative scenarios for the regime transition. Among other results our simulations suggest that the continuation of the exchange rate band system could have been unsustainable while anticipating the transition to inflation targeting before the Russian crisis of 1998 could have benefited the economy. Additionally, we show that a structural break test applied to the whole data sample correctly identifies the regime change in 1999.

\section{Keywords}

Monetary Policy; DSGE Model; Structural Break; Bayesian Estimation; Fixed Exchange Rate; Inflation Targeting; 


\section{Sumário}

$\begin{array}{lll}1 & \text { Introdução } & 10\end{array}$

2 Estimação com quebra de regime $\quad 13$

2.1 Modelo 13

2.2 Metodologia de estimação 22

2.3 Dados 29

2.4 Resultados 30

3 Experimentos contrafactuais $\quad 37$

$\begin{array}{lll}3.1 \text { Metodologia } & 37\end{array}$

$\begin{array}{lll}3.2 & \text { Resultados } & 39\end{array}$

$4 \quad$ Teste de quebra estrutural $\quad \mathbf{4 4}$

4.1 Metodologia $\quad 45$

4.2 Aplicação do teste em dados simulados 47

4.3 Aplicação do teste nos dados observados 47

4.4 Considerações finais 48

5 Conclusão $\quad 50$

Referências Bibliográficas $\quad 52$

A Derivação do modelo $\quad 55$

A.1 Condições de equilíbrio $\quad 55$

A.2 Log-linearização $\quad 58$

B Modelo log-linearizado $\quad 64$

C Filtro de Kalman com mudança de regime $\quad 66$

$\begin{array}{ll}\text { D Tabelas e figuras } & 68\end{array}$ 


\section{Lista de figuras}

2.1 Taxa de câmbio nominal e bandas cambiais. 19

D.1 VAR - Estados Unidos - 3 month / 5 year rate 69

D.2 Séries temporais transformadas utilizadas na estimação. $\quad 70$

D.3 Distribuição a priori e a posteriori - Regime de bandas cambiais. $\quad 72$

D.4 Distribuição a priori e a posteriori - Regime de metas para a inflação. 73

D.5 Resposta das variáveis a um choque contracionista de política monetária. 74

D.6 Resposta das variáveis a um choque contracionista na política monetária externa. $\quad 75$

D.7 Resposta das variáveis a um choque de custos (importações). $\quad 76$

D.8 Resposta das variáveis a um choque no prêmio de risco. $\quad 77$

D.9 Resposta das variáveis a um choque de tecnologia. 78

D.10 Choques exógenos extraídos do modelo $\quad 81$

D.11 Choques exógenos extraídos do modelo (Somente inovações) 82

D.12 Prêmio de risco: Choques exógenos e índice Embi+ Brazil (JP Morgan)

D.13 Contrafactual: Simulação dos efeitos da manutenção do regime de bandas cambiais.

D.14 Contrafactual: Simulação de uma desvalorização cambial mais acentuada no regime de bandas cambiais.

D.15 Contrafactual: Simulação da antecipação do regime de metas para a inflação - Pré-crise da Ásia 1997 / Meta 8\% a.a.

D.16 Contrafactual: Simulação da antecipação do regime de metas para a inflação - Pré-crise da Rússia 1998 / Meta 8\% a.a.

D.17 Contrafactual: Simulação da antecipação do regime de metas para a inflação - Pré-crise da Rússia 1998 / Meta 5\% a.a.

D.18 Contrafactual: Simulação da antecipação do regime de metas para a inflação - Pré-crise da Rússia 1998 / Meta 10\% a.a.

D.19 Teste de quebra: Dados simulados

D.20 Teste de quebra: Dados observados

D.21 Teste de quebra: Dados observados 


\section{Lista de tabelas}

2.1 Bandas cambiais no Brasil 19

2.2 Regra de política monetária: Comparação entre os regimes 31

4.1 Parâmetros utilizados na simulação de base de dados 47

D.1 Fontes dos dados utilizados na estimação. $\quad 68$

D.2 Distribuições a priori e a posteriori dos parâmetros.

D.3 Decomposição de variância : Regime de bandas cambiais 79

D.4 Decomposição de variância : Regime de metas para a inflação $\quad 80$ 


\section{Introdução}

A flutuação e desvalorização do Real em 1999 caracterizou uma das mudanças mais significativas na condução da política monetária no Brasil desde o início do Plano Real em 1994. O sistema de bandas de flutuação para a taxa de câmbio nominal foi abandonado e passou a vigorar o sistema de metas para a inflação. Esta transição entre regimes se deu em meio a uma sucessão de crises externas ${ }^{1}$ caracterizando um período de grande instabilidade macroeconômica na economia brasileira.

Quebras estruturais de política monetária e transmissão de choques externos são os nossos objetos de interesse neste trabalho e vamos explorálos em um modelo DSGE estimado para a economia brasileira neste período. Diante de ambientes econômicos desta natureza, marcados pela volatilidade das variáveis econômicas, a incorporação de quebras estruturais na especificação e estimação destes modelos é essencial para que capturem satisfatoriamente a dinâmica macroeconômica.

Naturalmente, a primeira questão que enfrentamos ao lidar com quebras estruturais é acerca de sua existência. Há casos em que a ocorrência da quebra é inequívoca, como foi, no caso brasileiro, a adoção do sistema de metas para a inflação em 1999. Em outros casos, a quebra não é explícita e devemos conduzir testes para a identificação da data de ocorrência. Ambas as situações serão contempladas.

No primeiro caso, seguimos a metodologia de estimação apresentada por Curdia e Finocchiaro (2012). Tendo conhecimento da data da quebra, este método permite que a política monetária seja corretamente caracterizada de acordo com as características específicas de cada regime. A estimação estrutural é realizada através de métodos bayesianos com a utilização de todo o período amostral, uma vantagem em contraponto a algumas abordagens que realizam a estimação separadamente para cada subperíodo da amostra.

Utilizamos na estimação um modelo DSGE de pequena economia aberta no qual introduzimos algumas modificações na especificação apresentada por Galí e Monacelli (2002) e Justiniano e Preston (2010). Para a incorporação da mudança de regime, assim como Curdia e Finocchiaro (2012), assumimos que os parâmetros tecnológicos e comportamentais inerentes às firmas e aos agentes são constantes nos dois subperíodos distintos, com exceção daqueles

\footnotetext{
${ }^{1}$ Crise do México em 1995, Ásia em 1997 e Rússia em 1998
} 
relacionados à política monetária. Obtemos assim duas regras de política caracterizando o comportamento distinto da autoridade monetária no regime de bandas cambiais e no regime de metas para a inflação.

Como esperado, no regime de bandas cambiais os parâmetros estimados indicam uma política monetária fortemente restrita à manutenção da taxa de câmbio nominal nos níveis desejados. Já no regime de metas para a inflação os parâmetros estimados sugerem uma política monetária mais direcionada à estabilização da inflação. Adicionalmente, verificamos um comportamento mais previsível e sistemático da autoridade monetária sob este último regime, indicado pela trajetória mais suave da taxa de juros e pela menor variância do componente não antecipado da política monetária.

Passamos à investigação das relações entre estes dois regimes de política monetária e a estabilidade macroeconômica. O objetivo é comparar os mecanismos de transmissão e propagação de choques exógenos sob cada configuração. Novamente encontramos diferenças significativas, sendo mais marcantes em relação aos choques relacionados com o setor externo da economia. A clássica propriedade da taxa de câmbio nominal flutuante de absorver este tipo de perturbação é um fator determinante para as diferenças verificadas.

São estas diferenças na dinâmica do ciclo de negócios implicadas por cada regime que nos levam a questionar o que ocorreria caso a transição do sistema de bandas cambiais para o sistema de metas para a inflação tivesse ocorrido sob outras condições. Estas transformações estruturais nas políticas monetária e cambial brasileira ocorreram em um ambiente marcado por incertezas domésticas e por uma sucessão de choques externos causados pelas crises que se sucederam.

Neste contexto, dedicamos um capítulo à realização de experimentos contrafactuais em que simulamos como configurações alternativas de política monetária impactariam a trajetória da economia brasileira frente aos choques que vieram a ocorrer neste período. O que ocorreria se o sistema de bandas cambiais não fosse abandonado? Ou se o ritmo de desvalorização seguido neste regime tivesse sido maior? E se a flexibilização cambial tivesse ocorrido antes da crise da Rússia em 1998 ou da crise asiática em 1997? Como diferentes níveis de metas para a inflação modificariam estes cenários? A partir da recuperação dos choques exógenos que ocorreram neste período iremos formular hipóteses para estes questionamentos sob a luz do nosso modelo.

Finalizamos este trabalho retomando a discussão sobre a ocorrência de quebras estruturais. Se concordamos que a correta caracterização da política monetária vigente é essencial para avaliarmos a dinâmica macroeconômica em um modelo DSGE, então é essencial que a ocorrência destas quebras seja 
identificada antes do procedimento de estimação.

Este é o tema do nosso último capítulo, em que aplicaremos um teste de hipóteses buscando evidências da manifestação de quebras estruturais na política monetária em algum outro período após a entrada em vigor do sistema de metas para a inflação, ou seja, quando desconhecemos a data de ocorrência. Para este fim, utilizaremos a metodologia de Andrews (1993).

Demonstraremos que o teste é adequado para o nosso objetivo através da aplicação deste em uma base de dados simulada que permite a quebra estrutural apenas nos parâmetros da regra de política monetária. Em seguida mostramos que o teste, quando aplicado sobre todo nosso período amostral, identifica corretamente a data de abandono do regime de bandas cambiais em 1999. Quanto ao período posterior à entrada em vigor do sistema de metas para a inflação, os resultados não apontam evidência de mudança estrutural na condução da política monetária. Há algumas considerações que devem ser feitas na interpretação destes resultados e as deixamos para discussão no capítulo.

A literatura relacionada a este trabalho é abrangente. Ela engloba os métodos bayesianos de estimação de modelos DSGE, modelos de pequena economia aberta, regimes cambiais, testes de quebra estrutural e a interpretação dos fatos econômicos ocorridos no Brasil no período aqui considerado. Ao longo da exposição de cada tema nos próximos capítulos mencionaremos as principais referências que nos guiaram.

Na sequência desta introdução, o segundo capítulo apresenta a especificação e solução do modelo de pequena economia aberta, a metodologia de estimação, os dados utilizados e os resultados da estimação, estes últimos compostos pela distribuição a posteriori e pela análise da transmissão e propagação dos choques exógenos. O terceiro capítulo apresenta a metodologia e os resultados dos experimentos contrafactuais. O quarto capítulo é dedicado ao teste de quebra estrutural. O quinto capítulo é a conclusão. Os apêndices incluem o detalhamento da derivação e log-linearização do modelo e todas as tabelas e gráficos contendo os resultados mencionados no texto. 


\section{2}

\section{Estimação com quebra de regime}

Este capítulo apresenta a especificação e solução do modelo de pequena economia aberta utilizado neste trabalho, as etapas da metodologia de estimação bayesiana incorporando quebras estruturais e os resultados desta estimação, com ênfase na comparação da distribuição a posteriori dos parâmetros estruturais e dos mecanismos de transmissão e propagação dos choques exógenos implicados por cada um dos regimes de política monetária considerados.

\section{1}

\section{Modelo}

Utilizamos como principal referência o modelo novo keynesiano de pequena economia aberta de Justiniano e Preston (2010), no qual introduzimos algumas modificações em relação à modelagem do setor externo da economia e à atuação da autoridade monetária.

Para caracterizarmos as diferenças entre os regimes de bandas cambiais e de metas para a inflação permitiremos que a regra de política monetária seja distinta em cada um dos períodos. Adicionalmente, iremos incorporar explicitamente no modelo o centro das bandas cambiais e a meta para a inflação, estando ambas as variáveis presentes na função de reação do Banco Central.

O modelo apresenta ainda indexação de inflação e rigidez de preços a la Calvo para os bens domésticos e importados, além de pass-through incompleto da taxa de câmbio devido à violação da Lei do Preço Único ${ }^{1}$.

\subsection{1}

\section{Agente representativo}

Assumimos um agente representativo maximizando utilidade esperada:

$$
\mathbb{E}_{0} \sum_{t=0}^{\infty} \beta^{t} \tilde{\varepsilon}_{g, t}\left[\frac{\left(C_{t}-h \tilde{C}_{t-1}\right)^{1-\sigma}}{1-\sigma}-\frac{N_{t}^{1+\varphi}}{1+\varphi}\right]
$$

onde $\tilde{\varepsilon}_{g, t}$ é um choque de preferências (demanda), $H_{t}=h C_{t-1}$ é um termo de formação de hábito tido como exógeno pelo agente, $N_{t}$ a oferta de trabalho, $\sigma$ o inverso da elasticidade de substituição intertemporal e $\varphi$ o inverso da elasticidade da oferta de trabalho.

${ }^{1}$ A Lei do Preço Único postula que, desconsiderados custos de transportes e outras barreiras econômicas, um bem deveria ser vendido pelo mesmo valor em mercados distintos. 
O consumo agregado é dado por:

$$
C_{t}=\left[(1-\alpha)^{\frac{1}{\eta}} C_{H, t}^{\frac{\eta-1}{\eta}}+\alpha^{\frac{1}{\eta}} C_{F, t}^{\frac{\eta-1}{\eta}}\right]^{\frac{\eta}{1-\eta}}
$$

onde $\eta$ é a elasticidade de substituição entre bens domésticos e importados e $\alpha$ é a participação dos bens importados no consumo total, uma medida do grau de abertura ao comércio externo da economia. $C_{H, t}$ e $C_{F, t}$ são cestas de bens produzidos domesticamente e importados, respectivamente, compostas através da agregação das diferentes variedades $C_{H, t}(i)$ e $C_{F, t}(i)$.

$$
C_{H, t}=\left[\int_{0}^{1} C_{H, t}(i)^{\frac{\varepsilon-1}{\varepsilon}} d i\right]^{\frac{\varepsilon}{\varepsilon-1}} \quad C_{F, t}=\left[\int_{0}^{1} C_{F, t}(i)^{\frac{\varepsilon-1}{\varepsilon}} d i\right]^{\frac{\varepsilon}{\varepsilon-1}}
$$

O agente representativo está sujeito a uma restrição orçamentária intertemporal, dada por:

$$
\begin{aligned}
& \int_{0}^{1}\left[P_{H, t}(i) C_{H, t}(i)+P_{F, t}(i) C_{F, t}(i)\right] d i+D_{t}+e_{t} B_{t}= \\
& \quad=D_{t-1}\left(1+\tilde{i}_{t-1}\right)+e_{t}+B_{t-1}\left(1+\tilde{i}_{t-1}^{*}\right) \phi_{t}\left(A_{t}\right)+W_{t} N_{t}+\Pi_{H, t}+\Pi_{F, t}+T_{t}
\end{aligned}
$$

onde $D_{t}$ sao títulos denominados em moeda doméstica e $B_{t}$ são títulos estrangeiros denominados em moeda estrangeira com respectivas taxas de juros $\tilde{i}_{t}$ e $\tilde{i}_{t}^{*}$. $W_{t}$ é a remuneração pela oferta de trabalho, $T_{t}$ sao transferências e impostos lump-sum e $\Pi_{H, t}$ e $\Pi_{F, t}$ são os lucros das firmas produtoras domésticas e das firmas importadoras, respectivamente.

A obtenção de fundos no exterior está sujeita a um prêmio de risco associado ao endividamento externo, caracterizado pela função $\phi\left(A_{t}\right)$. Formalmente, seguindo Benigno (2001) e Schmitt-Grohé e Uribe (2002), temos:

$$
\begin{gathered}
\phi_{t}=\exp \left[-\chi\left(A_{t}+\tilde{\phi}_{t}\right)\right] \\
A_{t}=\frac{\tilde{e}_{t} B_{t}}{\bar{Y} P_{t}}
\end{gathered}
$$

onde $\bar{Y}$ é o produto doméstico em estado estacionário e $\tilde{\phi}_{t}$ é um choque no prêmio de risco. Esta forma funcional é utilizada para garantir estacionariedade no endividamento externo e permite introduzir um choque economicamente interpretável necessário para a estimação do modelo.

Sob esta especificação, a alocação ótima de consumo dentro de cada categoria de produtos (domésticos e importados) implica nas seguintes funções de demanda por cada variedade destes:

$$
C_{H, t}(i)=\left(\frac{P_{H, t}(i)}{P_{t}}\right)^{-\epsilon} \quad \text { e } \quad C_{F, t}(i)=\left(\frac{P_{F, t}(i)}{P_{t}}\right)^{-\epsilon}
$$


com respectivos índices de preços para cada categoria dados por:

$$
P_{H, t}=\left(\int_{0}^{1} P_{H, t}(i)^{1-\epsilon} d i\right)^{\frac{1}{1-\epsilon}} \quad \text { e } P_{F, t}=\left(\int_{0}^{1} P_{F, t}(i)^{1-\epsilon} d i\right)^{\frac{1}{1-\epsilon}}
$$

A decisão de consumo também implica na alocação ótima entre cada categoria, gerando as seguintes funções de demanda agregadas:

$$
C_{H, t}=(1-\alpha)\left(\frac{P_{H, t}}{P_{t}}\right)^{-\eta} C_{t} \quad C_{F, t}=\alpha\left(\frac{P_{F, t}}{P_{t}}\right)^{-\eta} C_{t}
$$

a partir das quais obtemos o índice de preços geral da economia:

$$
P_{t}=\left[(1-\alpha) P_{H, t}^{1-\eta}+\alpha P_{F, t}^{1-\eta}\right]^{\frac{1}{1-\eta}}
$$

Dada estas demandas, o agente maximiza sua utilidade esperada (21) sujeita à restrição orçamentária (2-4) decidindo o quanto irá consumir, trabalhar e investir, gerando as seguintes condições de otimalidade:

$$
\begin{gathered}
W_{t} / P_{t}=N_{t} \varphi\left(C_{t}-h C_{t-1}\right)^{\sigma} \\
\varepsilon_{g, t}\left(C_{t}-h C_{t-1}\right)^{-\sigma}=\beta \mathbb{E}_{t}\left[\varepsilon_{g, t+1}\left(C_{t+1}-h C_{t}\right)^{-\sigma}\left(1+i_{t}\right) / \pi_{t+1}\right] \\
\left(1+i_{t}\right)=\mathbb{E}_{t}\left[\frac{e_{t+1}}{e_{t}} \phi_{t+1}\right]\left(1+i_{t}^{*}\right)
\end{gathered}
$$

A equação (2-11) define a oferta ótima de trabalho, a equação (212) é a equação de Euler padrão e a equação (2-13) é uma condição de arbitragem restringindo os movimentos relativos das taxas de juros domésticas e estrangeiras e da taxa de câmbio nominal.

\subsection{2}

\section{Firmas: Produtores domésticos}

\section{Tecnologia}

Há um contínuo de firmas idênticas operando em concorrência monopolística indexadas por $i \in[0,1]$. Cada firma produz bens diferenciados $y_{H, t}(i)$ utilizando apenas trabalho como insumo e estão sujeitas a um mesmo choque de tecnologia, dado por $\tilde{\epsilon}_{a, t}$. A função de produção individual é representada pela equação (2-14), o custo marginal real pela equação (2-15) e o lucro individual a cada período pela equação (2-16) .

$$
\begin{gathered}
y_{H, t}(i)=\tilde{\epsilon}_{a, t} N_{t}(i) \\
M C_{H, t}=\frac{W_{t}}{\tilde{\epsilon}_{a, t} P_{H, t}}
\end{gathered}
$$




$$
\Pi_{H, t}(i)=y_{H, t}(i)\left(P_{H, t}(i)-P_{H, t} M C_{H, t}\right)
$$

Os bens produzidos são substitutos imperfeitos, o que implica que cada firma possui algum grau de poder de monopólio na fixação de seu preço e portanto está sujeita a uma curva de demanda negativamente inclinada, apresentada na equação (2-7).

\section{Mecanismo de precificação}

Assumimos que a precificação segue um mecanismo de Calvo (1983) com indexação de preços. Assim, em cada período $t$ há uma fração $\left(1-\theta_{H}\right)$ de firmas que reajustam seus preços de maneira ótima, enquanto o restante $0 \leq \theta_{H} \leq 1$ seguem uma regra de indexação na forma da equação (2-17), ou seja, o preço praticado no período anterior é automaticamente corrigido pela inflação dos bens domésticos.

$$
P_{H, t}(i)=P_{H, t-1}\left(\frac{P_{H, t-1}}{P_{H, t-2}}\right)^{\delta_{H}}
$$

O parâmetro $\delta_{H}$ representa o grau de indexação à inflação passada. Como cada firma tem a oportunidade de reajustar otimamente seus preços em algum período $t$, todas enfrentam a mesma decisão de precificação diante da possibilidade de reajuste dos preços, e consequentemente irão escolher o mesmo preço $P_{H, t}^{*}(i)=P_{H, t}^{*}$. Portanto, o índice agregado de preços para os bens domésticos evolui de acordo com a seguinte regra:

$$
P_{H, t}=\left[\left(1-\theta_{H}\right) P_{H, t}^{*(1-\varepsilon)}+\theta_{H}\left(P_{H, t-1}\left(\frac{P_{H, t-1}}{P_{H, t-2}}\right)^{\delta_{H}}\right)^{1-\varepsilon}\right]^{1 /(1-\varepsilon)}
$$

As firmas vendem seus bens tanto no mercado doméstico como no mercado externo. Assumindo que a demanda externa possui a mesma forma funcional da demanda doméstica (2-7), uma firma que reajustou seu preço no período $t$ está sujeita à seguinte sequência de demandas:

$$
y_{H, t+\tau \mid t}=\left(\frac{P_{H, t}^{*}}{P_{H, t+\tau}}\left(\frac{P_{H, t+\tau-1}}{P_{H, t-1}}\right)^{\delta_{H}}\right)^{-\varepsilon}\left(C_{H, t+\tau}+C_{H, t+\tau}^{*}\right)
$$

Uma firma escolhendo o preço ótimo no período $t$ maximiza o valor presente do seu lucro esperado(2-20), levando em consideração a probabilidade de não ser possível reajustar seus preços futuramente e sujeita à sequência de demandas (2-19).

$$
\mathbb{E}_{t} \sum_{\tau=0}^{\infty} \theta_{H}^{\tau} Q_{t, t+\tau} y_{H, t+\tau \mid t}\left[P_{H, t}^{*}\left(\frac{P_{H, t+\tau-1}}{P_{H, t-1}}\right)^{\delta_{H}}-P_{H, t+\tau} M C_{t+\tau}\right]
$$


onde $Q_{t, t+\tau}=\beta^{\tau} \frac{\tilde{\varepsilon}_{g, t+\tau}}{\tilde{\varepsilon}_{g, t}} \frac{P_{t}}{P_{t+\tau}} \frac{U_{c, t+\tau}}{U_{c, t}}$ é o fator de desconto intertemporal implicado pelo comportamento do consumidor.

\subsection{3}

\section{Firmas: Varejistas importadores domésticos}

Os varejistas domésticos importam bens diferenciados e os revendem aos consumidores no mercado doméstico. O setor varejista também é caracterizado por competição monopolística de maneira que cada firma possui um certo grau de poder de monopólio ao fixar seu preço de revenda. Ou seja, as importações estão sujeitas a precificação em moeda local, o que acarreta em desvios da Lei do Preço Único ${ }^{2}$.

O problema de precificação dos varejistas domésticos é análogo ao dos produtores domésticos. Consideramos um mecanismo de Calvo (1983) com indexação, sendo $\theta_{F}$ o parâmetro da rigidez de preços e $\delta_{F}$ o parâmetro de indexação. O índice de preços agregado para os bens importados $P_{F, t}$ e a regra de indexação possuem portanto formas funcionais análogas às equações (2-18) e (2-17) respectivamente.

As firmas que reajustarem seus preços em um determinado período $t$ determinam um preço $P_{F, t}^{*}$ de maneira a maximizarem o valor presente dos lucros esperados (2-21) sujeitas à sequência de demandas (2-22), levando em conta a probabilidade de não poderem reajustar seus preços no futuro.

$$
\begin{gathered}
\mathbb{E}_{t} \sum_{\tau=0}^{\infty} \theta_{F}^{\tau} Q_{t, t+\tau} C_{F, t+\tau \mid t}\left[P_{F, t}^{*}\left(\frac{P_{F, t+\tau-1}}{P_{F, t-1}}\right)^{\delta_{F}}-\tilde{e}_{t+\tau} P_{F, t+\tau}^{*}\right] \\
C_{F, t+\tau \mid t}=\left(\frac{P_{F, t}^{*}}{P_{F, t+\tau}}\left(\frac{P_{F, t+\tau-1}}{P_{F, t-1}}\right)^{\delta_{F}}\right)^{-\varepsilon} C_{F, t+\tau}
\end{gathered}
$$

\subsection{4}

\section{Lei do preço único, taxas de câmbio e termos de troca}

Os termos de troca $S_{t}$ representam o preço relativo das importações e das exportações de uma economia.

$$
S_{t}=P_{F, t} / P_{H, t}
$$

A taxa de câmbio nominal é dada por $\tilde{e}_{t}$ e taxa de câmbio real $\tilde{q}_{t}$ é definida como:

$$
\tilde{q}_{t}=\tilde{e}_{t} P_{t}^{*} / P_{t}
$$

${ }^{2}$ A Lei do Preço Único postula que, desconsiderados custos de transportes e outras barreiras econômicas, um bem deveria ser vendido pelo mesmo valor em mercados distintos. 
Podemos notar que esta relação se mantém independentemente do grau de pass-through existente na economia.

Definimos a diferença de preços entre o preço do produto importado no mercado externo e no mercado doméstico, em moeda local, como:

$$
\tilde{\Psi}_{F, t}=\tilde{e}_{t} P_{t}^{*} / P_{F, t}
$$

Quando $\tilde{\Psi}_{F, t} \neq 1$ verificamos o que Monacelli(2005) denomina como Desvio da Lei do Preço Único.

Em a relação à paridade descoberta da taxa de juros derivada das condições de otimalidade do agente representativo, a expressão log-linearizada é dada por:

$$
i_{t}=i_{t}^{*}+\mathbb{E}_{t} e_{t+1}+e_{t}-\chi a_{t}+\varepsilon_{s, t}
$$

onde:

$$
\varepsilon_{s, t}=\rho_{s} \varepsilon_{s, t}+\sigma_{s} \epsilon_{s, t}
$$

\subsection{5}

\section{Autoridade monetária}

Assumimos que a política monetária é caracterizada por uma regra de juros distinta para cada regime. Na primeira parte da amostra, correspondente ao sistema de bandas cambiais, iremos modelar explicitamente a reação da autoridade monetária aos desvios da taxa de câmbio nominal em relação ao seu nível desejado. Na segunda parte da amostra, correspondente ao sistema de metas para a inflação, utilizamos uma regra de Taylor na qual a taxa de juros responde a desvios da inflação em relação a meta, nível do produto e variação da taxa de câmbio nominal.

\section{Regime de bandas cambiais}

Dentro do processo de estabilização econômica deflagrado pelo Plano Real, em março de 1995 houve uma modificação estrutural na condução da política cambial brasileira com a adoção do sistema de bandas cambiais pelo Banco Central do Brasil.

Neste sistema haveria livre flutuação da taxa de câmbio entre limites mínimos e máximos estabelecidos pela autoridade monetária. A manutenção da taxa de câmbio nominal dentro dos limites estabelecidos era administrada com o auxílio de intervenções do Banco Central no mercado de câmbio comprando ou vendendo moeda estrangeira.

Naturalmente, a taxa de câmbio nominal também dependia diretamente da taxa de juros doméstica uma vez que o diferencial de juros entre a economia 
doméstica e externa é um dos fatores determinantes do fluxo de capitais estrangeiros entre países.

A tabela 2.1 apresenta os limites inferiores e superiores para a taxa de câmbio nominal adotados pelo Banco Central enquanto este regime cambial vigorou.

Tabela 2.1: Bandas cambiais no Brasil

\begin{tabular}{ccc}
\hline \hline Início & $\begin{array}{c}\text { Banda Inferior } \\
(\mathrm{R} \$ / \mathrm{US} \$)\end{array}$ & $\begin{array}{c}\text { Banda Superior } \\
(\mathrm{R} \$ / \mathrm{US} \$)\end{array}$ \\
\hline $06 / 03 / 95$ & 0.86 & 0.90 \\
$10 / 03 / 95$ & 0.88 & 0.93 \\
$22 / 06 / 95$ & 0.91 & 0.99 \\
$30 / 01 / 96$ & 0.97 & 1.06 \\
$18 / 02 / 97$ & 1.05 & 1.14 \\
$20 / 01 / 98$ & 1.12 & 1.22 \\
\hline
\end{tabular}

Para fins de modelagem da regra de juros utilizada durante o regime de bandas cambiais iremos assumir que a autoridade monetária tem como objetivo a manutenção da taxa de câmbio nominal no centro das bandas cambiais. Esta premissa é compatível com o comportamento da taxa de câmbio nominal neste período como pode ser observado na figura 2.1.

Figura 2.1: Taxa de câmbio nominal e bandas cambiais.
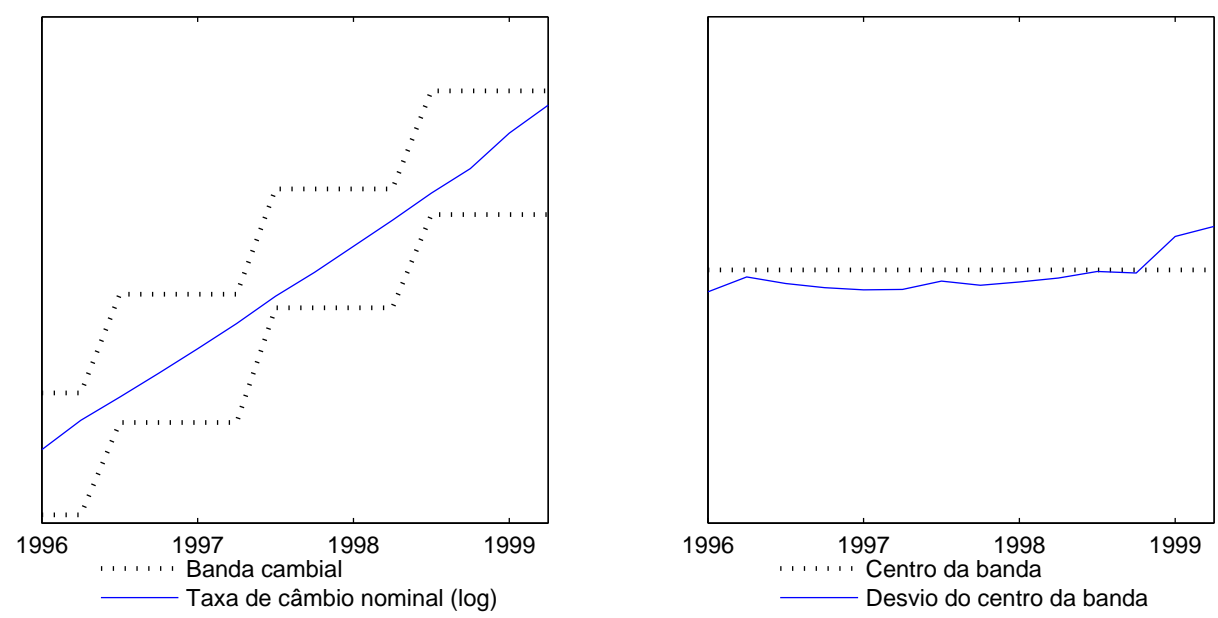

Como ressaltam Curdia e Finocchiaro (2012), o sistema de bandas cambiais, comparado a um sistema de câmbio fixo puro, proporciona aos Bancos Centrais maior flexibilidade na administração da taxa de câmbio. Embora o 
Banco Central esteja restrito a utilizar seu instrumento de política para manter a taxa de câmbio dentro do intervalo desejado, a política monetária, respeitada esta restrição, pode ainda ser utilizada para outros propósitos. Portanto, iremos representar a política monetária neste regime por uma regra de Taylor modificada, que além das variáveis usuais (inflação e produto), inclui o desvio da taxa de câmbio nominal do centro das bandas cambiais.

$$
i_{t}=\rho_{i, 1}^{B C} i_{t-1}+\rho_{i, 2}^{B C} i_{t-2}+\left(1-\rho_{i, 1}^{B C}-\rho_{i, 2}^{B C}\right)\left(\lambda_{\pi}^{B C} \pi_{t}+\lambda_{y}^{B C} y_{t}+\lambda_{e}^{B C} e_{x, t}\right)+\varepsilon_{m, t}^{B C}
$$

onde definimos $e_{x, t}$ como o desvio da taxa de câmbio nominal do centro das bandas cambiais $e_{c, t}$. Assim:

$$
e_{x, t}=e_{t}-e_{c, t}
$$

Para fins que discutiremos no capítulo posterior, assumimos que a variação do centro da banda cambial segue um processo $\mathrm{AR}(1)$ exógeno:

$$
\begin{gathered}
e_{c, t}-e_{c, t-1}=g_{t} \\
g_{t}=\rho_{g} g_{t-1}+\varepsilon_{g, t}
\end{gathered}
$$

Ainda sobre a regra de política monetária representada pela equação 2-27 incluímos duas defasagens da taxa de juros para capturar o interesse da autoridade monetária em suavizar a trajetória dos juros. Por fim, $\varepsilon_{m, t}$ é um choque de política exógeno, que pode ser interpretado como o componente não sistemático da política monetária.

\section{Regime de metas para a inflação}

A política monetária no regime de metas para a inflação, em vigor desde junho de 1999, será caracterizada por uma regra de Taylor modificada. Embora a política cambial neste regime seja a de livre flutuação da taxa de câmbio nominal, iremos permitir uma resposta da autoridade monetária à variação cambial do período ${ }^{3}$. Definimos então a regra ${ }^{4}$ :

$i_{t}=\rho_{i, 1}^{I T} i_{t-1}+\rho_{i, 2}^{I T} i_{t-2}+\left(1-\rho_{i, 1}^{I T}-\rho_{i, 2}^{I T}\right)\left[\lambda_{\pi}^{I T}\left(\pi_{t}-\pi_{t}^{M}\right)+\lambda_{y}^{I T} y_{t}+\lambda_{e}^{I T} \Delta e_{t}\right]+\varepsilon_{m, t}^{I T}$

${ }^{3}$ Possibilidade de ocorrência de algum grau de flutuação suja (Dirty Float).

${ }^{4}$ Caracterização similar para a regra de política monetária é encontrada nos trabalhos de Curdia e Finocchiaro (2012) para o caso da Suécia, de Del Negro e Schorfheide (2008) para o caso do Chile, e de Justiniano e Preston (2010) para os casos de Canadá, Nova Zelândia e Austrália. 
onde a interpretação dos parâmetros é análoga ao exposto para o sistema de bandas cambiais e $\pi_{t}^{M}$ é a meta para a inflação do período, a qual modelamos como um processo exógeno autocorrelacionado.

$$
\pi_{t}^{M}=\rho_{\pi}^{M} \pi_{t-1}^{M}+\sigma_{\pi}^{M} \epsilon_{\pi^{M}, t}
$$

As equações que representam a regra de política monetária são as únicas que são dependentes do regime de política.

\subsection{6}

\section{Setor externo}

Consideramos a economia doméstica como uma pequena economia aberta, e portanto a dinâmica das variáveis econômicas domésticas não afeta o setor externo, tratado como exógeno e estimado como um VAR(1) com choques identificados por ordenação de Cholesky ${ }^{5}$.

A estrutura do $\operatorname{VAR}(1)$ é apresentada em seguida, sendo $Y_{t}^{*}$ o produto externo, $\pi_{t}^{*}$ a inflação externa e $i_{t}^{*}$ a taxa de juros externa. $\varepsilon_{y}^{*}, \varepsilon_{\pi}^{*}$ e $\varepsilon_{i}^{*}$ são os respectivos choques não correlacionados.

$$
A_{0}\left[\begin{array}{c}
Y_{t}^{*} \\
\pi_{t}^{*} \\
i_{t}^{*}
\end{array}\right]=A_{1}\left[\begin{array}{c}
Y_{t-1}^{*} \\
\pi_{t-1}^{*} \\
i_{t-1}^{*}
\end{array}\right]+\left[\begin{array}{c}
\varepsilon_{y}^{*} \\
\varepsilon_{\pi}^{*} \\
\varepsilon_{i}^{*}
\end{array}\right]
$$

onde as matrizes com os coeficientes são:

$$
A_{0}=\left[\begin{array}{ccc}
1 & 0 & 0 \\
a_{0, \pi y} & 1 & 0 \\
a_{0, i y} & a_{0, i \pi} & 1
\end{array}\right] \quad A_{t}=\left[\begin{array}{ccc}
a_{t, y y} & a_{t, y \pi} & a_{t, y i} \\
a_{t, \pi y} & a_{t, \pi \pi} & a_{t, \pi i} \\
a_{t, i y} & a_{t, i \pi} & a_{t, i i}
\end{array}\right] \quad t=1
$$

\subsection{7}

\section{Equilíbrio geral}

O equilíbrio no mercado de bens doméstico requer que o produto doméstico seja equivalente ao consumo dos bens domésticos consumidos domesticamente e exportados.

$$
Y_{t}=C_{H, t}+C_{H, t}^{*}
$$

Para a demanda externa pelos bens produzidos domesticamente consideramos a seguinte forma funcional:

${ }^{5}$ Os coeficientes do $\operatorname{VAR}(1)$ são estimados previamente e mantidos fixos durante a estimação da economia doméstica. 


$$
C_{H, t}^{*}=\left(\frac{P_{H, t}^{*}}{P_{t}^{*}}\right)^{-\lambda} Y_{t}^{*}
$$

Para fins de simplificação iremos assumir que o parâmetro $\lambda$, que representa a elasticidade de substituição entre bens domésticos e importados no mercado externo, seja igual ao parâmetro $\eta$, seu análogo no mercado doméstico.

Assumimos ainda que em equilíbrio não haja endividamento doméstico em termos líquidos, de maneira que $D_{t}=0$ em todo período.

\subsection{8}

\section{Estrutura dos choques}

Há oito choques estruturais no modelo ${ }^{6}$, sendo cinco na economia doméstica e três relacionados ao setor externo. Os choques estruturais relacionados à economia doméstica são: preferências, tecnologia, prêmio de risco, custos e política monetária. Para os quatro primeiros assumimos um processo estocástico AR(1). Para o choque de política monetária e choques no setor externo assumimos processos i.i.d.

$$
\begin{gathered}
\varepsilon_{a, t}=\rho_{a} \varepsilon_{a, t-1}+\sigma_{a} \epsilon_{a, t} \\
\varepsilon_{g, t}=\rho_{g} \varepsilon_{g, t-1}+\sigma_{g} \epsilon_{g, t} \\
\varepsilon_{c p, t}=\rho_{c p} \varepsilon_{c p, t-1}+\sigma_{c p} \epsilon_{c p, t} \\
\varepsilon_{s, t}=\rho_{s} \varepsilon_{s, t-1}+\sigma_{s} \epsilon_{s, t} \\
\varepsilon_{m, t}=\sigma_{m} \epsilon_{m, t} \\
\varepsilon_{y^{*}, t}=\sigma_{y^{*}} \epsilon_{y^{*}, t} \\
\varepsilon_{\pi^{*}, t}=\sigma_{\pi^{*}} \epsilon_{\pi^{*}, t} \\
\varepsilon_{i^{*}, t}=\sigma_{i^{*}} \epsilon_{i^{*}, t} \\
\epsilon_{x, t} \sim N(0,1) ; \quad \mathbb{E}\left[\epsilon_{x} \epsilon_{y}\right]=0, x \neq y ; \quad \mathbb{E}\left[\epsilon_{x, t} \epsilon_{x, s}\right]=0, t \neq s
\end{gathered}
$$

\section{2}

\section{Metodologia de estimação}

O conjunto das equações comportamentais dos agentes, regras de política, restrições agregadas, condições de equilíbrio de mercado e dos choques estruturais exógenos define o modelo DSGE que desejamos estimar.

\footnotetext{
${ }^{6}$ Não estamos computando os choques relacionados aos processos estocásticos da meta para a inflação e da variação do centro da banda cambial, que somente serão utilizados na realização dos experimentos contrafactuais no capítulo 3 .
} 
Nosso modelo é composto por dois conjuntos de equações, um para o regime de bandas cambiais e outro para o regime de metas para a inflação. Estes sistemas de equações são compostos pelas variáveis endógenas do modelo, expressas em função de seus valores passados, correntes e das expectativas para seus valores futuros, além das inovações estruturais exógenas que afetam a economia a cada período.

O objetivo da estimação é obter conhecimento sobre o conjunto de parâmetros estruturais da economia, representados pelo vetor $\theta$, tendo em consideração a mudança explícita de regime de política monetária ocorrida em 1999 quando o Banco Central do Brasil adotou o sistema de metas para a inflação. Diante deste fato, antes de descrevermos os métodos econométricos utilizados é importante ressaltar como a existência da quebra de regime de política impacta a estimação.

Há na literatura uma distinção entre quebra "pura", em que todo o vetor de parâmetros está sujeito a mudanças, e quebra "parcial" em que apenas alguns componentes do vetor de parâmetros estão sujeitos a mudanças.

No caso do modelo deste trabalho, estamos diante de uma quebra "parcial". Como apresentado na seção 2.1, apenas os parâmetros referentes à regra de política monetária estão sujeitos a variações entre os regimes. Assim podemos reescrever o vetor $\theta$ como:

$$
\theta=\left(\delta_{0}, \beta_{B C}, \beta_{I T}\right)
$$

onde $\delta_{0}$ são os parâmetros invariantes, enquanto $\beta_{B C}$ são parâmetros associados ao modelo válido para o regime de bandas cambiais e $\beta_{I T}$ parâmetros associados ao modelo válido para o regime de metas para a inflação.

Segundo Curdia e Finocchiaro (2012), sob esta configuração, se optássemos por estimar separadamente os parâmetros para cada regime dividindo a amostra em duas partes, estaríamos incorrendo em uma perda de informação que poderia ser evitada. Neste artigo, os autores realizam a estimação de um modelo DSGE para a economia sueca, abordando explicitamente a mudança de regime de metas de paridade cambial para o regime de metas para a inflação também ocorrido naquele país. Os autores utilizam métodos bayesianos na estimação e apresentam uma contribuição metodológica que permite que os parâmetros invariantes e os específicos a cada regime de poítica monetária sejam estimados conjuntamente.

Dada a semelhança da mudança de regime ocorrida nos dois países (Brasil e Suécia), iremos utilizar neste trabalho uma metodologia semelhante à destes autores, descrita nas próximas subseções. 


\subsection{1}

\section{Métodos bayesianos}

A estimação dos parâmetros do modelo foi realizada através de métodos bayesianos, seguindo metodologia usualmente adotada na literatura recente sobre o tema. As principais etapas da estimação serão discutidas brevemente em seguida. An e Schorfheide (2006), Fernandez-Villaverde (2009) e Guerron-Quintana e Nason (2012) apresentam uma exposição detalhada destes métodos e uma revisão abrangente dos desenvolvimentos recentes na área.

\section{2 .2}

\section{Aproximação log-linear}

A não linearidade e grande escala características dos modelos DSGE novo keynesianos tornam inviável a obtenção de uma solução de forma fechada para o sistema de equações formado pelas condições de otimalidade do modelo, razão pela qual utilizamos métodos de linearização que viabilizem uma solução aproximada.

Utilizamos uma aproximação log-linear das condições de equilíbrio ao redor de um estado estacionário não estocástico caracterizado por inflação zero e comércio balanceado.

A seção A.2 do apêndice apresenta em detalhes a log-linearização de todo o sistema de equações. O conjunto completo de equações log-linearizadas utilizadas na estimação encontra-se no apêndice B.

\subsection{3}

\section{Solução do modelo}

Uma vez obtido o conjunto de equações lineares que define o modelo estacionário para cada regime, estes podem ser expressos em representação matricial:

$$
\mathbb{E}_{t}\left\{f^{j}\left(X_{t+1}, X_{t}, X_{t-1}, \epsilon_{t+1}, \epsilon_{t} ; \theta\right)\right\}=0 \quad j=B C, I T
$$

onde $\theta$ é o vetor de parâmetros estruturais do modelo DSGE, $X_{t}$ é um vetor contendo as variáveis endógenas e $\epsilon_{t}$ é o vetor contendo as inovações estruturais exógenas, as quais assumimos serem processos gaussianos independentes satisfazendo as seguintes propriedades:

$$
\epsilon_{t} \sim N\left(0, \Sigma_{\epsilon}\right) ; \quad \mathbb{E}\left[\epsilon_{t} \epsilon_{s}\right]=0 \quad t \neq s
$$

Para obtermos uma solução para um modelo desta natureza, ou seja, uma trajetória para as variáveis endógenas em cada período, precisamos expressar 
estas variáveis em função do conjunto de informação disponível. Há potencialmente múltiplas soluções para os sistemas em 2-35, mas estamos interessados em soluções únicas e estáveis, de maneira que as variáveis endógenas possuam uma trajetória identificada e retornem a seu valor de estado estacionário após um choque.

Alguns dos métodos de solução frequentemente utilizados são: Sims (2002), Klein (2000) e Blanchard e Kahn (1980). Neste trabalho adotamos a metodologia de Sims, obtendo para cada conjunto de equações uma solução na qual as variáveis endógenas são expressas em função de seus valores passados e dos choques estruturais contemporâneos.

$$
X_{t}=A^{j}(\theta) X_{t-1}+B^{j}(\theta) \epsilon_{t} \quad j=B C, I T
$$

Estas equações matriciais são a representação em forma reduzida do modelo DSGE, que assume a estrutura de um modelo VAR. A diferença crucial é que as restrições impostas nos coeficientes das matrizes são originadas nos fundamentos econômicos do modelo, enquanto a identificação em modelos VAR não estão relacionadas a um modelo explícito.

\subsection{4}

\section{Representação estado-espaço}

A próxima etapa na preparação do modelo para a estimação consiste em obter uma relação direta entre o sistema em forma reduzida 2-36 e os dados observados que compõem a amostra. Esta relação é expressa através da representação estado-espaço, composta por uma equação de transição e uma equação de observação.

As equações de transição são específicas para cada regime e são os próprios sistemas em forma reduzida apresentados em 2-36. A equação de observação é a mesma para ambos os regimes e é dada por:

$$
Y_{t}=C(\theta) X_{t}+D(\theta) \omega_{t}
$$

onde $Y_{t}$ é o vetor de variáveis observadas e $\omega_{t}$ são potenciais erros de medida atribuídos aos dados utilizados. A composição do vetor observável $Y_{t}$ é discutida na seção 2.3.

Havendo suficiente número de choques estruturais e erros de medida, é possível calcular a função de verossimilhança para o vetor observável $Y_{t}$ dado um vetor de parâmetros $\theta$ através do filtro de Kalman ${ }^{7}$.

\footnotetext{
${ }^{7}$ Ver Hamilton (2004).
} 


\subsection{5}

\section{Distribuição a posteriori}

Como exposto por Guerron-Quintana e Nason (2012) o objetivo da estimação bayesiana é caracterizar a distribuição a posteriori $P\left(\theta \mid Y_{T}\right)$ dos parâmetros $\theta$ do modelo DSGE condicional aos dados da amostra $Y_{T}$.

A estimação bayesiana explora o fato que a distribuição a posteriori é proporcional à função de verossimilhança do modelo DSGE $L\left(Y_{T} \mid \theta\right)$, multiplicada pela distribuição a priori $P(\theta)$ atribuída aos parâmetros do modelo.

$$
P\left(\theta \mid Y_{T}\right) \propto L\left(Y_{T} \mid \theta\right) \times P(\theta)
$$

Com a aplicação do filtro de Kalman na representação estado-espaço do modelo, calculamos a função de verossimilhança, que combinada com a distribuição a priori, permite a avaliação do valor da função de densidade $a$ posteriori.

Utilizando métodos de otimização numérica ${ }^{8}$, obtemos uma estimativa aproximada da moda da distribuição a posteriori dos parâmetros estruturais. Em seguida, utilizamos estas estimativas como ponto de partida para o algoritmo MH-MCMC (Metropolis Hastings - Markov Chain Monte Carlo) obtendo uma simulação da distribuição marginal de cada parâmetro. ${ }^{9}$.

A partir desta distribuição simulada, estimativas pontuais do vetor de parâmetros $\theta$ podem ser obtidas utilizando estatísticas de localização como a média ou mediana. De maneira similar, medidas de incerteza a respeito dos valores dos parâmetros podem ser obtidas computando o desvio padrão ou intervalos de probabilidade.

\footnotetext{
${ }^{8}$ Utilizamos o algoritmo de otimização para Matlab csminwel.m elaborado por Christopher Sims. Disponível em http://sims.princeton.edu/yftp/optimize.

${ }^{9}$ Utilizamos três cadeias de 200.000 observações para verificar a convergência da distribuição a posteriori.
} 


\subsection{6}

\section{Filtro de Kalman com mudança de regime}

Para incorporar a mudança de regime na estimação utilizamos a metodologia apresentada por Curdia e Finocchiaro (2012). O ponto de partida deste método consiste em reescrever a distribuição a posteriori considerando explicitamente as duas subamostras referentes a cada regime de política monetária. Assim temos:

$$
P\left(\theta \mid Y_{T}\right) \propto L\left(Y_{t \in B C} \mid \theta\right) \times L\left(Y_{t \in I T} \mid \theta\right) \times P(\theta)
$$

onde $L\left(Y_{t \in T Z} \mid \theta\right)$ e $L\left(Y_{t \in T Z} \mid \theta\right)$ correspondem às funções de verossimilhança dos dados para o períodos relacionados ao regime de bandas cambiais e regime de metas para a inflação respectivamente, calculadas com a utilização do filtro de Kalman. O apêndice $\mathrm{C}$ apresenta em detalhes o procedimento utilizado. A principal modificação deste método em relação ao procedimento usual de estimação diz respeito a como conectar os dois regimes ao aplicar o processo recursivo do filtro de Kalman.

Sobre a justificativa em se adotar esta metodologia de estimação, é importante termos em mente que ao lidarmos com quebras de regime devemos nos posicionar sobre as crenças dos agentes a respeito da probabilidade de ocorrência desta quebra.

Por um lado, estas expectativas podem ser explicitamente modeladas, como no trabalho de Davig e Leeper (2006), em que atribuem um processo de Markov switching à regra de política monetária em modelos DSGE.

Como alternativa, ao utilizarmos esta versão modificada do filtro de Kalman, como em Curdia e Finocchiaro (2012), estamos assumindo que a mudança de regime não foi antecipada. Embora seja uma premissa forte, visto que não podemos descartar que alguns agentes atribuíam uma probabilidade da quebra de regime ocorrer, esta premissa permite utilizarmos este método mais simplificado de estimação.

Podemos argumentar em favor desta premissa que na ausência das crises da Ásia em 1997 e da Rússia em 1998, a trajetória mais provável da política cambial seria a continuidade da desvalorização cambial gradual implicada pelo sistema de bandas cambiais. E portanto, somente no curto período entre a crise russa no fim de 1998 e a mudança de regime no início de 1999 teríamos os agentes atribuindo uma probabilidade mais elevada para a flutuação cambial. 


\subsection{7}

\section{Distribuição a priori}

A próxima etapa é a especificação da distribuição a priori para os parâmetros que desejamos estimar. Esta especificação consiste na seleção da forma funcional desta distribuição, assim como sua moda e variância.

A forma funcional é selecionada de maneira a estabelecer restrições convenientes no suporte de cada parâmetro. Utilizamos a distribuição beta para parâmetros restritos ao intervalo entre zero e um, a distribuição gama ou gama inversa para parâmetros que assumem valores positivos e a distribuição normal para parâmetros não limitados.

Para a atribuição da moda e variância agrupamos os parâmetros em duas categorias: a primeira corresponde aos parâmetros estruturais referentes a preferências, tecnologia, friç̧ões reais, rigidez nominal e política; a segunda engloba os parâmetros que caracterizam os choques exógenos. Para o primeiro grupo, a distribuição a priori é em geral informativa e se utiliza evidência empírica prévia. Para o segundo grupo, a estratégia é atribuir modas razoáveis e uma densidade com suporte amplo, ou seja uma distribuição pouco informativa.

Estimamos 28 parâmetros e as principais características da distribuicão a priori atribuída a cada um deles são apresentadas na tabela D.2. Utilizamos como principal referência as distribuições a priori utilizadas por de Castro et al. (2011) no modelo SAMBA, um DSGE de larga escala escala para a economia brasileira elaborado e estimado pelos autores.

Portanto, seguindo o modelo SAMBA, atribuímos ao parâmetro $\sigma$, o inverso da elasticidade de substituição intertemporal, uma distribuição gama com moda 1.30. Ao parâmetro $h$, referente à formação de hábito de consumo, uma distribuição beta com moda 0.85 . Ao parâmetro $\chi$, a elasticidade do prêmio de risco ao endividamento externo, atribuímos uma distribuição gama com moda 0.02

Ainda segundo o modelo de de Castro et al. (2011), atribuímos aos parâmetros de Calvo $\theta_{H}$ e $\theta_{F}$, correspondentes à rigidez nominal, uma distribuição beta com moda 0.65 e desvio padrão de 0.1 . Em relação aos parâmetros de indexação de preços $\delta_{F}$ e $\delta_{H}$ utilizamos também uma distribuição beta com moda 0.65 e desvio padrão de 0.2 visando uma distribuição mais difusa.

Para o parâmetro $\eta$, a elasticidade de substituição entre bens domésticos e importados, seguimos Justiniano e Preston (2010) e utilizamos uma distribuição gama com moda 1.0 e um desvio padrão de 0.5 , devido às diferentes estimativas encontradas para este parâmetro em trabalhos empíricos, como justificam estes autores. 
Em relação aos parâmetros da regra de política monetária utilizamos distribuições idênticas e relativamente difusas para os dois regimes de modo que as diferenças observadas após a estimação possam ser atribuídas à informação contida nos dados. Para os parâmetros $\rho_{i, 1}$ e $\rho_{i, 2}$, referentes a suavização da taxa de juros, atribuímos uma distribuição beta com moda 0.6 e desvio padrão de 0.15. Seguindo Curdia e Finocchiaro (2012), atribuímos aos parâmetros $\lambda_{\pi}$, $\lambda_{y}$ e $\lambda_{e}$, distribuições gama com modas $2.0,0.25$ e 1.5 respectivamente.

Para os parâmetros relacionados aos choques, seguimos novamente o modelo SAMBA e adotamos distribuições difusas. Utilizamos para os coeficientes autorregressivos distribuição beta com moda 0.5 e desvio padrão de 0.25 , enquanto para os parâmetros relacionados à variância dos choques exógenos, a distribuição atribuída é a gama inversa com moda 1.0 e desvio padrão de 0.75 .

Por fim, há alguns parâmetros que foram calibrados. Seguindo de Castro et al. (2011), o parâmetro $\beta$, o fator de desconto intertemporal, foi calibrado em 0.989 e o parâmetro $\phi$, o inverso da elasticidade de substituição de trabalho foi fixado em 1.0. O parâmetro $\alpha$, que pode ser interpretado como o grau de abertura da economia foi fixado em 0.25 , sendo este valor obtido através da razão entre o volume da corrente de comércio exterior (importações somadas às exportações anuais) e o produto interno bruto brasileiro no período amostral.

\section{3}

\section{Dados}

Os dados utilizados para a estimação correspondem a oito variáveis que compõem o vetor de observáveis $Y_{t}$ do modelo: produto doméstico, taxa de juros doméstica, inflação doméstica, termos de troca, taxa de câmbio nominal, produto externo, taxa de juros externa e inflação externa. A fonte de dados para cada série utilizada pode ser verificada na tabela D.1 do apêndice D.

$$
Y_{t}=\left(y_{t}, i_{t}, p i_{t}, s_{t}, e_{t}, y_{t}^{*}, i_{t}^{*}, \pi_{t}^{*}\right)
$$

A periodicidade da base de dados é trimestral e se inicia no terceiro trimestre de 1995 com fim no segundo trimestre de 2013. O período considerado para o regime de bandas cambiais se encerra no quarto trimestre de 1998. Mesmo com a flutuação cambial tendo ocorrido em fevereiro de 1999 consideramos o primeiro trimestre de 1999 pertencente ao período referente ao regime de metas para a inflação.

As séries de dados transformadas utilizadas na estimação são apresentadas na figura D.1 do apêndice. Utilizamos os valores em $\log$ de todas as séries e subtraímos a tendência linear, com exceção para o gap do produto doméstico, 
calculado como a diferença entre a série e a tendência extraída pelo filtro HP, e também das séries da taxa de câmbio nominal e inflação domésticas, cujas transformações são abordadas em seguida.

Há um fator complicador na utilização das séries do centro das bandas cambiais e das metas para a inflação, dado que estas séries se aplicam especificamente a somente um dos regimes considerados. Portanto optamos por não incluí-las como variáveis observadas e assumir algumas premissas simplificadoras para que as séries da taxa de câmbio nominal e de inflação incorporem de maneira aproximada estes dados.

Quanto à taxa de câmbio nominal, começamos por calcular a tendência linear do centro das bandas cambiais durante o período em que vigora este regime. Em seguida, extrapolamos esta tendência para todo o período amostral e subtraímos da taxa de câmbio nominal. Desta maneira, a série da taxa de câmbio nominal representará o próprio desvio do centro da banda cambial, que é a quantidade de interesse na função de reação da autoridade monetária para este regime. Como no regime de metas para a inflação a regra de política monetária não considera este desvio, mas sim a variação da taxa de câmbio nominal, este procedimento nos fornecerá as duas medidas corretamente.

Em relação à inflação doméstica, subtraímos a média da própria série durante todo o período amostral ${ }^{10}$. A consequência desta transformação é a perda da variabilidade das metas que houve no início deste regime, antes de se estabilizar no patamar de $4.5 \%$ a.a. a partir de 2005. Apesar da simplificação, este procedimento não inviabiliza a comparação das regras de política monetária entre os regimes em relação à resposta da taxa de juros à variação do índice de preços ${ }^{11}$.

Por fim, utilizamos para as variáveis do setor externo as séries de dados da economia dos Estados Unidos.

\section{4}

\section{Resultados}

\subsection{1}

\section{Distribuição a posteriori}

A tabela D.2 apresenta a moda e o desvio padrão da distribuição $a$ posteriori obtida para cada parâmetro estimado. A tabela apresenta em primeiro lugar os parâmetros estruturais invariantes e em seguida os parâmetros indexados por $B C$ e $I T$, que assumem valores distintos no regime de bandas cambiais

\footnotetext{
${ }^{10}$ Realizamos também a estimação com a série de inflação subtraída da média das metas para a inflação e as estimativas dos parâmetros se mantiveram estáveis.

${ }^{11}$ Esta simplificação também é utilizada em Curdia e Finocchiaro (2012).
} 
e de metas para a inflação respectivamente. A comparação entre as distribuições a priori e a posteriori também pode ser visualizada nas figuras D.3 e D.4, que apresentam os histogramas das distribuições obtidas no procedimento de simulação ${ }^{12}$.

Estamos particularmente interessados em verificar se há diferenças significativas nos parâmetros referentes à regra de política monetária associada a cada regime e de fato as encontramos. Esta comparação é resumida na tabela 2.2 em seguida.

Tabela 2.2: Regra de política monetária: Comparação entre os regimes

\begin{tabular}{ccccc}
\hline \hline & \multicolumn{2}{c}{$1995 / \mathrm{Q} 2$ a $1998 / \mathrm{Q} 4$} & \multicolumn{2}{c}{$1999 / \mathrm{Q} 2$ a $2013 / \mathrm{Q} 2$} \\
Parâmetro & Moda & DP & Moda & DP \\
\hline$\rho_{i, 1}$ & 0.32 & 0.07 & 0.57 & 0.06 \\
$\rho_{i, 2}$ & 0.30 & 0.03 & 0.22 & 0.03 \\
$\lambda_{\pi}$ & 1.43 & 0.15 & 1.94 & 0.11 \\
$\lambda_{y}$ & 0.49 & 0.03 & 0.55 & 0.06 \\
$\lambda_{e} / \lambda_{\Delta e}$ & 1.75 & 0.11 & 0.16 & 0.04 \\
$\sigma_{m}$ & 1.47 & 0.11 & 0.92 & 0.08 \\
\hline
\end{tabular}

Podemos observar que os parâmetros da regra de política estimada refletem as principais características que esperávamos verificar para cada regime. Em primeiro lugar, no regime de bandas cambiais destacamos a magnitude da resposta da taxa de juros ao desvio da taxa de câmbio nominal do centro da banda cambial. A moda estimada para o parâmetro $\lambda_{e}$ é de 1.75 , refletindo a vinculação da política monetária para a manutenção da taxa de câmbio nominal nos centro da banda.

Já para o regime de metas para a inflação verificamos, como esperado, que a autoridade monetária passa a responder com maior intensidade à variação de preços. O coeficiente $\lambda_{\pi}$ tem moda estimada de 1.43 no regime de bandas cambiais e 1.94 no regime de metas para a inflação.

Verificamos também nos parâmetros estimados a redução da volatilidade da taxa básica de juros, expressa pelo parâmetro $\sigma_{m}$, cuja moda no regime de metas para a inflação é inferior ao valor obtido para o regime de bandas cambiais. Esta redução era esperada visto que os choques externos passam a ser absorvidos pela flutuação da taxa de câmbio nominal e porque a política monetária sob o regime de metas para a inflação é implementada através de diretrizes predefinidas, o que reduz a variância do componente não sistemático

\footnotetext{
${ }^{12}$ Apresentamos apenas os histogramas dos parâmetros variáveis para efeitos de comparação entre os regimes.
} 
da regra de política monetária. Esta maior previsibilidade da taxa básica também está refletida nos parâmetros $\rho_{i, 1}$ e $\rho_{i, 2}$, que apontam para uma trajetória mais suave da taxa de juros sob o regime de metas para a inflação.

Por fim comparamos o coeficiente $\lambda_{y}$ referente a resposta da taxa de juros ao desvio do produto de seu nível potencial. O resultado da estimação sugere uma resposta com maior intensidade verificada no regime de metas para a inflação, em que a moda estimada foi de 0.55 contra 0.49 para o regime de bandas cambiais. É interessante ressaltar que, com exceção deste último parâmetro, as diferenças entre os dois regimes verificadas na estimação são semelhantes às encontradas por Curdia e Finocchiaro (2012) para o caso da economia sueca. No trabalho destes autores, os parâmetros estimados apontaram sentido oposto, ou seja, uma redução do coeficiente relacionado ao nível de atividade econômica quando implementado o sistema de metas para a inflação.

Em relação aos parâmetros invariantes, os resultados obtidos são semelhantes aos verificados em outros trabalhos na literatura de estimação de modelos DSGE de economia aberta ${ }^{13}$.

\subsection{2}

\section{Mecanismos de transmissão e propagação dos choques}

A importância da correta caracterização da política monetária associada a cada regime fica evidente quando analisamos os canais de transmissão e propagação dos choques exógenos. Nesta seção comparamos as funções de resposta a impulso implicadas por cada regime e constatamos que a dinâmica das variáveis macroeconômicas em reação a cada choque apresenta diferenças quantitativas e qualitativas, especialmente quando relacionadas a choques relacionados ao setor externo da economia. Em seguida mostramos que estas diferenças também se manifestam na contribuição de cada choque para a volatilidade das principais variáveis do modelo através de uma análise de decomposição de variância.

\section{A. Choque contracionista de politica monetária doméstica - Figura D.5}

Estamos diante do caso clássico da ineficácia da política monetária sob um regime de câmbio fixo, decorrente do comprometimento da autoridade monetária com a manutenção da taxa de câmbio nominal em um nível predeterminado. O choque de política monetária neste caso é apenas ilustrativo, visto que o aumento da taxa de juros desestabiliza a taxa de câmbio e é imediata-

\footnotetext{
${ }^{13}$ Por exemplo, os parâmetros $\sigma, h, \theta_{H}$ e $\chi$ foram estimados no modelo SAMBA em 1.26, $0.65,0.74$ e 0.03 respectivamente. São valores semelhantes embora o modelo SAMBA tenha maior escala.
} 
mente revertido no período seguinte para trazer a cotação de volta ao centro da banda cambial. Já no regime de metas para a inflação a taxa de juros nominal é um instrumento com maior eficácia para a estabilização dos preços e do nível de atividade, como pode ser constatado nos gráficos, em que uma contração monetária de mesma magnitude provoca efeitos amplificados na variação do nível de atividade e na inflação. Ainda sob o arranjo de câmbio flexível, a apreciação da moeda doméstica induzida pelo aumento do diferencial de juros reduz o preço dos importados e desloca consumo para estes bens, contribuindo assim para a reduções adicionais da inflação e do produto.

B. Choque contracionista de política monetária externa - Figura D.6

Quando a contração monetária é gerada no exterior haverá pressão para a depreciação da moeda doméstica. No regime de bandas cambiais em geral verificamos um comportamento positivamente correlacionado da autoridade monetária doméstica, reagindo com o aumento da taxa de juros para manter a taxa de câmbio nominal nos níveis desejados, ocasionando redução do consumo e de atividade econômica.

No regime de metas para a inflação transparece a propriedade de absorção de choques externos da taxa de câmbio flutuante, um resultado já apontado por Friedman (1966) em seu ensaio "The Case for Flexible Exchange Rates" onde argumenta que em havendo rigidez de preços, um regime de câmbio flutuante possui a propriedade de isolar a economia de choques externos, pois permite o ajuste de preços relativos mais rápidos.

De fato podemos constatar nos gráficos o comportamento relativamente estável da taxa de juros, produto, inflação e consumo após o aperto monetário externo, assim como é nítida a absorção do choque através da depreciação da taxa de câmbio nominal.

Um resultado aparentemente não intuitivo é o aumento inicial do produto doméstico em resposta a um choque externo contracionista. Entretanto, como argumenta Monacelli (2000), sob câmbio flexível, uma contração monetária gerada no exterior pode ser transmitida via dois canais de sinais opostos. Um deles opera através da depreciação da moeda doméstica, aumento das exportações e do produto. No outro a demanda agregada externa decresce e com ela a demanda por exportações. O efeito dominante se alterna em diferentes estudos empíricos. No caso aqui estudado, a redução da demanda externa é mais do que compensada pelo aumento dos lucros do setor exportador.

C. Choque de custos (importações) - Figura D.7

Este choque pode ser interpretado como uma variação ineficiente de mark-up no mecanismo de precificação dos importadores. O aumento do preço 
dos produtos importados ocasiona uma depreciação nos termos de troca, o que eleva o custo marginal e consequentemente os preços domésticos, relação esta representada pela curva de Phillips. Este choque gera uma pressão para apreciação da moeda doméstica.

No regime de metas para a inflação, a taxa de câmbio nominal se ajusta a seu novo nível de equilíbrio e a autoridade monetária eleva a taxa nominal de juros para conter a pressão inflacionária, o que diminui o consumo corrente e o nível de atividade. Além disso, a apreciação cambial prejudica o setor exportador, contribuindo para a redução do produto.

No regime de bandas cambiais, a autoridade monetária irá manter a taxa de câmbio nominal no nível anterior ao choque. É interessante notar neste caso que a inflação dos produtos importados foi ocasionada por um desvio da $L e i$ do Preço Único, devido ao mark-up ineficiente aplicado pelos importadores. Assim, embora a taxa de câmbio nominal permaneça em um patamar estável acima de seu nível de equilíbrio, observamos uma apreciação da taxa de câmbio real. O efeito positivo no produto doméstico que o câmbio desvalorizado gera via aumento de exportações líquidas no mecanismo de transmissão de outros choques não se manifesta nesse caso. O maior nível de atividade econômica verificada neste regime se deve ao menor patamar da taxa de juros nominal, que estimula o consumo corrente.

D. Choque no prêmio de risco - Figura D.8

O choque exógeno no prêmio de risco é importante na medida em que impacta diretamente a taxa de câmbio nominal, invalidando a paridade descoberta da taxa de juros. No caso da economia brasileira, alguns estudos empíricos concluem que esta condição de paridade é flagratemente violada, como argumenta Garcia (2001). No caso de um aumento do prêmio de risco a pressão para a depreciação da moeda doméstica terá efeitos bem distintos em cada um dos regimes monetários. No regime de bandas cambiais o efeito imediato é a elevação da taxa de juros para conter a apreciação cambial. Embora a inflação dos produtos importados seja contida com este movimento, os efeitos contracionistas se manifestam na redução do produto, consumo e inflação doméstica. Quando passamos ao regime de metas para a inflação verificamos novamente o impacto positivo do câmbio desvalorizado sobre o setor exportador, o que ocasiona o aumento inicial do produto doméstico, devido àquele efeito prevalecer sobre a contração da atividade doméstica induzida pelo aumento da taxa de juros nominal. 


\section{E. Choque de tecnologia - Figura D.9}

É interessante também compararmos os efeitos de um choque real sob ambos os regimes monetários. Consideremos portanto um choque tecnológico positivo na economia, tal que o ganho de eficiência das firmas induza uma redução dos preços domésticos. Em ambos os regimes verificamos uma deterioração dos termos de troca e uma pressão para a apreciação cambial.

Entretanto, no regime de bandas cambiais, a manutenção da taxa de câmbio nos níveis anteriores ao choque significa que a mesma estará acima de seu novo nível de equilíbrio, e portanto desvalorizada, gerando um incremento das exportações líquidas e portanto da atividade econômica. Sob o arranjo de câmbio flutuante, note que embora a expansão do produto seja de menor magnitude, o componente de consumo é mais elevado. Isto se deve ao deslocamento de demanda interna para bens importados somado ao estímulo ao consumo corrente ocasionado pela redução mais acentuada da taxa de juros nominal. Ou seja, o choque tecnológico gera efeitos positivos na atividade econômica em ambos regimes mas a composição do produto entre consumo e exportações líquidas é distinta.

\section{F. Decomposição de Variância - Tabelas D.3 e D.4}

Enquanto as funções de resposta a impulso apresentadas anteriormente permitem visualizarmos o mecanismo de transmissão dos choques exógenos tomados isoladamente, a análise da decomposição da variância das variáveis econômicas em cada regime de política nos permite avaliar a importância relativa de cada choque para a volatilidade da economia.

As tabelas D.3 e D.4 apresentam a decomposição da variância para horizontes de tempo de 1, 4 e 20 trimestres. Em cada linha, temos a participação relativa de cada choque para a volatilidade de algumas variáveis selecionadas.

Concentraremos nossa análise nos choques relacionados ao setor externo da economia, os quais agrupamos entre os originados diretamente no exterior e o choque no prêmio de risco, vinculado diretamente à economia brasileira.

O primeiro grupo consiste nos choques originados na economia americana $\left(Y^{*}, \pi^{*}, i^{*}\right)$, tomada como o setor externo na estimação. Verificamos que o choque de política monetária externa tem maior participação na volatilidade da taxa de câmbio nominal no regime de metas para a inflação, ao mesmo tempo em que afeta em menor intensidade produto, inflação e taxa de juros domésticas, o que confirma o papel de absorção de choques externos atribuído ao câmbio flutuante. Já no regime de bandas cambiais, a maior contribuição deste choque para a volatilidade da taxa de juros doméstica ilustra a restrição imposta à política monetária pela manutenção da taxa de câmbio nominal dentro das bandas cambiais. 
Quanto ao choque no prêmio de risco $\varepsilon_{s}$ destacamos o fato de que este é o principal componente da volatilidade da taxa de câmbio nominal em ambos os regimes, sendo também mais relevante no regime de metas para a inflação. Ainda em relação ao setor externo, notamos que, tomados em conjunto, os choques $\left(Y^{*}, \pi^{*}, i^{*}\right)$ possuem participação moderada na variância de todas as variáveis selecionadas, indicando que as principais fontes de volatilidade doméstica estão associadas a fatores internos. 


\section{3}

\section{Experimentos contrafactuais}

As transformações estruturais nas políticas monetária e cambial que marcaram o período pós Plano Real se deram em meio a um ambiente de incertezas e instabilidade macroeconômica. Os choques externos que afetavam a economia brasileira neste período exigiam respostas adequadas e imediatas do governo. De acordo com Goldfajn (2000),

On top of the lack of competitiveness and poor GDP growth, fiscal performance deteriorated in 1997 and 1998 which led the Brazilian economy to be vulnerable to external shocks. There were three major external shocks after the Real plan, the Tequila effect in 1995, the Asian crisis in 1997 and the Russian crisis in 1998. The reaction to the crisis was similar in all cases. Nominal interest rates were doubled and a fiscal package promised. This strategy was successful in averting a crisis after the Tequila and Asia shocks. However, after the Russian crisis, this same strategy had a perverse effect. Instead of attracting capital, the strategy this time induced capital outflows. The reason was that the fiscal package was not credible and the higher interest rates increased nominal fiscal deficits and raised fears of a sovereign default. As a consequence, large withdrawals followed and the currency came under pressure.

Decorrida esta fase de transição econômica podemos nos questionar sobre quais seriam os impactos de respostas alternativas de política monetária frente aos choques que vieram a ocorrer neste período.

Este é o objetivo deste capítulo. Vamos estimar os choques exógenos ocorridos no período em questão e conduzir alguns experimentos contrafactuais em que simulamos as trajetórias de algumas variáveis econômicas sob diferentes configurações de política monetária.

\section{1}

\section{Metodologia}

Para recuperar os choques exógenos que afetaram a economia brasileira no contexto do modelo utilizado neste trabalho utilizamos o algoritmo de suavização de Kalman, um método comumente utilizado na literatura de estimação de modelos DSGE ${ }^{1}$.

Resumidamente, após realizarmos a estimação dos parâmetros estruturais via métodos bayesianos, tomamos suas estimativas pontuais e então aplica-

\footnotetext{
${ }^{1}$ Nos referimos a Bauer et al. (2003) pra uma exposição detalhada sobre esta metodologia.
} 
mos o algoritmo de suavização de Kalman sobre a representação estado-espaço de cada regime, obtendo assim uma estimativa da série de qualquer variável não observada do modelo condicional a todos os dados da amostra.

Entre estas variáveis não observadas estão os choques estruturais exógenos, compostos por distúrbios gaussianos independentes aos quais atribuímos um processo estocástico específico, geralmente autorregressivo.

Apresentamos o resultado deste procedimento no apêndice D. Enquanto na figura D.10 temos os oito choques exógenos do modelo, a figura D.11 apresenta apenas o componente de inovação dos mesmos.

Os experimentos contrafactuais são realizados com a aplicação das inovações de um determinado período na representação estado-espaço de interesse. Podemos então simular como seria a trajetória da economia se a política monetária fosse distinta da que vigorava quando ocorreram os choques.

No caso deste trabalho, após a obtenção de estimativas dos parâmetros associados a cada regime de política monetária, obtivemos duas representações estado-espaço distintas, uma associada ao regime de bandas cambiais e outra ao regime de metas para inflação.

A estas estruturas iremos adicionar os processos que regem o deslocamento do centro das bandas cambiais e das metas para a inflação, pois não foram incluídos explicitamente na estimação.

Como já discutido na apresentação do modelo teórico, para o centro das bandas cambiais o processo estocástico é atribuído à variação e não ao nível desta variável, o que nos permitirá simular diferentes taxas de desvalorização ou apreciação cambial, calibrando convenientemente o parâmetro $\rho_{g}$ e a magnitude do choque $\epsilon_{g, t}$ :

$$
\begin{gathered}
e_{c, t}-e_{c, t-1}=g_{t} \\
g_{t}=\rho_{g} g_{t-1}+\epsilon_{g, t}
\end{gathered}
$$

Para as metas para a inflação, assumimos que esta é regida por um processo autorregressivo persistente, e calibramos o parâmetro $\rho_{\pi}^{M}$ em 0,99 . Portanto para simularmos diferentes níveis de meta de inflação basta atribuir choques $\epsilon_{\pi^{M}, t}$ adequados.

$$
\pi_{t}^{M}=\rho_{\pi}^{M} \pi_{t-1}^{M}+\epsilon_{\pi^{M}, t}
$$

Em um modelo de expectativas racionais é fundamental atribuirmos uma lei de movimento para o centro da banda cambial e para as metas para a inflação para que os agentes incorporem a nova trajetória destas variáveis em suas decisões. Não podemos tratá-los como uma sucessão de choques que 
ocorrem a cada período pois os agentes econômicos só reagem aos choques após a ocorrência dos mesmos, dada a natureza imprevisível destes.

Entretanto, mais relevante que a estrutura assumida para estes choques é a interpretação econômica que nos permitimos atribuir a estas variáveis. Como ressalta Bauer et al. (2003), os choques exógenos são claramente condicionados ao modelo teórico utilizado.

\section{2 \\ Resultados}

O propósito da realização dos experimentos contrafactuais é a formulação hipóteses a respeito dos prováveis rumos que a economia brasileira seguiria em determinado momento caso uma política monetária alternativa estivesse em vigor. Estes resultados, assim como os choques exógenos recuperados, também são condicionados ao modelo utilizado.

Esta ressalva é importante pois as hipóteses que apresentaremos poderiam ser melhor fundamentadas se incluíssemos em nosso modelo elementos cruciais para a condução da política monetária no período, como por exemplo o nível de reservas internacionais utilizadas para as intervenções no mercado de câmbio e a sustentabilidade do serviço da dívida em razão das altas taxas de juros praticadas.

Contudo, a ausência destes componentes não invalida os resultados que apresentamos nesta seção, apenas exige que os interpretemos tendo em mente as restrições impostas pelo modelo teórico utilizado. Ainda, o julgamento de valoração que atribuímos às diferentes políticas devem ser tomados apenas como hipóteses. Desconsideramos nesta análise os efeitos de segunda ordem que seriam implicados ao bem estar dos agentes.

Os resultados dos três experimentos realizados são apresentados no apêndice D. Concentramos nossa análise nos períodos próximos ao abandono do regime de bandas cambiais em 1999.

Para a apresentação dos resultados foram desfeitas as transformações das séries temporais ${ }^{2}$. A unidade da taxa de juros nominal é a taxa trimestral anualizada. Para a inflação utilizamos a variação percentual trimestral. A taxa de câmbio nominal está expressa em seu nível. Produto, consumo e termos de troca são apresentados em números índice.

A - Manutenção do regime de bandas cambiais - Figura D.13

Neste experimento pretendemos avaliar o que ocorreria se o regime de bandas cambiais não fosse abandonado no início de 1999. Para a simulação,

\footnotetext{
${ }^{2}$ Reincorporamos as tendências e médias subtraídas e desfazemos as transformações logaritmicas.
} 
reconstruímos as séries utilizando a partir de 1999 a representação estadoespaço do regime de bandas cambiais. Assumimos também que as bandas manteriam a taxa de desvalorização cambial de aproximadamente $7 \%$ a.a.

Começando por uma breve descrição do ambiente econômico àquela época, a economia brasileira apresentava um quadro recessivo e estava diante de um cenário externo desfavorável. A taxa de câmbio tida como apreciada impactava negativamente a balança comercial e contribuía para a grande perda de reservas utilizadas para a manutenção dos limites das bandas cambiais. Somados aos fatores internos, os efeitos da crise da Ásia em 1997 e da Rússia em 1998 vieram agravar ainda mais a vulnerabilidade externa da economia brasileira.

A crise cambial iminente deflagrou um grande movimento de fuga de capitais no início de 1999, e em fevereiro deste ano foi adotado o sistema de câmbio flutuante. Nos primeiros dois meses do novo regime observamos uma desvalorização cambial de aproximadamente $50 \%$, fomentada adicionalmente pelas incertezas acerca do desempenho da economia brasileira sob este novo arranjo.

Voltando ao experimento contrafactual, verificamos que a manutenção do regime de bandas cambiais sob o mesmo ritmo de desvalorização exigiria a continuidade das taxas de juros elevadas nos períodos que seguem a flutuação cambial para a contenção dos choques que pressionavam pela desvalorização do câmbio. Cabe ressaltar que mesmo após a flutuação cambial a taxa básica de juros já tinha atingido patamar superior a $45 \%$ a.a. no primeiro trimestre de 1999. Outro efeito marcante nos gráficos é que o quadro recessivo já presente na economia seria agravado com a contração monetária e com a manutenção da taxa de câmbio apreciada.

Deixando à parte considerações sobre os efeitos que as taxas de juros mais elevadas teriam sobre as reservas internacionais e serviço da dívida e nos retendo a nosso modelo estilizado, o experimento contrafactual favorece a opinião predominante que a manutenção do regime de bandas cambiais seria insustentável.

Complementando a análise, na figura D.10 podemos verificar que os choques de prêmio de risco e de política monetária ambos exerceram pressão para desvalorização cambial nos anos seguintes à flutuação. E são exatamente estes os choques que contribuem com maior intensidade para a volatilidade de curto prazo da taxa de câmbio nominal no regime de bandas cambiais, como demonstrado na análise de decomposição de variância (tabela D.3).

B - Ritmo de desvalorização cambial mais acentuado - Figura D.14

Como já mencionado, as bandas cambiais sofreram reajustes anuais de 
aproximadamente $7 \%$ ao ano enquanto este sistema esteve em vigor. Nesta simulação iremos dobrar o ritmo de reajuste para os três últimos anos deste regime, resultando em uma desvalorização adicional acumulada ao final de 1998 de $25 \%$.

Nos restringindo ao período anterior à mudança de regime, observamos diferenças significativas na trajetória da economia neste período. Por um lado, como pode ser observado no incremento dos termos de troca, a desvalorização fortalece o setor exportador gerando impacto positivo para o crescimento econômico. Por outro, a desvalorização encarece os produtos importados, gerando pressão inflacionária. O resultado é o aumento da taxa de juros para fazer frente às expectativas de desvalorização cambial e à inflação dos produtos importados, com efeitos negativos sobre o consumo que praticamente anulam os ganhos do setor exportador.

Estes resultados podem ser interpretados à luz dos que se posicionavam a favor da ancoragem cambial à época. O argumento era que a manutenção de uma taxa de câmbio apreciada era necessária para para garantir a continuidade da estabilidade de preços obtida após o Plano Real. A economia brasileira gradativamente se tornava mais aberta, com os bens importados adquirindo participação crescente no consumo doméstico, e portanto havia o receio de que uma desvalorização cambial voltasse a deflagrar uma alta de preços generalizada, demandando novas contrações monetárias com impacto negativo na atividade econômica.

Entretanto, os dados simulados não deixam de sinalizar que haveria melhoras no saldo comercial, beneficiando as contas externas e o crescimento do produto. Há de se avaliar o custo destes benefícios expressos na elevação da taxa de juros e da inflação. De 1996 a 1998, as respectivas taxas de juros anuais foram aproximadamente $22 \%, 37 \%$ e $29 \%$, patamares elevados que já comprimiam a atividade e prejudicavam o endividamento público. Elevações adicionais seriam provavelmente insustentáveis.

$C$ - Antecipação do regime de metas para a inflação e câmbio flutuante

Por fim, iremos simular os efeitos de se antecipar a flutuação cambial e implementação do sistema de metas para a inflação. Quando era maior a pressão para a desvalorização cambial? Qual seria a trajetória da taxa de câmbio, taxa de juros, produto e inflação se a flexibilização cambial tivesse sido adotada antes das crises externas ocorridas no período? Como o comprometimento com diferentes níveis de metas para a inflação afetaria estes cenários? Vamos concentrar nossa análise no período anterior à flutuação cambial e elaboramos quatro cenários distintos na tentativa de responder a estas perguntas. 
Nas figuras D.15 e D.16 simulamos a flutuação cambial em períodos anteriores às crises da Ásia em 1997 e da Rússia em 1998 respectivamente. Para efeitos de comparação estabelecemos uma meta de $8 \%$ a.a. para a inflação, a mesma que foi implementada quando este sistema passou a vigorar de fato.

O primeiro fato que destacamos quando comparamos estes dois cenários é a trajetória da taxa de câmbio nominal. Enquanto nas vésperas da crise da Rússia observamos um incremento no ritmo de desvalorização que vigorava no sistema de bandas cambiais ${ }^{3}$, o efeito oposto é observado quando a transição entre regimes se dá antes da crise da Ásia. Este resultado corrobora o argumento de que a pressão para a desvalorização cambial se acentuou ao longo deste período que antecedeu o abandono do sistema de bandas cambiais.

Nos restringindo a nosso modelo, podemos interpretar este fato retomando a análise de decomposição de variância apresentada nas tabelas D.3 e D.4. Note que sob o regime de metas para a inflação o choque no prêmio de risco é o principal fator de volatilidade de curto prazo da taxa de câmbio nominal, com $71.23 \%$ de participação. Assim, uma análise do comportamento deste choque no período nos fornece boas hipóteses sobre os determinantes da flutuação cambial.

A figura D.12 apresenta uma comparação dos choques de prêmio de risco extraídos do modelo e do índice Embi + Brazil - JP Morgan, relacionado ao spread da dívida soberana de países emergentes. Em primeiro lugar destacamos como os choques exógenos são altamente correlacionados com o índice. Em seguida, verificamos que a direção dos choques força a apreciação cambial no período anterior à crise asiática e causa pressões para a desvalorização da moeda antes da crise russa.

Damos prosseguimento à comparação destes dois cenários avaliando os impactos da flexibilização cambial na atividade econômica. Um efeito comum e benéfico nos dois casos são os menores níveis observados para a taxa de juros, decorrente do papel de absorção de choques externos da taxa de câmbio nominal. Entretanto, quando a flutuação ocorre antes da crise da Ásia verificamos uma diminuição (apreciação) dos termos de troca. A diminuição das exportações líquidas superam o incremento do consumo, ocasionando um nível de produto em média inferior ao observado sob o regime de bandas cambiais. Em relação ao cenário pré-crise russa, os efeitos da antecipação da flutuação cambial são mais favoráveis. A desvalorização cambial não é muito acentuada e seus efeitos positivos sobre o setor exportador se somam a um ligeiro incremento de consumo impulsionado pelos menores níveis de taxa de

\footnotetext{
${ }^{3} \mathrm{~A}$ tendência de desvalorização de $7 \%$ a.a. observada no regime de bandas cambiais foi extraída da série da taxa de câmbio nominal.
} 
juros, levando ao incremento da atividade econômica. Portanto, concluímos que até o momento as simulações fornecidas por nosso modelo favorecem a hipótese de que a flutuação cambial permitida antes da crise da Rússia teria efeitos positivos na economia.

Complementamos nossa análise simulando como diferentes níveis de metas para a inflação afetariam este cenário. As figuras D.17 e D.18 apresentam a mesma simulação realizada com metas para a inflação de 5\% a.a. e $10 \%$ a.a. respectivamente. Observamos que metas mais elevadas pressionam a desvalorização cambial, têm efeito positivo no produto e demandam um nível mais elevado para a taxa de juros nominal e inflação. No cenário com meta de $5 \%$ a.a. a trajetória do produto é inferior à observada no sistema de bandas cambiais e verificamos uma apreciação da moeda brasileira. No cenário com a meta de $10 \%$ a.a. apesar do crescimento mais acentuado do produto, verificamos níveis mais elevados de inflação e taxa de juros. Embora o objetivo destas simulações não seja quantificar uma meta ótima para a inflação do período, consideramos que um valor intermediário entre estes extremos seria mais adequado à luz de nosso modelo. 


\section{Teste de quebra estrutural}

Os resultados verificados nos capítulos anteriores demonstram que diferentes regimes de política monetária podem afetar substancialmente a dinâmica macroeconômica implicada por um modelo DSGE de pequena economia aberta.

No caso estudado, a transição do sistema de bandas cambiais para o sistema de metas para a inflação ocorrida no Brasil, estamos diante de uma quebra de regime amplamente divulgada e de fato implementada. $\mathrm{O}$ conhecimento preciso da data de quebra foi o que possibilitou realizar a estimação utilizando o método descrito.

Entretanto nem sempre é trivial caracterizar a ocorrência de uma quebra de regime, especialmente ao lidar com modelos altamente parametrizados e de grande escala como são os modelos DSGE. Tendo em conta a relevância da correta caracterização de mudanças de regime de política na estimação de modelos desta natureza, nosso interesse agora recai na investigação de quebras estruturais cujas datas de ocorrência são desconhecidas.

O escopo de investigação deste capítulo deve ser bem delimitado. Iremos aplicar um teste de hipóteses com o objetivo de identificar se há indícios de ocorrência de quebra estrutural de politica monetária em alguma outra data após a implementação do regime de metas para a inflação. Para este fim utilizaremos a metodologia de teste proposta por Andrews (1993).

É crucial ressaltarmos neste momento que ao investigar quebras estruturais estamos assumindo que a mudança nos parâmetros do modelo ocorre subitamente ou em curtíssimo período de duração, se estabilizando em novo patamar após a transição. Portanto, os resultados aqui apresentados devem ser interpretados sob esta premissa.

Há abordagens na literatura que investigam mudanças nos parâmetros de interesse sob outra perspectiva. Pode-se considerar, por exemplo, que a política monetária assuma instâncias que se alternam ao longo do tempo, como o fazem Davig e Leeper (2006) utilizando processos Markovswitching para os parâmetros da regra de política. Outra possibilidade é assumir parâmetros variantes no tempo (parameter drifting), como em Fernandez-Villaverde e Rubio-Ramirez (2007), para um modelo DSGE, ou Sims e Zha (2004), para um modelo VAR. 


\section{1 \\ Metodologia}

A metodologia adotada é a de Andrews (1993), que apresenta uma classe de testes para identificar a instabilidade de parâmetros quando a data de quebra é desconhecida. Uma aplicação desta metodologia em modelos DSGE pode ser encontrada em Inoue e Rossi (2011), embora com escopo distinto. A proposta destes autores é identificar entre todos os parâmetros de um modelo DSGE, o conjunto destes que pode ser considerado estáveis, além de obter uma estimativa da data a partir da qual se verifica a maior instabilidade no modelo. No nosso trabalho partimos de uma premissa simplificadora de que todos os parâmetros são invariantes com exceção aos relacionados à regra de política monetária.

As justificativas para a utilização deste teste são apresentadas pelo próprio Andrews (1993), dentre as quais ressaltamos as mais relevantes. Em primeiro lugar, o teste se aplica tanto ao caso de quebra "pura" em que todo o vetor de parâmetros está sujeito a mudanças, quanto ao caso de quebra "parcial" em que apenas alguns componentes do vetor de parâmetros está sujeito a mudanças, que é o caso em que temos interesse. Além disso, o teste pode ser aplicado para o casos em que o ponto de quebra está restrito a um intervalo especificado ou quando o ponto de quebra é completamente desconhecido. Por fim, mesmo quando a quebra estrutural não ocorre de maneira abrupta, havendo um período de transição entre um regime e outro, é mostrado pelo autor que os testes possuem algum poder, embora não seja esta a classe de hipóteses alternativas para as quais o teste foi designado originalmente.

\subsection{1}

\section{O método de Andrews (1993)}

Como mencionado na seção 2.2, o caso em que estamos interessados corresponde a uma quebra estrutural parcial, caracterizada por uma amostra dividida em duas partes e um modelo paramétrico indexado pelo vetor de parâmetros $\theta=\left(\delta_{0}, \beta_{1}, \beta_{2}\right)$, onde $\delta_{0}$ são os parâmetros invariantes, $\beta_{1}$ são parâmetros associados ao modelo válido para a primeira parte da amostra e $\beta_{2}$ parâmetros associados ao modelo válido para a segunda parte.

A hipótese nula de interesse é a estabilidade dos parâmetros:

$$
H_{0}: \theta=\left(\delta_{0}, \beta_{0}, \beta_{0}\right) \quad \forall t \geq 1
$$

A hipótese alternativa, considerando uma única mudança estrutural ocorrida na data $\pi T$ é dada por: 


$$
H_{1}(\pi T): \theta=\left(\delta_{0}, \beta_{1}, \beta_{2}\right) \quad \beta_{1} \neq \beta_{2}
$$

onde $T$ é o tamanho da amostra e $\pi \in(0,1)$. Assim $\beta_{1}$ são parâmetros associados ao modelo válido para a subamostra $t \in(1, \pi T)$ e $\beta_{2}$ parâmetros associados ao modelo válido para a subamostra $t \in(\pi T+1, T)$.

O procedimento desenvolvido por Andrews (1993) requer primeiramente determinarmos um candidato a ponto de quebra $\pi \in \Pi$ onde $\Pi$ é um subconjunto de $[0,1]^{1}$.

Esta característica do procedimento de teste implica que podemos determinar um subperíodo da amostra no qual queremos investigar a ocorrência de uma quebra estrutural. Se não há um período específico de interesse, a recomendação do próprio autor é a utilização de um intervalo para П que exclua alguns períodos iniciais e finais da amostra de modo a conferir maior poder ao teste $^{2}$.

Definido o intervalo de busca $\Pi$, o candidato a ponto de quebra $\pi^{*} \in \Pi$ é tal que:

$$
L R_{T}\left(\pi^{*}\right)=\sup _{\pi \in \Pi} L R_{T}(\pi)
$$

onde $L R_{T}(\pi)$ é uma estatística de teste do tipo razão de verossimilhança calculada para todo período $\pi \in \Pi$. Especificamente, calculamos a $L R_{T}(\pi)^{3}$ como a diferença entre a função de log-verossimilhança do modelo irrestrito $L\left(\delta_{0}, \beta_{1}, \beta_{2} \mid Y_{T}\right)$ e do modelo restrito $L\left(\delta_{0}, \beta_{0}, \beta_{0} \mid Y_{T}\right)$. A maior diferença verificada caracteriza o candidato a ponto de quebra $\pi^{*}$. Assim:

$$
L R_{T}(\pi)=\left[L_{1}+L_{2}-L\right]
$$

onde:

$$
\begin{gathered}
L=L\left(\delta_{0}, \beta_{0}, \beta_{0} \mid Y_{T}\right) \\
L_{1}=L\left(\delta_{0}, \beta_{1}, \beta_{2} \mid Y_{t}\right), \quad t<\pi T \\
L_{2}=L\left(\delta_{0}, \beta_{1}, \beta_{2} \mid Y_{t}\right), \quad t \geq \pi T
\end{gathered}
$$

A hipótese nula de invariância dos parâmetros é rejeitada para valores elevados de $\sup _{\pi \in \Pi} L R_{T}(\pi)$. Os valores críticos para esta estatística de teste são apresentados no artigo de Andrews (1993) e dependendem dos limites do intervalo П e do número de parâmetros variáveis entre as subamostras.

\footnotetext{
${ }^{1} \mathrm{O}$ valor de $\pi$ corresponde portanto à fração da amostra a partir da qual há uma potencial quebra estrutural.

${ }^{2} \mathrm{O}$ intervalo $[0.15,0.85]$ é sugerido nestes casos.

${ }^{3}$ Equação 4.5 de Andrews(1993).
} 


\section{2}

\section{Aplicação do teste em dados simulados}

Nosso primeiro objetivo é verificar se o teste proposto é capaz de identificar uma quebra estrutural parcial no modelo DSGE utilizado neste trabalho. Simulamos uma base de dados com cem períodos utilizando a representação estado-espaço do regime de metas para a inflação. Os parâmetros foram calibrados com os valores resultantes da estimação da distribuição $a$ posteriori apresentados na tabela D.2. A quebra estrutural ocorre na metade da amostra apenas nos parâmetros da regra de política monetária, calibrados com os valores da tabela 4.1.

Tabela 4.1: Parâmetros utilizados na simulação de base de dados

\begin{tabular}{ccc}
\hline \hline Parâmetro & Regime 1 & Regime 2 \\
\hline$\rho_{i, 1}$ & 0.30 & 0.60 \\
$\lambda_{\pi}$ & 1.50 & 2.10 \\
$\lambda_{y}$ & 0.35 & 0.65 \\
$\lambda_{\Delta}$ & 1.50 & 0.30 \\
$\sigma_{m}$ & 1.50 & 0.50 \\
\hline
\end{tabular}

O resultado do teste é apresentado na parte superior da figura D.19. O gráfico apresenta a estatística de razão de verossimilhança calculada para cada data candidata a ponto de quebra. A data onde esta razão atinge o maior valor é a potencial data de quebra, e a estatística de teste é dada pelo valor associado a esta data. Os valores críticos associados aos níveis de 1\% e $10 \%$ de confiança estão representados pelas duas linhas horizontais. A hipótese nula é a estabilidade dos parâmetros. Como o valor da estatística de teste é superior aos valores críticos, rejeitamos a hipótese nula e concluímos a favor da existência da quebra nesta data. O teste foi bem sucedido e indicou com precisão a data em que ocorreu a quebra.

Para ilustração, aplicamos o mesmo teste em uma base de dados simulada sem a ocorrência de quebra. O resultado é apresentado na parte inferior da figura D.19. Neste caso o teste também foi bem sucedido. A estatística de teste é inferior aos valores críticos e não rejeitamos a hipótese nula de estabilidade.

\section{3}

\section{Aplicação do teste nos dados observados}

Passando aos dados observados, propomos um exercício inicial. Queremos verificar se o teste de quebra é capaz de identificar a transição de regime de política ocorrida em 1999. 
Para este fim, aplicamos o teste utilizando todo o período amostral utilizado na estimação ${ }^{4}$ utilizando o modelo associado ao regime de metas para a inflação. O teste é do tipo quebra parcial, e permitimos que apenas os parâmetros da regra de política monetária sejam variáveis. O resultado é apresentado na parte superior da figura D.20 cuja interpretação é a mesma descrita para o teste com dados simulados. É interessante notar como o teste indica com precisão a data de quebra no segundo trimestre de 1999. Caso ignorássemos os eventos ocorridos neste período teríamos uma forte evidência a favor de alguma mudança significativa de política ocorrida nesta data.

Naturalmente surge o questionamento sobre a possibilidade de ocorrência de outras quebras estruturais nos dados. Particularmente, estamos interessados em identificar se há indícios de quebra estrutural de política monetária no período após a implementação do regime de metas para a inflação.

Neste caso podemos utilizar um procedimento sequencial bem simples, apresentado por Bai e Perron (1995). Tomamos todo o período e realizamos o teste de quebra como proposto por Andrews (1993). Se rejeitamos a hipótese que não haja quebra, então dividimos a amostra em duas partes anterior e posterior à data de quebra estimada. O teste é reaplicado em cada subamostra e o procedimento repetido até que não haja mais rejeição da hipótese nula.

O gráfico inferior da figura D.20 apresenta o resultado do teste aplicado na subamostra que se inicia no segundo trimestre de 1999. O valor máximo atingido pela sequência de testes indica a potencial data de quebra para o fim de 2008 mas notamos que os valores críticos são superiores à estatística de teste nesta data. Formalmente não rejeitamos a hipótese de estabilidade.

Fazendo um pequeno desvio do procedimento sequencial, ao restringir a amostra para os últimos dez anos, o teste também não rejeita a hipótese de estabilidade, como pode ser verificado na figura D.21

\section{4}

\section{Considerações finais}

Um ponto fundamental a ser ressaltado se refere à possibilidade de aplicação do teste de Andrews (1993) em um modelo DSGE estimado por métodos bayesianos. Para esta discussão, nos referimos ao trabalho de Inoue e Rossi (2011) no qual aplicam sua metodologia ao modelo de Smets e Wouters (2007), argumentando que utilizam métodos bayesianos apenas como instrumentos de estimação, utilizando a correspondência entre os estimadores clássicos de máxima verossimilhança e os estimadores bayesianos em grandes amostras. Assintoticamente os efeitos da distribuição a priori são

\footnotetext{
${ }^{4}$ Início no terceiro trimestre de 1995 e fim no segundo trimestre de 2013.
} 
dissipados e os resultados do teste são válidos. Em pequenas amostras, entretanto, poderíamos observar discrepâncias entre os dois métodos, o que nos leva a considerar os resultados obtidos nesta seção apenas como evidências sobre a ocorrência ou não das quebras estruturais.

Por fim, enfatizando os comentários iniciais deste capítulo, neste trabalho estamos sempre assumindo a estabilidade da condução da política monetária. Quando há variação nos parâmetros, permitimos somente a quebra estrutural, em que a mudança é abrupta e um novo patamar estável é atingido. Dentro de um modelo DSGE, se quisermos investigar mudanças de política monetária menos radicais, com variações graduais ou dadas por instâncias que se alternam ao longo do tempo, devemos adotar outras técnicas econométricas.

Neste sentido, os testes confirmam a quebra de política ocorrida no início de 1999 e rejeitam que tenha havido alguma mudança considerada estrutural no período após a entrada em vigor do regime de metas para a inflação. 


\section{Conclusão}

Como ressaltado por Tovar (2008), a especificação de modelos DSGE que capturem satisfatoriamente a dinâmica de economias emergentes não é uma tarefa trivial. Além de exibirem componentes estruturais idiossincráticos e transitórios, apresentam histórico de vulnerabilidade a fatores externos e períodos recorrentes de instabilidade macroeconômica.

No caso da economia brasileira, temos todos estes elementos presentes no período que se segue após a implementação do Plano Real e culmina na flutuação e desvalorização cambial em 1999. Consequentemente a grande maioria dos modelos DSGE estimados para a economia brasileira encontrados na literatura utilizam como amostra somente o período posterior à entrada em vigor do sistema de metas para inflação por ser considerado mais estável ${ }^{1}$.

Neste contexto, nos propusemos neste trabalho a contribuir para interpretação das transformações estruturais ocorridas na economia brasileira neste período de transição as incorporando em um modelo DSGE que permita a quebra estrutural da regra de política monetária. Embora os modelos DSGE ainda não tenham se consolidado como instrumentos de previsão econômica, a utilização destes como instrumentos de auxílio para a compreensão de fenômenos econômicos e avaliação de impacto de políticas é cada vez mais consolidada.

Neste trabalho comparamos o desempenho da política monetária brasileira sob os regimes de bandas cambiais e de metas para a inflação. Como esperado, o resultado da estimação indicou para o primeiro regime a preocupação com a manutenção da taxa de câmbio nominal nos níveis desejados, em contraponto à estabilização da inflação e suavização da taxa de juros no segundo regime.

Avaliamos também os mecanismos de transmissão dos choques exógenos na economia, constatando que os choques relacionados ao setor externo contribuíam para a volatilidade da economia doméstica com maior intensidade enquanto vigorava o sistema de bandas cambiais.

Em seguida, conduzimos experimentos contrafactuais com o objetivo de formular hipóteses sobre quais seriam impactos econômicos caso a transição entre estes regimes se desse sob diferentes condições ou em outras datas. Sob a luz de nosso modelo, as simulações sugeriram que a manutenção do sistema de bandas cambiais seria insustentável, e que a flexibilização cambial, caso tivesse

\footnotetext{
${ }^{1}$ Naturalmente esta é a estratégia correta se o escopo de análise é contemporâneo.
} 
ocorrido antes da crise da Rússia em 1998, deixaria a economia brasileira em condições mais favoráveis.

Oportunamente, fazemos a ressalva de que todas estas conclusões devem ser interpretadas dentro das restrições impostas pelo modelo estilizado que adotamos. O nível das reservas internacionais utilizadas para a intervenção no mercado de câmbio, o impacto da política monetária na sustentabilidade do endividamento público externo e os desbalanços nos fluxos de capitais estrangeiros são componentes essenciais para a interpretação dos fatos econômicos da época. Portanto, embora a ausência destes elementos em nosso modelo não nos impeça de formular hipóteses, deixamos em aberto a possibilidade de aplicar esta metodologia e realizar os mesmos experimentos em um modelo de maior escala. 


\section{Referências Bibliográficas}

ANDREWS, D. W. K.. Tests for parameter instability and structural change with unknown change point. Econometrica, 61(4):821-56, July 1993.

AN, S.; SCHORFHEIDE, F.. Bayesian analysis of DSGE models. Working Papers 06-5, Federal Reserve Bank of Philadelphia, 2006.

BAI, J.; PERRON, P.. Estimating and testing linear models with multiple structural changes. Working papers 95-17, Massachusetts Institute of Technology (MIT), Department of Economics, 1995.

BÄUERLE, G.; MENZ, T.. Monetary policy in a small open economy model: A DSGE-VAR approach for Switzerland. Working Papers 08.03, Swiss National Bank, Study Center Gerzensee, 2008.

BENIGNO, P.. Price stability with imperfect financial integration. CEPR Discussion Papers 2854, C.E.P.R. Discussion Papers, 2001.

BLANCHARD, O.; KAHN, C. M.. The solution of linear difference models under rational expectations. Econometrica, 48(5):1305-11, 1980.

CALVO, G. A.. Staggered prices in a utility-maximizing framework. Journal of Monetary Economics, 12(3):383-398, 1983.

CURDIA, V.; FINOCCHIARO, D.. Monetary regime change and business cycles. Working Paper Series 2013-02, Federal Reserve Bank of San Francisco, 2012.

DEL NEGRO, M.; SCHORFHEIDE, F.. Inflation dynamics in a small open-economy model under inflation targeting: some evidence from Chile. Staff Reports 329, Federal Reserve Bank of New York, 2008.

FERNANDEZ-VILLAVERDE, J.. The econometrics of DSGE models. Pier working paper archive, Penn Institute for Economic Research, Department of Economics, University of Pennsylvania, 2009.

FRIEDMAN, M.. Essays in positive economics. University of Chicago Press, 0 edition, 1966.

GALÍ, J.; MONACELLI, T.. Monetary policy and exchange rate volatility in a small open economy. CEPR Discussion Papers 3346, C.E.P.R. Discussion Papers, Apr. 2002. 
GARCIA, M.. O prêmio de risco da taxa de câmbio no brasil durante o plano real. Revista Brasileira de Economia, 55(2), April 2001.

GELMAN, A.; ROBERTS, G. ; GILKS, W.. Weak convergence and optimal scaling of random walk Metropolis algorithms. The Annals of Applied Probability, 7(1):110-120, 1997.

GOLDFAJN, I.. The swings in capital flows and the brazilian crisis. Textos para discussão 422, Department of Economics PUC-Rio (Brazil), 2000.

GUERRON-QUINTANA, P. A.; NASON, J. M.. Bayesian estimation of DSGE models. Cama working papers, Centre for Applied Macroeconomic Analysis, Crawford School of Public Policy, The Australian National University, 2012.

HAMILTON, J.. Time series analysis. Princeton University Press, 2004.

INOUE, A.; ROSSI, B.. Identifying the sources of instabilities in macroeconomic fluctuations. The Review of Economics and Statistics, 93(4):1186-1204, November 2011.

JUSTINIANO, A.; PRESTON, B.. Monetary policy and uncertainty in an empirical small open-economy model. Journal of Applied Econometrics, 25(1):93-128, 2010.

KLEIN, P.. Using the generalized Schur form to solve a multivariate linear rational expectations model. Journal of Economic Dynamics and Control, 24(10):1405-1423, 2000.

DAVIG, T.; LEEPER, E.. Generalizing the taylor principle. Caepr Working Papers 2006-001, Center for Applied Economics and Policy Research, Economics Department, Indiana University Bloomington, 2006.

MONACELLI, T.. Into the Mussa puzzle: Monetary policy regimes and the real exchange rate in a small open economy. Boston College Working Papers in Economics 437, Boston College Department of Economics, 2000.

MONACELLI, T.. Monetary policy in a low pass-through environment. Working Paper Series 0227, European Central Bank, Apr. 2003.

BAUER, A.; HALTOM, N. ; RUBIO-RAMIREZ, J. F.. Using the Kalman filter to smooth the shocks of a dynamic stochastic general equilibrium model. Working Paper 2003-32, Federal Reserve Bank of Atlanta, 2003. 
DE CASTRO, M.; GOUVEA, S.; MINELLA, A.; SANTOS, R. ; SOBRINHO, N.. SAMBA: Stochastic analytical model with a bayesian approach. Working Papers Series 239, Banco Central do Brasil, 2011.

SIMS, C.. Solving linear rational expectations models. Computational Economics, 20(1-2):1-20, October 2002.

SIMS, C.; ZHA, T.. Were there regime switches in U.S. monetary policy? Working Paper 2004-14, Federal Reserve Bank of Atlanta, 2004.

SMETS, F. R.; WOUTERS, R.. Shocks and frictions in US business cycles: A bayesian DSGE approach. CEPR Discussion Papers 6112, C.E.P.R. Discussion Papers, 2007.

SVENSSON, L. E. O.. Why exchange rate bands? monetary independence in spite of fixed exchange rates. NBER Working Papers 4207, National Bureau of Economic Research, Inc, 1994.

TAYLOR, J. B.. Discretion versus policy rules in practice. CarnegieRochester Conference Series on Public Policy, 39(1):195-214, 1993.

TOVAR, C. E.. DSGE models and central banks. Economics Discussion Papers 2008-30, Kiel Institute for the World Economy, 2008.

SCHMITT-GROHÉ, S.; URIBE, M.. Closing small open economy models. NBER Working Papers 9270, National Bureau of Economic Research, Inc, 2002. FERNANDEZ-VILLAVERDE, J.; RUBIO-RAMIREZ, J. F.. How structural are structural parameters? NBER Working Papers 13166, National Bureau of Economic Research, Inc, 2007.

WOODFORD, M.. Interest and prices. Princeton University Press, 2003. 


\section{A \\ Derivação do modelo}

Neste apêndice apresentamos a derivação das condições de equilíbrio resultantes dos problemas de otimização do agente representativo e das firmas. Em seguida apresentamos um detalhamento da log-linearização do sistema de equações do modelo ${ }^{1}$.

\section{A.1}

\section{Condições de equilíbrio}

\section{A.1.1}

\section{Agente representativo}

Em primeiro lugar, obtemos a combinação de cestas de bens domésticos e importados que minimize o custo de qualquer nível de consumo agregado.

$$
\min _{C_{H, t}, C_{F, t}} P_{H, t} C_{H, t}+P_{F, t} C_{F, t} \quad \text { s.a. } \quad C_{t}=\left[(1-\alpha)^{\frac{1}{\eta}} C_{H, t}^{\frac{\eta-1}{\eta}}+\alpha^{\frac{1}{\eta}} C_{F, t}^{\frac{\eta-1}{\eta}}\right]^{\frac{\eta}{1-\eta}}
$$

Solucionamos para $C_{H, t}$ e $C_{F, t}$, utilizando $P_{t}$ como multiplicador da restrição. As condições de primeira ordem da otimização são:

$$
\begin{aligned}
& {\left[C_{H, t}\right]: P_{H, t}=P_{t}\left(\frac{\eta}{\eta-1}\right) C_{t}^{1 / \eta}(1-\alpha)^{1 / \eta}\left(\frac{\eta-1}{\eta}\right) C_{H, t}^{-1 / \eta}} \\
& {\left[C_{F, t}\right]: P_{F, t}=P_{t}\left(\frac{\eta}{\eta-1}\right) C_{t}^{1 / \eta}(1-\alpha)^{1 / \eta}\left(\frac{\eta-1}{\eta}\right) C_{F, t}^{-1 / \eta}}
\end{aligned}
$$

E portanto, a composição ótima do consumo de bens domésticos e importados é dada por:

$$
C_{H, t}=(1-\alpha)\left(\frac{P_{H, t}}{P_{t}}\right)^{-\eta} C_{t} \quad C_{F, t}=(1-\alpha)\left(\frac{P_{F, t}}{P_{t}}\right)^{-\eta} C_{t}
$$

Substituindo estas demandas na equação do consumo total agregado obtemos o índice de preços da economia:

$$
P_{t}=\left[(1-\alpha) P_{H, t}^{1-\eta}+\alpha P_{F, t}^{1-\eta}\right]^{\frac{\eta}{1-\eta}}
$$

\footnotetext{
${ }^{1}$ Seguimos Bäuerle e Menz (2008) nas etapas de log-linearização de algumas equações desta seção.
} 
Dada a composição ótima para o consumo de bens domésticos e importados, obtemos a demanda por cada variedade $(i)$ dos produtos de cada categoria através de problema de minimização de custos semelhante ao anterior.

$$
\begin{array}{lll}
\min _{C_{H, t}(i)} P_{H, t}(i) C_{H, t}(i) & \text { s.a. } & C_{H, t}=\left[\int_{0}^{1} C_{H, t}(i)^{\frac{\varepsilon-1}{\varepsilon}} d i\right]^{\frac{\varepsilon}{\varepsilon-1}} \\
\min _{C_{F, t}(i)} P_{F, t}(i) C_{F, t}(i) & \text { s.a. } & C_{F, t}=\left[\int_{0}^{1} C_{F, t}(i)^{\frac{\varepsilon-1}{\varepsilon}} d i\right]^{\frac{\varepsilon}{\varepsilon-1}}
\end{array}
$$

O método de solução é análogo ao exposto no início desta seção e possibilita a obtenção das equações de demanda por cada variedade:

$$
\begin{aligned}
C_{H, t}(i) & =\left(\frac{P_{H, t}(i)}{P_{t}}\right)^{-\epsilon} \\
C_{F, t}(i) & =\left(\frac{P_{F, t}(i)}{P_{t}}\right)^{-\epsilon}
\end{aligned}
$$

Substituindo estas demandas na equação do consumo agregado de cada categoria obtemos o índice de preços para cada categoria:

$$
\begin{aligned}
& P_{H, t}=\left(\int_{0}^{1} P_{H, t}(i)^{1-\epsilon} d i\right)^{\frac{1}{1-\epsilon}} \\
& P_{F, t}=\left(\int_{0}^{1} P_{F, t}(i)^{1-\epsilon} d i\right)^{\frac{1}{1-\epsilon}}
\end{aligned}
$$

Dada estas demandas, redefinimos a restrição orçamentária em função do consumo agregado e reformulamos o problema de otimização do agente. As condições de otimalidade resultantes deste problema foram apresentadas na seção 2.1 .

$$
\begin{aligned}
\max _{C_{t}, N_{t}, B_{t}, D_{t}} \mathbb{E}_{0} \sum_{t=0}^{\infty} \beta^{t} \tilde{\varepsilon}_{g, t}\left[\frac{\left(C_{t}-h \tilde{C}_{t-1}\right)^{1-\sigma}}{1-\sigma}-\frac{N_{t}^{1+\varphi}}{1+\varphi}\right] \\
\text { s.a } \quad P_{t} C_{t}+D_{t}+e_{t} B_{t}=D_{t-1}\left(1+\tilde{i}_{t-1}\right)+e_{t} \\
+B_{t-1}\left(1+\tilde{i}_{t-1}^{*}\right) \phi_{t}\left(A_{t}\right)+W_{t} N_{t}+\Pi_{H, t}+\Pi_{F, t}+T_{t}
\end{aligned}
$$




\section{A.1.2}

\section{Firmas produtoras domésticas}

As firmas que reajustarem seus preços em um determinado período $t$ determinam um preço $P_{H, t}^{*}$ de maneira a maximizarem o valor presente dos lucros esperados sujeitas à sequência de demandas (2-19), levando em conta a probabilidade de não poderem reajustar seus preços no futuro.

$$
\begin{array}{r}
\max _{P_{H, t}^{*}} \mathbb{E}_{t} \sum_{\tau=0}^{\infty} \theta_{H}^{\tau} Q_{t, t+\tau} y_{H, t+\tau \mid t}\left[P_{H, t}^{*}\left(\frac{P_{H, t+\tau-1}}{P_{H, t-1}}\right)^{\delta_{H}}-P_{H, t+\tau} M C_{t+\tau}\right] \\
\text { s.a. } y_{H, t+\tau \mid t}=\left(\frac{P_{H, t}^{*}}{P_{H, t+\tau}}\left(\frac{P_{H, t+\tau-1}}{P_{H, t-1}}\right)^{\delta_{H}}\right)^{-\varepsilon}\left(C_{H, t+\tau}+C_{H, t+\tau}^{*}\right)
\end{array}
$$

As condições de primeira ordem deste problema são dadas por:

$$
\mathbb{E}_{t} \sum_{\tau=0}^{\infty} \theta_{H}^{\tau} Q_{t, t+\tau} y_{H, t+\tau \mid t}\left[P_{H, t}^{*}\left(\frac{P_{H, t+\tau-1}}{P_{H, t-1}}\right)^{\delta_{H}}-\frac{\varepsilon}{\varepsilon-1} P_{H, t+\tau} M C_{t+\tau}\right]
$$

\section{A.1.3}

\section{Firmas importadoras domésticas}

O problema de otimização da firma importadora é análogo ao da firma produtora doméstica. Neste caso o custo marginal corresponde ao valor do produto importado, dado por $\tilde{e}_{t+\tau} P_{F, t+\tau}^{*}$. 


\section{A.2}

\section{Log-linearização}

Para a estimação do modelo utilizamos uma aproximação log-linear das condições de equilíbrio ao redor de um estado estacionário não estocástico. O estado estacionário do modelo é caracterizado por inflação zero e comércio balanceado. Portanto temos $P=P_{H}=P_{F}$,

\section{A.2.1}

\section{Equação de Euler}

A log-linearização da equação (2-12) é direta e resulta na expressão:

$$
c_{t}-h c_{t-1}=\mathbb{E}_{t}\left(c_{t+1}-h c_{t}\right)-\frac{1-h}{\sigma}\left(i_{t}-\mathbb{E}_{t} \pi_{t+1}\right)+\frac{1-h}{\sigma}\left(\varepsilon_{g, t}-\mathbb{E}_{t} \varepsilon_{g, t+1}\right)
$$

\section{A. 2.2}

\section{Equilíbrio no mercado doméstico de bens}

Em primeiro lugar, linearizamos o índice geral de preços domésticos (2-18), obtendo:

$$
p_{t}=(1-\alpha) p_{H, t}+\alpha p_{F, t}
$$

Linearizando a expressão dos termos de troca (2-23) obtemos $s_{t}=$ $p_{F, t}-p_{H, t}$, e tomando a primeira diferença obtemos:

$$
\Delta s_{t}=\pi_{F, t}-\pi_{H, t}
$$

Combinando as equações (A-4) e (A-5) obtemos uma relação entre os termos de troca, a inflação dos bens domésticos e a inflação geral doméstica:

$$
\pi_{t}=\pi_{H, t}+\alpha \Delta s_{t}
$$

A expressão linear da taxa de câmbio real é $q_{t}=e_{t}+p_{t}^{*}-p_{t}$ e o desvio da Lei do Preço Único é representado por $\Psi_{F, t}=e_{t}+p_{t}^{*}-p_{F, t}$. Então obtemos uma expressão relacionando estas variáveis com os termos de troca:

$$
q_{t}=\Psi_{F, t}+(1-\alpha) s_{t}
$$

O próximo passo é linearizar a condição de equilíbrio no mercado doméstico de bens $Y_{t}=C_{H, t}+C_{H, t}^{*}$. Substituindo as equações de demanda doméstica (2-9) e demanda externa (2-34) nesta condição obtemos:

$$
Y_{t}=(1-\alpha)\left(\frac{P_{H, t}}{P_{t}}\right)^{-\eta} C_{t}+\left(\frac{P_{H, t}^{*}}{P_{t}^{*}}\right)^{-\lambda} Y_{t}^{*}
$$


Iremos assumir que a Lei do Preço Único se aplica à importação dos bens domésticos pelo setor externo, e desta maneira $P_{H, t}=\tilde{e}_{t} P_{H, t}^{*}=\tilde{e}_{t} P_{t}^{*}$.

Assim,

$$
\left(\frac{P_{H, t}^{*}}{P_{t}^{*}}\right)^{-\lambda}=\left(\frac{e_{t} P_{t}^{*}}{P_{F, t}} \frac{P_{F, t}}{P_{H, t}}\right)^{\lambda}=\left(\tilde{\Psi}_{F, t} S_{t}\right)^{\lambda}
$$

E portanto:

$$
Y_{t}=(1-\alpha)\left(\frac{P_{H, t}}{P_{t}}\right)^{-\eta} C_{t}+\left(\tilde{\Psi}_{F, t} S_{t}\right)^{\lambda} Y_{t}^{*}
$$

Ao linearizar esta expressão obtemos:

$$
Y y_{t}=C_{H}\left[\eta\left(p_{t}-p_{H, t}\right)+c_{t}\right]+C_{H}^{*}\left[\lambda\left(\psi_{F, t}+s_{t}\right)+y_{t}^{*}\right]
$$

Da equação do consumo agregado (2-2) obtemos as relações de estado estacionário $C_{H}=(1-\alpha) C$ e $C_{F}=\alpha C$. Como assumimos comércio balanceado no estado estacionário temos exportações $C_{H}^{*}$ iguais às importações $C_{F}$. Utilizando ainda a relação (A-6) e assumindo que as elasticidades de substituição das demandas doméstica $\eta$ e externa $\lambda$ são idênticas, podemos reescrever a expressão acima como:

$$
y_{t}=(1-\alpha) c_{t}+\alpha \eta(2-\alpha) s_{t}+\alpha \eta \Psi_{F, t}+\alpha y_{t}^{*}
$$

\section{A.2.3 \\ Restrição Orçamentária}

Para a log-linearização da equação da restrição orçamentária, supomos que as transferências do governo são feitas para eliminar as distorções causadas pela concorrência monopolística no lucro das firmas de propriedade do agente representativo. Adicionalmente, tomamos o lucro da firma produtora de bens finais, dado por $\Pi_{f g, t}=P_{t} C_{t}-P_{F, t} C_{F, t}-P_{H, t} C_{H, t}$, e introduzimos na restrição orçamentária. Como a firma opera em mercado competitivo e obtém lucro zero a restrição não é afetada. Consideramos ainda o equilíbrio do mercado doméstico de títulos no qual $D_{t}=0$ em todo período.

$$
P_{t} C_{t}+\tilde{e}_{t} B_{t}=\tilde{e}_{t}+B_{t-1}\left(1+\tilde{i}_{t-1}^{*}\right) \phi_{t}\left(A_{t}\right)+W_{t} N_{t}+\Pi_{H, t}+\Pi_{F, t}+\Pi_{f g, t}+T_{t}
$$

Dados os lucros da firma produtora de bens domésticos $\Pi_{H, t}=C_{H, t} P_{H, t}+$ $\tilde{e}_{t} C_{H, t}^{*} P_{H, t}^{*}-W_{t} N_{t}$ e da firma varejista importadora $\Pi_{F, t}=C_{F, t} P_{F, t}-\tilde{e}_{t} P_{t}^{*} C_{F, t}$, temos que:

$$
\Pi_{H, t}+\Pi_{F, t}+\Pi_{f g, t}+T_{t}=P_{t} C_{t}+\tilde{e}_{t} C_{H, t}^{*} P_{H, t}^{*}-\tilde{e}_{t} P_{t}^{*} C_{F, t}-W_{t} N_{t}
$$


Substituindo na restrição orçamentária, obtemos:

$$
\tilde{e}_{t} B_{t}=\tilde{e}_{t} B_{t-1}\left(1+\tilde{i}_{t-1}^{*}\right) \phi_{t}+\tilde{e}_{t} C_{H, t}^{*} P_{H, t}^{*}-\tilde{e}_{t} P_{t}^{*} C_{F, t}
$$

O desvio da Lei do Preço Único só ocorre na importação de bens para o mercado doméstico. Para os bens domésticos exportados podemos considerar a relação $P_{H, t}=\tilde{e}_{t} P_{H, t}^{*}$ válida. Dividindo toda a equação por $P_{t} Y$ e utilizando as definições do endividamento externo $A_{t}=\frac{\tilde{e}_{t} B_{t}}{Y P_{t}}$ e da taxa de câmbio real $\tilde{q}_{t}=\tilde{e}_{t} P_{t}^{*} / P_{t}$ obtemos:

$$
A_{t}=A_{t-1} \frac{\tilde{q}_{t}}{\tilde{q}_{t-1}} \frac{1}{\Pi_{t-1}^{*}}\left(1+\tilde{i}_{t-1}^{*}\right) \phi_{t}+\frac{1}{Y}\left(\frac{P_{H, t}}{P_{t}} C_{H, t}^{*}-\tilde{e}_{t} \frac{P_{t}^{*}}{P_{t}} C_{F, t}\right)
$$

Substituímos as equações de demanda e manipulamos a equação considerando que as elasticidades de substituição entre os bens domésticos e importados são iguais e que $\left(\frac{P_{H, t}^{*}}{P_{t}^{*}}\right)^{-\lambda}=\left(\frac{e_{t} P_{t}^{*}}{P_{F, t}} \frac{P_{F, t}}{P_{H, t}}\right)^{\lambda}=\left(\tilde{\Psi}_{F, t} S_{t}\right)^{\lambda}$. Então:

$$
\begin{aligned}
& A_{t}=A_{t-1} \frac{\tilde{q}_{t}}{\tilde{q}_{t-1}} \frac{1}{\Pi_{t-1}^{*}}\left(1+\tilde{i}_{t-1}^{*}\right) \phi_{t}+\frac{1}{Y}\left(\frac{P_{H, t}}{P_{t}}\left(\frac{P_{H, t}^{*}}{P_{t}^{*}}\right)^{-\eta} Y_{t}^{*}-q_{t}(1-\alpha)\left(\frac{P_{F, t}}{P_{t}}\right)^{-\eta} C_{t}\right) \\
& A_{t}=A_{t-1} \frac{\tilde{q}_{t}}{\tilde{q}_{t-1}} \frac{1}{\Pi_{t-1}^{*}}\left(1+\tilde{i}_{t-1}^{*}\right) \phi_{t}+\frac{1}{Y}\left(\frac{P_{H, t}}{P_{t}}\left(\tilde{\Psi}_{F, t} S_{t}\right)^{\eta} Y_{t}^{*}-q_{t}(1-\alpha)\left(\frac{P_{F, t}}{P_{t}}\right)^{-\eta} C_{t}\right)
\end{aligned}
$$

Para a linearização do primeiro termo do lado direito da equação anterior utilizamos a relação de estado estacionário $1 / \beta=\left(1-i^{*}\right) / \Pi^{*}$ obtida a partir das condições de primeira ordem do problema do agente representativo. Como o endividamento externo líquido $A_{t}$ pode assumir valores negativos, esta variável somente é linearizada, e não log-linearizada. Por fim, utilizamos a definição que no estado estacionário temos $A=0$. Para o segundo termo da equação, utilizamos as relações já utilizadas na log-linearização da condição de equilíbrio no mercado doméstico de bens $C_{H}^{*}=Y^{*}=\alpha C=\alpha Y$, e obtemos a expressão:

$$
a_{t}=\frac{1}{\beta} a_{t-1}+\alpha\left(p_{H, t}-p_{t}+\eta\left(\psi_{F, t}+s_{t}\right)+y_{t}^{*}-q_{t}+\eta\left(p_{F, t}-p_{t}\right)-c_{t}\right)
$$

Utilizando as relações $p_{H, t}-p_{t}=-\alpha s_{t}, p_{F, t}-p_{t}=(1-\alpha) s_{t}, q_{t}=\psi_{F, t}+(1-\alpha) s_{t}$ e $y_{t}^{*}-c_{t}=\frac{y_{t}-c_{t}}{\alpha}-\eta(2-\alpha)$, obtemos a expressão final para a restrição orçamentária:

$$
a_{t}=\beta^{-1} a_{t-1}-\alpha\left(s_{t}+\Psi_{F, t}\right)+y_{t}-c_{t}
$$




\section{A.2.4}

\section{Curva de Philips: Produtores domésticos}

Iniciamos com a log-linearização da equação de precificação das firmas domésticas (A-2). Dividindo a equação por $P_{H, t-1}$ obtemos:

$$
\mathbb{E}_{t} \sum_{\tau=0}^{\infty} \theta_{H}^{\tau} Q_{t, t+\tau} y_{H, t+\tau \mid t}\left[\frac{P_{H, t}^{*}}{P_{H, t-1}} \Pi_{H, t-1, t+\tau-1}^{\delta_{H}}-\frac{\varepsilon}{\varepsilon-1} \Pi_{H, t-1, t+\tau} M C_{t+\tau}\right]=0
$$

No estado estacionário o custo marginal é $\frac{\epsilon-1}{\epsilon}$, o fator de desconto estocástico é $Q_{t, t+\tau}=\beta^{\tau}$ e a condição de inflação zero implica que $P_{H}^{*}=P_{H}=$ $P$. Utilizando estas relações obtemos a log-linearização da equação acima:

$$
\mathbb{E}_{t} \sum_{\tau=0}^{\infty}\left(\theta_{H} \beta\right)^{\tau}\left[p_{t}^{*}-p_{H, t-1}+\delta_{H}\left(p_{H, t+\tau-1}-p_{H, t-1}\right)-\left(m c_{t+\tau}+p_{H, t+\tau}-p_{H, t-1}\right)\right]
$$

Manipulando a equação obtemos:

$$
p_{t}^{*}-p_{H, t-1}=\mathbb{E}_{t} \sum_{\tau=0}^{\infty}\left(\theta_{H} \beta\right)^{\tau}\left[\left(1-\theta_{H} \beta\right) m c_{t+\tau}+\left(1-\delta_{H} \theta_{H} \beta\right) \pi_{H, t+\tau}\right]
$$

E então uma representação recursiva:

$$
p_{t}^{*}-p_{H, t-1}=\left(1-\theta_{H} \beta\right) m c_{t}+\left(1-\theta_{H} \beta\right) m c_{t}+\left(\theta_{H} \beta\right) \mathbb{E}_{t}\left[p_{t+1}^{*}-p_{H, t}\right]
$$

A próxima etapa é obter a expressão log-linearizada do índice geral de preços doméstico (2-18):

$$
p_{H, t}=\left(1-\theta_{H}\right) p_{H, t}^{*}+\theta_{H}\left(\left(1+\delta_{H}\right) p_{H, t-1}-\delta_{H} p_{H, t-2}\right)
$$

Subtraindo $p_{H, t-1}$ de ambos os lados e rearranjando obtemos:

$$
p_{H, t}^{*}-p_{H, t-1}=\frac{\pi_{H, t}}{1-\theta_{H}}-\frac{\theta_{H} \delta_{H}}{1-\theta_{H}} \pi_{H, t-1}
$$

Por fim substituímos esta expressão na equação recursiva anterior para obter a curva de Philips:

$$
\pi_{H, t}-\delta_{H} \pi_{H, t-1}=\frac{\left(1-\theta_{H}\right)\left(1-\theta_{H} \beta\right)}{\theta_{H}} m c_{t}+\beta \mathbb{E}_{t}\left(\pi_{H, t+1}-\delta_{H} \pi_{H, t}\right)
$$




\section{A.2.5}

\section{Curva de Philips: Importadores}

O procedimento de derivação da curva de Philips para os varejistas importadores domésticos é análogo ao apresentado na seção anterior. A expressão final é:

$$
\pi_{F, t}-\delta_{F} \pi_{F, t-1}=\frac{\left(1-\theta_{F}\right)\left(1-\theta_{F} \beta\right)}{\theta_{F}} \Psi_{F, t}+\beta \mathbb{E}_{t}\left(\pi_{F, t+1}-\delta_{F} \pi_{F, t}\right)+\varepsilon_{c p, t}
$$

Seguindo a abordagem de Justiniano e Preston (2010), introduzimos nesta curva de Philips um choque de custos $\varepsilon_{c p, t}$ para capturar variações ineficientes no mark-up.

\section{A.2.6}

\section{Custo marginal}

Iniciamos com a log-linearização das equações do custo marginal dos produtores domésticos (2-15), da oferta ótima de trabalho pelos agentes (2-11) e da função de produção (2-14), obtendo respectivamente:

$$
\begin{gathered}
m c_{t}=w_{t}-p_{H, t}-\varepsilon_{a, t} \\
w_{t}-p_{t}=\varphi n_{t}+\sigma(1-h)^{-1}\left(c_{t}-h c_{t-1}\right) \\
y_{H, t}=n_{t}+\varepsilon_{a, t}
\end{gathered}
$$

Agregando estas equações obtemos:

$$
m c_{t}=p_{t}-p_{H, t}+\phi y_{t}+\sigma(1-h)^{-1}\left(c_{t}-h c_{t-1}\right)-(1+\varphi) \varepsilon_{a, t}
$$

Por fim, utilizando a relação $p_{t}-p_{H, t}=\alpha s_{t}$, obtemos a expressão final:

$$
m c_{t}=\alpha s_{t}+\phi y_{t}+\sigma(1-h)^{-1}\left(c_{t}-h c_{t-1}\right)-(1+\varphi) \varepsilon_{a, t}
$$

\section{A.2.7}

\section{Paridade descoberta da taxa de juros}

Iniciamos com a log-linearização da condição de otimalidade 2-13 do problema do consumidor, obtendo:

$$
i_{t}=\mathbb{E}_{t} e_{t+1}-e_{t}+i_{t}^{*}+\hat{\phi}_{t+1}
$$


Em seguida obtemos a expressão log-linear para a equação 2-5 que representa o prêmio de risco:

$$
\hat{\phi}_{t+1}=-\chi a_{t}+\varepsilon_{s, t}
$$

Agregando estas duas equações obtemos a expressão final para a paridade descoberta da taxa de juros:

$$
i_{t}=i_{t}^{*}+\mathbb{E}_{t} e_{t+1}-e_{t}-\chi a_{t}+\varepsilon_{s, t}
$$


B

\section{Modelo log-linearizado}

Nesta seção apresentamos o sistema completo de equações loglinearizadas utilizadas na estimação.

- Equação de Euler

$$
c_{t}-h c_{t-1}=\mathbb{E}_{t}\left(c_{t+1}-h c_{t}\right)-\frac{1-h}{\sigma}\left(i_{t}-\mathbb{E}_{t} \pi_{t+1}\right)+\frac{1-h}{\sigma}\left(\varepsilon_{g, t}-\mathbb{E}_{t} \varepsilon_{g, t+1}\right)
$$

- Equilíbrio no mercado de bens

$$
y_{t}=(1-\alpha) c_{t}+\alpha \eta(2-\alpha) s_{t}+\alpha \eta \Psi_{F, t}+\alpha y_{t}^{*}
$$

- Definição de termos de troca

$$
\Delta s_{t}=\pi_{F, t}-\pi_{H, t}
$$

- Relação entre taxa de câmbio real e termos de troca:

$$
q_{t}=\Psi_{F, t}+(1-\alpha) s_{t}
$$

- Relação entre taxa de câmbio real e nominal

$$
q_{t}=q_{t-1}+e_{t}-e_{t-1}+\pi_{t}^{*}-\pi_{t}
$$

- Curva de Philips: Produtores domésticos

$$
\begin{gathered}
\pi_{H, t}-\delta_{H} \pi_{H, t-1}=\frac{\left(1-\theta_{H}\right)\left(1-\theta_{H} \beta\right)}{\theta_{H}} m c_{t}+\beta \mathbb{E}_{t}\left(\pi_{H, t+1}-\delta_{H} \pi_{H, t}\right) \\
\text { onde: }
\end{gathered}
$$

$$
m c_{t}=\alpha s_{t}+\phi y_{t}+\sigma(1-h)^{-1}\left(c_{t}-h c_{t-1}\right)-(1+\varphi) \varepsilon_{a, t}
$$

- Curva de Philips: Importadores

$$
\pi_{F, t}-\delta_{F} \pi_{F, t-1}=\frac{\left(1-\theta_{F}\right)\left(1-\theta_{F} \beta\right)}{\theta_{F}} \Psi_{F, t}+\beta \mathbb{E}_{t}\left(\pi_{F, t+1}-\delta_{F} \pi_{F, t}\right)+\varepsilon_{c p, t}
$$

- Relação entre inflação e termos de troca

$$
\pi_{t}=\pi_{H, t}+\alpha \Delta s_{t}
$$

- Restrição orçamentária

$$
a_{t}=\beta^{-1} a_{t-1}-\alpha\left(s_{t}+\Psi_{F, t}\right)+y_{t}-c_{t}
$$


- Paridade descoberta da taxa de juros

$$
i_{t}=i_{t}^{*}+\mathbb{E}_{t} e_{t+1}+e_{t}-\chi a_{t}+\varepsilon_{s, t}
$$

- Regra de política monetária

- Regime de bandas cambiais

$$
i_{t}=\rho_{i, 1}^{B C} i_{t-1}+\rho_{i, 2}^{B C} i_{t-2}+\left(1-\rho_{i, 1}^{B C}-\rho_{i, 2}^{B C}\right)\left(\lambda_{\pi}^{B C} \pi_{t}+\lambda_{y}^{B C} y_{t}+\lambda_{e}^{B C} e_{x, t}\right)+\varepsilon_{m, t}^{B C}
$$

- Regime de metas para a inflação

$$
i_{t}=\rho_{i, 1}^{I T} i_{t-1}+\rho_{i, 2}^{I T} i_{t-2}+\left(1-\rho_{i, 1}^{I T}-\rho_{i, 2}^{I T}\right)\left(\lambda_{\pi}^{I T} \pi_{t}+\lambda_{y}^{I T} y_{t}+\lambda_{e}^{I T} \Delta e_{t}\right)+\varepsilon_{m, t}^{I T}
$$

- Setor externo

$$
A_{0}\left[\begin{array}{c}
Y_{t}^{*} \\
\pi_{t}^{*} \\
i_{t}^{*}
\end{array}\right]=A_{1}\left[\begin{array}{c}
Y_{t-1}^{*} \\
\pi_{t-1}^{*} \\
i_{t-1}^{*}
\end{array}\right]+\left[\begin{array}{c}
\varepsilon_{y}^{*} \\
\varepsilon_{\pi}^{*} \\
\varepsilon_{i}^{*}
\end{array}\right]
$$

$$
A_{0}=\left[\begin{array}{ccc}
1 & 0 & 0 \\
a_{0, \pi y} & 1 & 0 \\
a_{0, i y} & a_{0, i \pi} & 1
\end{array}\right] \quad A_{t}=\left[\begin{array}{ccc}
a_{t, y y} & a_{t, y \pi} & a_{t, y i} \\
a_{t, \pi y} & a_{t, \pi \pi} & a_{t, \pi i} \\
a_{t, i y} & a_{t, i \pi} & a_{t, i i}
\end{array}\right] \quad t=1
$$

- Choques estruturais

$$
\begin{gathered}
\varepsilon_{a, t}=\rho_{a} \varepsilon_{a, t-1}+\sigma_{a} \epsilon_{a, t} \\
\varepsilon_{g, t}=\rho_{g} \varepsilon_{g, t-1}+\sigma_{g} \epsilon_{g, t} \\
\varepsilon_{c p, t}=\rho_{c p} \varepsilon_{c p, t-1}+\sigma_{c p} \epsilon_{c p, t} \\
\varepsilon_{s, t}=\rho_{s} \varepsilon_{s, t-1}+\sigma_{s} \epsilon_{s, t} \\
\varepsilon_{m, t}=\sigma_{m} \epsilon_{m, t} \\
\varepsilon_{y^{*}, t}=\sigma_{y^{*}} \epsilon_{y^{*}, t} \\
\varepsilon_{\pi^{*}, t}=\sigma_{\pi^{*}} \epsilon_{\pi^{*}, t} \\
\varepsilon_{i^{*}, t}=\sigma_{i^{*}} \epsilon_{i^{*}, t} \\
\epsilon_{x, t} \sim N(0,1) \quad \mathbb{E}\left[\epsilon_{x} \epsilon_{y}\right]=0, \quad \forall x, y
\end{gathered}
$$




\section{C \\ Filtro de Kalman com mudança de regime}

Descrevemos nesta seção o procedimento recursivo utilizado por Curdia e Finocchiaro (2012) para o cálculo da função de verossimilhança incorporando a mudança de regime através da utilização do filtro de Kalman.

Como descrito na seção 2.2 a distribuição a posteriori dos parâmetros é proporcional ao produto da distribuição a priori e da função de verossimilhança para os dados de cada subperíodo da amostra correspondente aos dois regimes de política monetária.

$$
P\left(\theta \mid Y_{T}\right) \propto L\left(Y_{t \in B C} \mid \theta\right) \times L\left(Y_{t \in I T} \mid \theta\right) \times P(\theta)
$$

Iniciamos o procedimento recursivo aplicando o filtro de Kalman na representação estado-espaço correspondente ao regime de bandas cambiais reproduzida em seguida:

$$
\begin{gathered}
X_{t}=A^{B C}(\theta) X_{t-1}+B^{B C}(\theta) \epsilon_{t} \\
Y_{t}=C(\theta) X_{t}+D(\theta) \omega_{t}
\end{gathered}
$$

Nosso modelo não apresenta erros de medidas na equação de observação e portanto a matriz $D$ é nula. Assumindo normalidade para os choques exógenos $\epsilon_{t}$ teremos para cada periodo de tempo:

$$
y_{t} \mid\left\{y_{s}\right\}_{s=0}^{t-1} \sim N\left(\mu_{t}(\theta), \Sigma_{t}(\theta)\right)
$$

onde $\mu_{t}(\theta)$ e $\Sigma_{t}(\theta)$ são respectivamente a média e variância condicionais de $y_{t}$, calculada através do filtro de Kalman.

O procedimento é iniciado com a atribuição de condições iniciais para o vetor de estados $X_{t}$. Adotamos para a média $X_{t-1 \mid t-1}$ um vetor de zeros e para a variância $P_{t-1 \mid t-1}$ utilizamos a variância incondicional de $X_{t}$. Então iteramos para frente até o último período do regime de bandas cambiais, como se segue:

$$
\begin{gathered}
X_{t \mid t-1}=A^{B C} X_{t-1 \mid t-1} \\
P_{t \mid t-1}=A^{B C} P_{t-1 \mid t-1}\left(A^{B C}\right)^{\prime}+B^{B C}\left(B^{B C}\right)^{\prime} \\
K_{t}=P_{t \mid t-1} C^{\prime}\left(C P_{t \mid t-1} C^{\prime}\right)^{-1} \\
X_{t \mid t}=X_{t \mid t-1}+K_{t} u_{t} \\
P_{t \mid t}=\left(I-K_{t} C\right) P_{t \mid t-1}
\end{gathered}
$$


A cada período computamos o erro de previsão e a função de logverossimilhança:

$$
\begin{gathered}
u_{t}=Y_{t}-Y_{t \mid t-1} \\
\Sigma_{u, t}=u_{t} u_{t}^{\prime} \\
l_{t}=-\frac{T}{2} \ln (2 \pi)-\ln \left|\Sigma_{u, t}^{-1}\right|+u_{t}^{\prime} \Sigma_{u, t} u_{t}
\end{gathered}
$$

Ao final da recursão é computada a log-verossimilhança da subamostra correspondente ao regime de bandas cambiais.

$$
\mathcal{L}^{B C}=\sum_{t \in B C} l_{t}
$$

Na transição para o período correspodente ao regime de metas para a inflação devemos fazer algumas considerações a respeito do estado inicial da economia a ser utilizado na recursão.

Para a média iremos utilizar o vetor de estados do último período do regime de bandas cambiais. De maneira similar, utilizamos a variância do último período do regime de bandas cambiais.

Definido o estado inicial, procedemos com o procedimento recursivo análago ao utilizado para o regime anterior, mas utilizando a representação estado-espaço associada ao regime de metas para a inflação. Portanto teremos deste período em diante:

$$
\begin{gathered}
X_{t \mid t-1}=A^{I T} X_{t-1 \mid t-1} \\
P_{t \mid t-1}=A^{I T} P_{t-1 \mid t-1}\left(A^{I T}\right)^{\prime}+B^{I T}\left(B^{I T}\right)^{\prime} \\
K_{t}=P_{t \mid t-1} C^{\prime}\left(C P_{t \mid t-1} C^{\prime}\right)^{-1} \\
X_{t \mid t}=X_{t \mid t-1}+K_{t} u_{t} \\
P_{t \mid t}=\left(I-K_{t} C\right) P_{t \mid t-1}
\end{gathered}
$$

Por fim, ao final da recursão é computada a log-verossimilhança da subamostra correspondente ao regime de metas para a inflação, computada de maneira similar ao regime anterior.

$$
\mathcal{L}^{I T}=\sum_{t \in I T} l_{t}
$$


D

\section{Tabelas e figuras}

Tabela D.1: Fontes dos dados utilizados na estimação.

\begin{tabular}{clc}
\hline \hline & Série & Fonte \\
\hline$y_{t}$ & PIB - Preços de mercado - Dessazonalizado & IBGE \\
$\pi_{t}$ & IPCA - Geral - Índice - Mensal & IBGE \\
$i_{t}$ & Taxa de juros - Over / SELIC (\% a.m.) & BCB \\
$s_{t}$ & Termos de troca - Índice & FUNCEX \\
$e_{t}$ & Taxa de câmbio nominal - R\$/US\$ - Compra & BCB \\
Exp. & Exportações (FOB) - US\$ (milhões) & FUNCEX \\
Imp. & Importações (FOB) - US\$ (milhões) & FUNCEX \\
$y_{t} *$ & USA Real GDP - Seasonally adjusted - & FRED St. \\
& Quarterly & Louis \\
$\pi_{t} *$ & USA CPI - All items - Quarterly & FRED St. \\
& USA 5-Year Treasury - Constant maturity & FRED St. \\
$i_{t}^{*}$ & Rate & Louis \\
\hline
\end{tabular}


Figura D.1: VAR - Estados Unidos - 3 month / 5 year rate
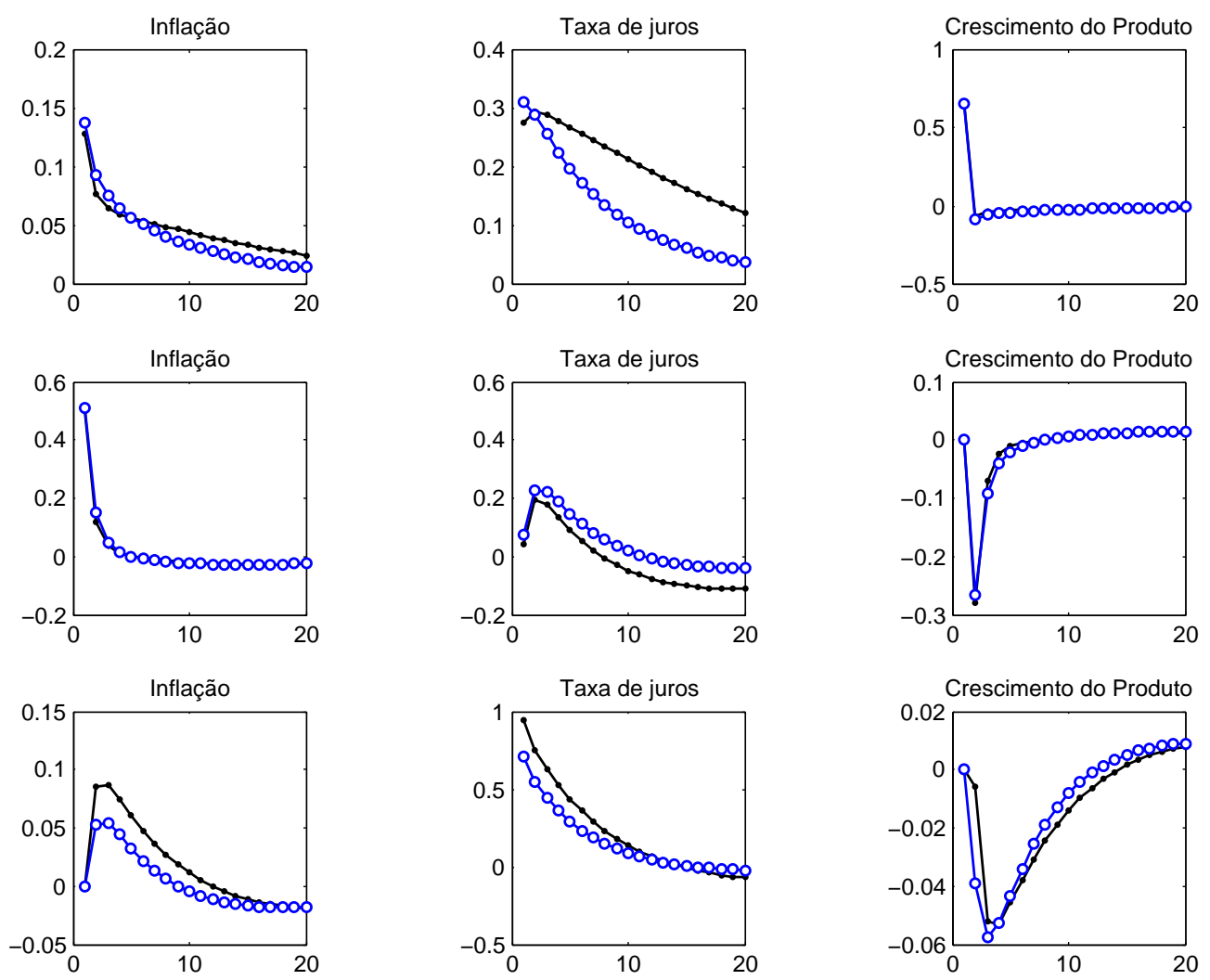

O setor externo, como apresentado na seção 2.1 é representado de forma simplificada por um $\operatorname{VAR}(1)$, no qual está incluída a taxa básica de juros. Embora a periodicidade dos dados seja trimestral, utilizaremos a taxa do título de cinco anos como variável observável. O objetivo é contornarmos o efeito do zero lower bound observado na série do instrumento de dívida trimestral americana a partir de 2009, sob consequência da crise financeira de 2008. A justificativa é simples. Verificamos que um modelo VAR com três variáveis (produto, inflação e taxa de juros) estimado para o período pré-crise com as taxas dos instrumentos de três meses ou de cinco anos produzem funções de resposta a impulso muito semelhantes. Como a taxa do instrumento de cinco anos manteve sua variabilidade no período posterior à crise consideramos que esta é mais apropriada para refletir as relações entre estas três variáveis que queremos capturar. 
Figura D.2: Séries temporais transformadas utilizadas na estimação.
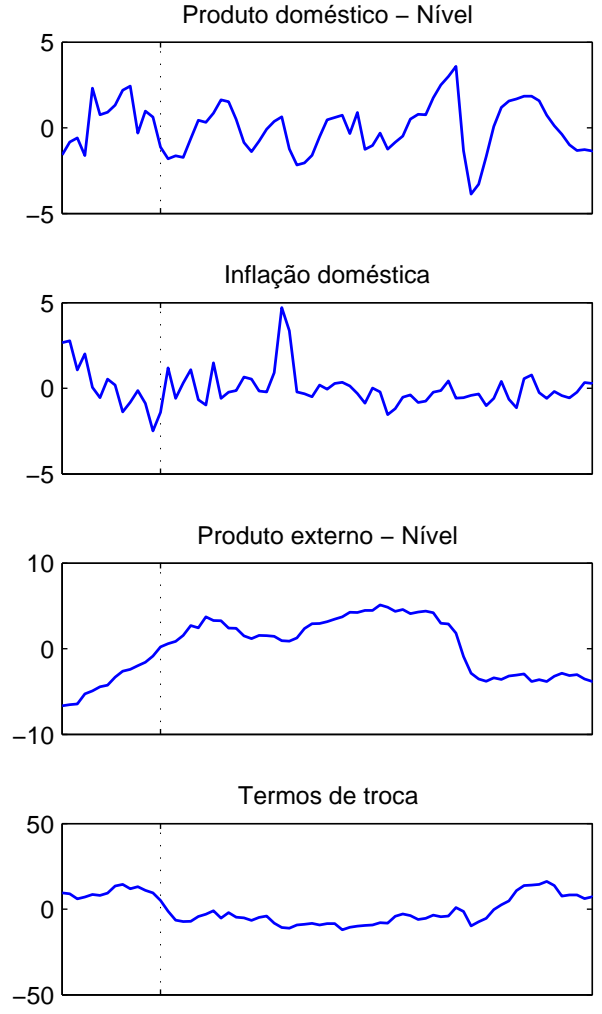
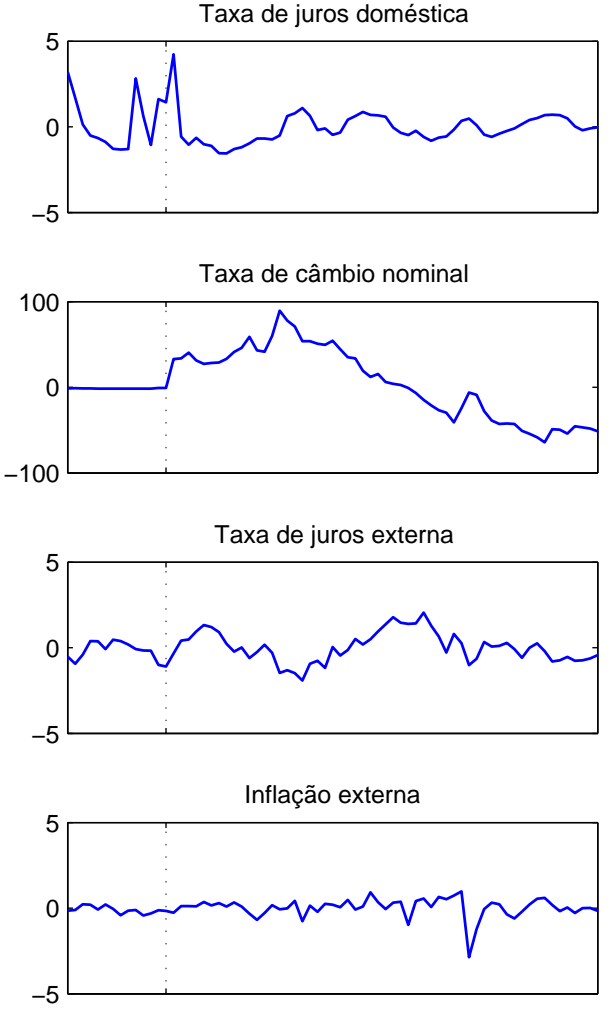
Tabela D.2: Distribuições a priori e a posteriori dos parâmetros.

\begin{tabular}{|c|c|c|c|c|c|}
\hline \multirow[b]{2}{*}{ Parâmetro } & \multirow[b]{2}{*}{ Distribuição } & \multicolumn{2}{|c|}{ a priori } & \multicolumn{2}{|c|}{ a posteriori } \\
\hline & & Moda & $\mathrm{DP}$ & Moda & $\mathrm{DP}$ \\
\hline$h$ & Beta & 0.85 & 0.05 & 0.70 & 0.03 \\
\hline$\sigma$ & Gama & 1.30 & 0.05 & 1.29 & 0.05 \\
\hline$\eta$ & Gama & 1.00 & 0.50 & 0.58 & 0.03 \\
\hline$\delta_{H}$ & Beta & 0.65 & 0.20 & 0.34 & 0.06 \\
\hline$\theta_{H}$ & Beta & 0.65 & 0.10 & 0.79 & 0.02 \\
\hline$\delta_{F}$ & Beta & 0.65 & 0.20 & 0.16 & 0.06 \\
\hline$\theta_{F}$ & Beta & 0.65 & 0.10 & 0.97 & 0.01 \\
\hline$\chi$ & Gama & 0.02 & 0.01 & 0.01 & 0.00 \\
\hline$\rho_{a}$ & Beta & 0.50 & 0.25 & 0.83 & 0.03 \\
\hline$\rho_{g}$ & Beta & 0.50 & 0.25 & 0.28 & 0.07 \\
\hline$\rho_{c p}$ & Beta & 0.50 & 0.25 & 0.14 & 0.06 \\
\hline$\sigma_{a}$ & Gama Inv & 1.00 & 0.75 & 6.02 & 0.26 \\
\hline$\sigma_{g}$ & Gama Inv & 1.00 & 0.75 & 9.94 & 0.63 \\
\hline$\sigma_{c p}$ & Gama Inv & 1.00 & 0.75 & 1.84 & 0.19 \\
\hline$\rho_{i, 1}^{B C}$ & Beta & 0.60 & 0.15 & 0.32 & 0.07 \\
\hline$\rho_{i, 2}^{B C}$ & Beta & 0.60 & 0.15 & 0.30 & 0.03 \\
\hline$\lambda_{\pi}^{B C}$ & Gama & 2.00 & 0.50 & 1.43 & 0.15 \\
\hline$\lambda_{y}^{B C}$ & Gama & 0.25 & 0.10 & 0.49 & 0.03 \\
\hline$\lambda_{e}^{B C}$ & Gama & 1.50 & 0.50 & 1.75 & 0.11 \\
\hline$\sigma_{m}^{B C}$ & Gama Inv & 1.00 & 0.75 & 1.47 & 0.11 \\
\hline$\rho_{s}^{B C}$ & Beta & 0.50 & 0.25 & 0.90 & 0.02 \\
\hline$\sigma_{s}^{B C}$ & Gama Inv & 1.00 & 0.75 & 0.98 & 0.15 \\
\hline$\rho_{i, 1}^{I T}$ & Beta & 0.60 & 0.15 & 0.54 & 0.06 \\
\hline$\rho_{i, 2}^{I T}$ & Beta & 0.60 & 0.15 & 0.22 & 0.03 \\
\hline$\lambda_{\pi}^{I T}$ & Gama & 2.00 & 0.50 & 1.94 & 0.11 \\
\hline$\lambda_{y}^{I T}$ & Gama & 0.25 & 0.10 & 0.55 & 0.06 \\
\hline$\lambda_{\Delta e}^{I T}$ & Gama & 1.50 & 0.50 & 0.16 & 0.04 \\
\hline$\sigma_{m}^{I T}$ & Gama Inv & 1.00 & 0.75 & 0.92 & 0.08 \\
\hline
\end{tabular}


Figura D.3: Distribuição a priori e a posteriori - Regime de bandas cambiais.

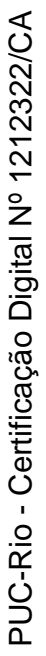
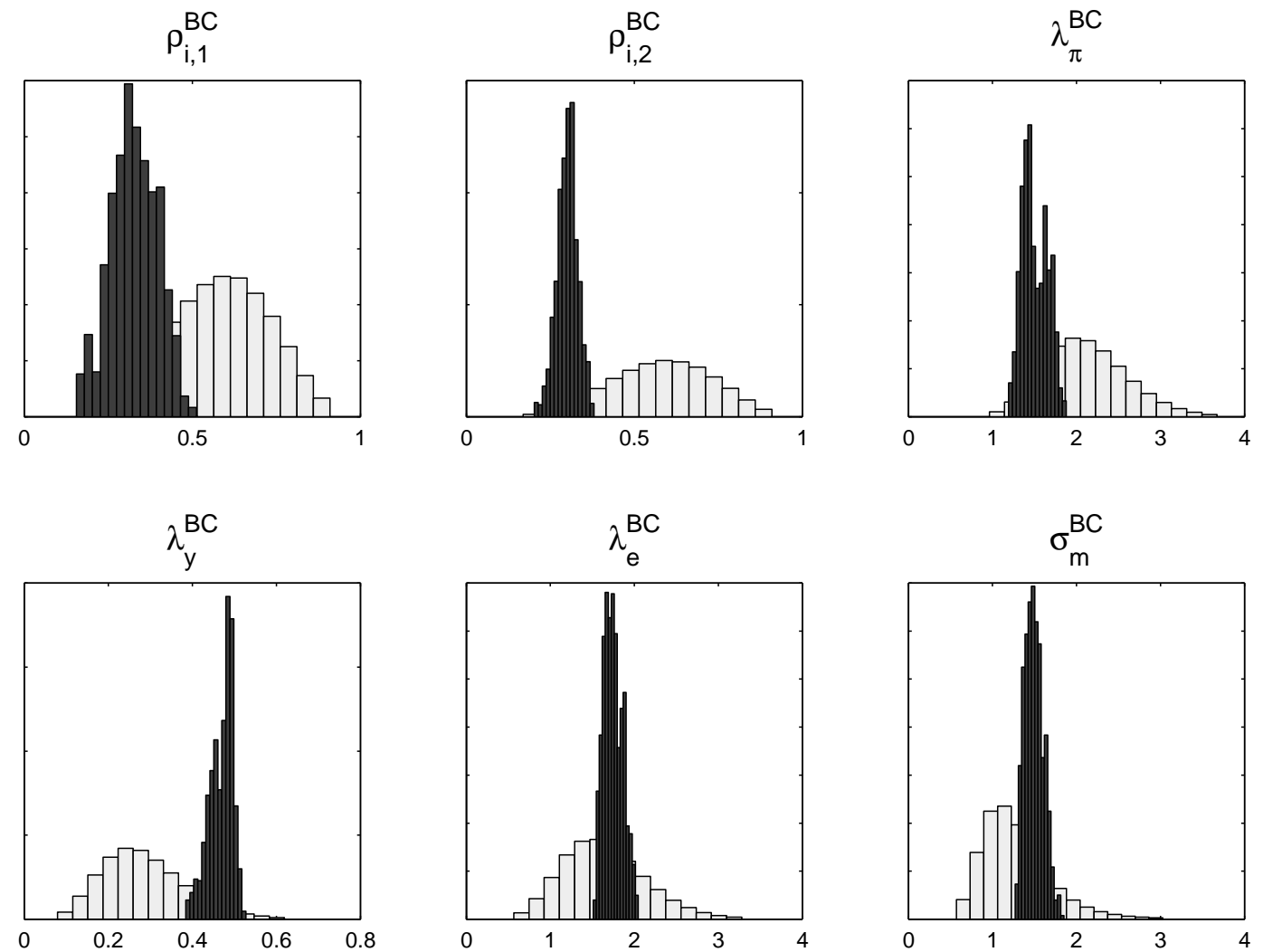

Dist. a priori (cor clara)| Dist. a posteriori (cor escura) 
Figura D.4: Distribuição a priori e a posteriori - Regime de metas para a inflação.

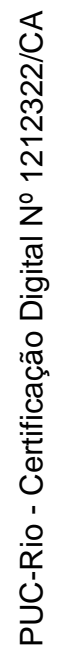
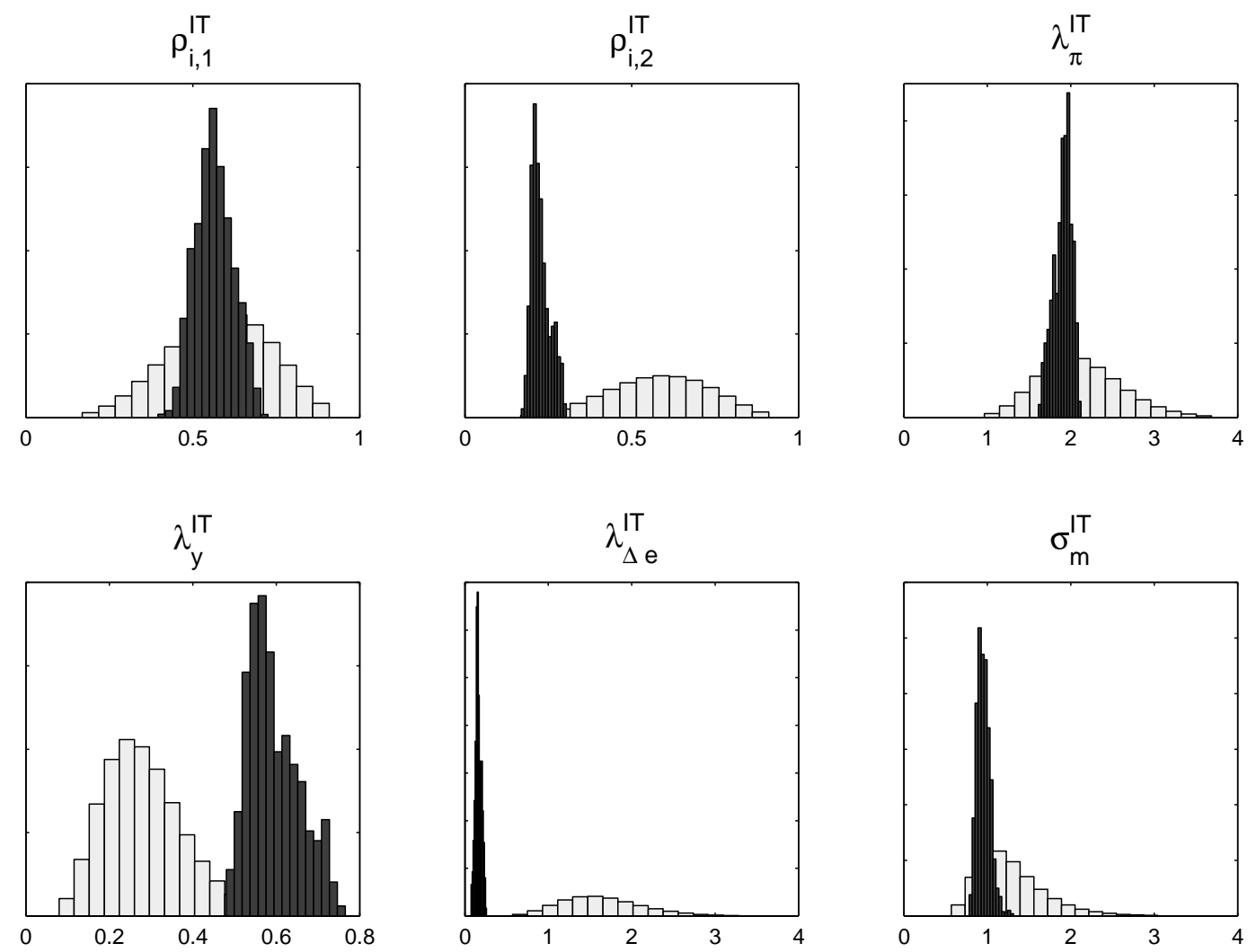

Dist. a priori (cor clara) | Dist. a posteriori (cor escura) 
Figura D.5: Resposta das variáveis a um choque contracionista de política monetária.
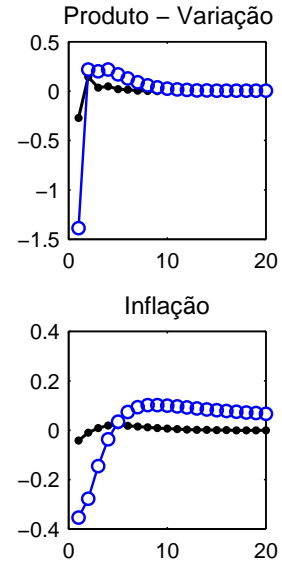

Câmbio nominal - Nível

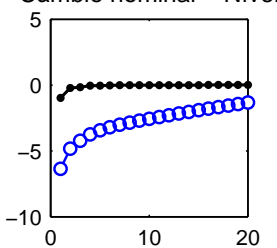

Câmbio nominal - Variação

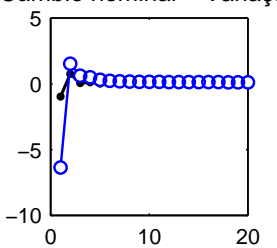

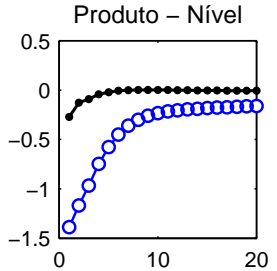

Inflação bens domésticos

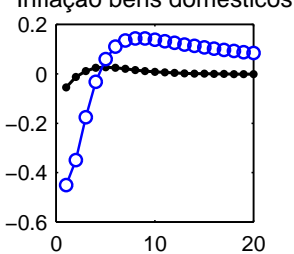

Câmbio real - Nível
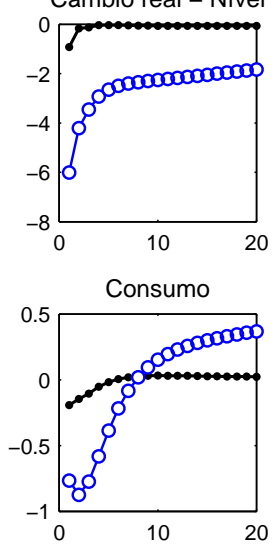

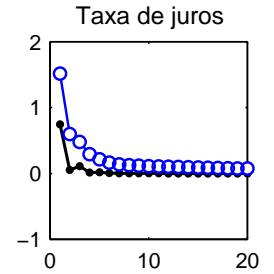

Inflação bens importados
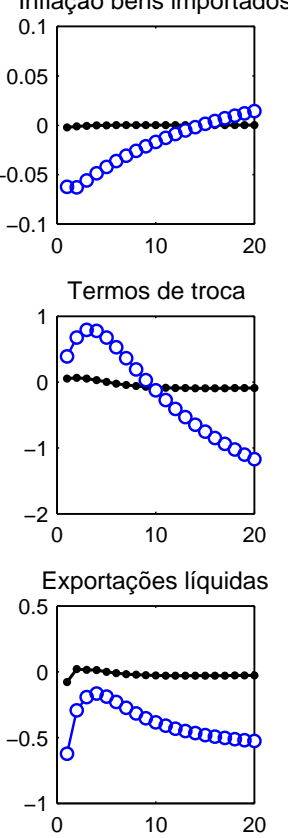
Figura D.6: Resposta das variáveis a um choque contracionista na política monetária externa.
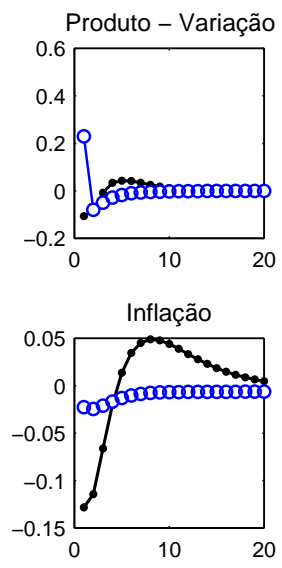

Câmbio nominal - Nível

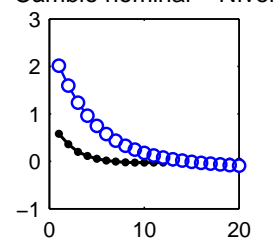

Câmbio nominal - Variação

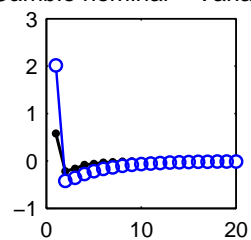

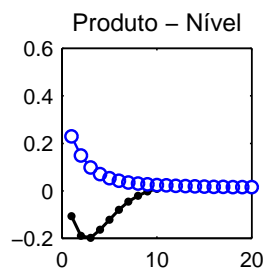

Inflação bens domésticos

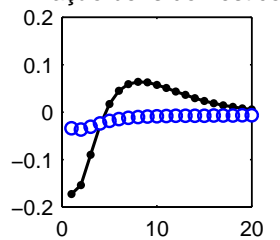

Câmbio real - Nível
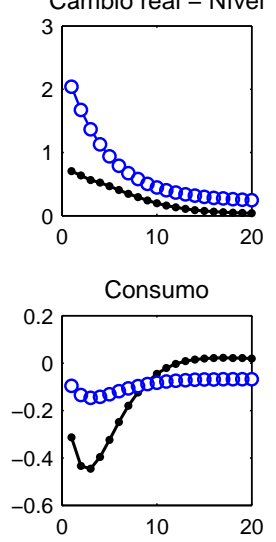

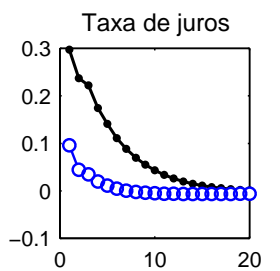

Inflaç̃ $\theta^{-B}$ Bens importados
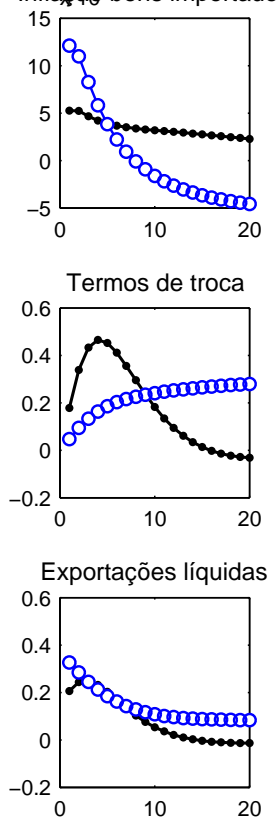
Figura D.7: Resposta das variáveis a um choque de custos (importações).

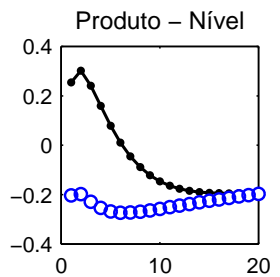

Inflação bens domésticos

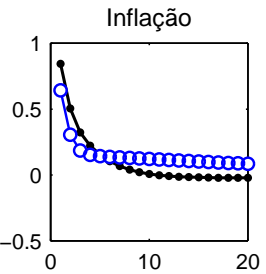

Câmbio nominal - Nível

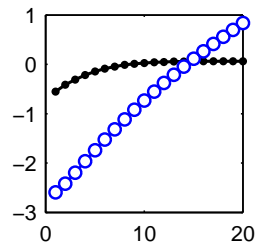

Câmbio nominal - Variação

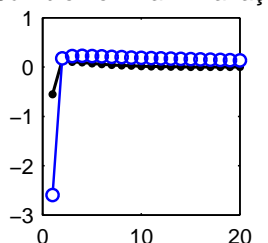

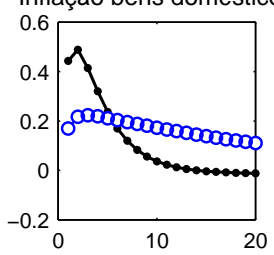
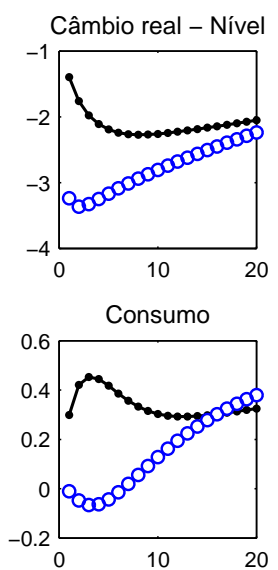

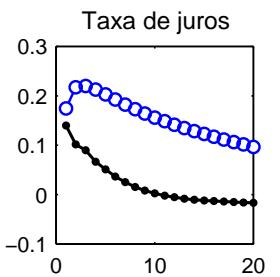

Inflação bens importados
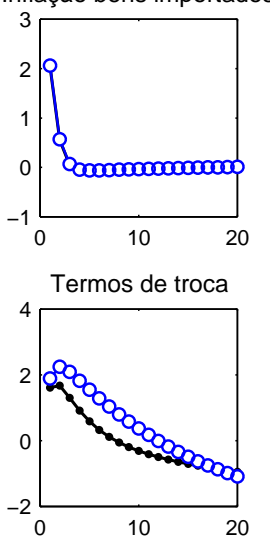

Exportações líquidas

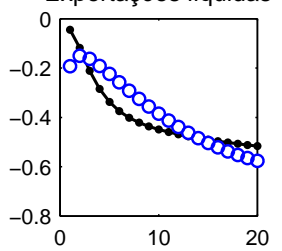


Figura D.8: Resposta das variáveis a um choque no prêmio de risco.
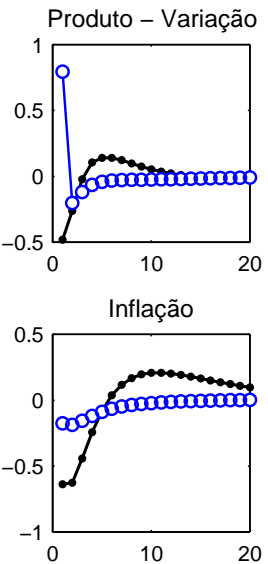

Câmbio nominal - Nível

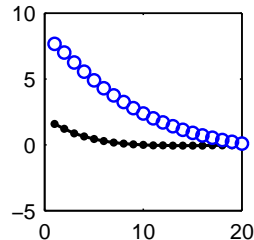

Câmbio nominal - Variação

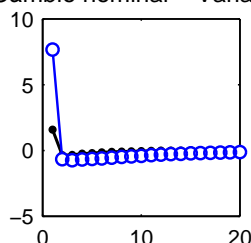

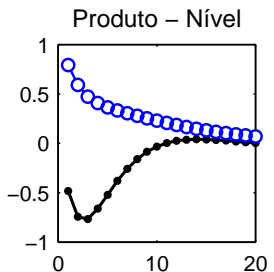

Inflação bens domésticos

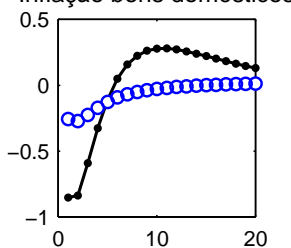

Câmbio real - Nível

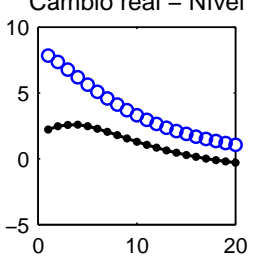

Consumo

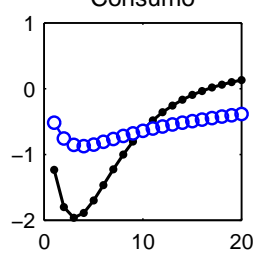

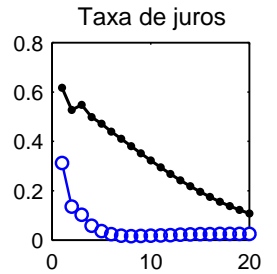

Inflação bens importados
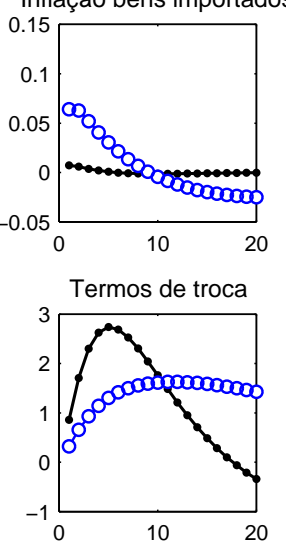

Exportações líquidas

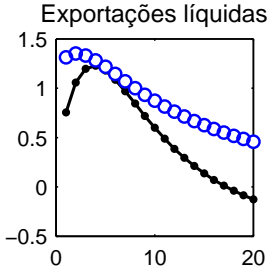


Figura D.9: Resposta das variáveis a um choque de tecnologia.

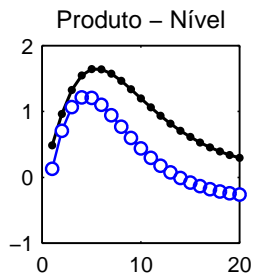

Inflação bens domésticos

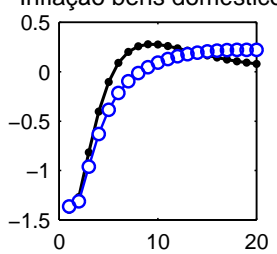

Câmbio real - Nível

Câmbio nominal - Nível

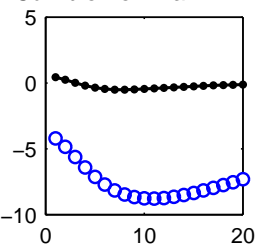

Câmbio nominal - Variação 2

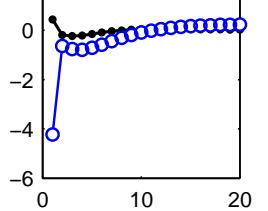

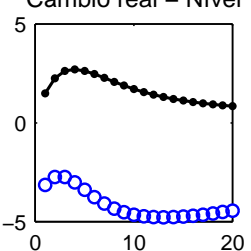

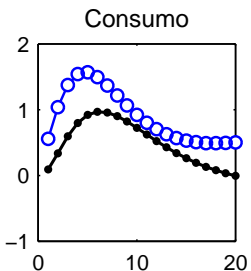

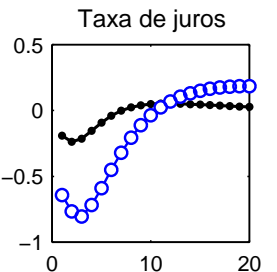

Inflação bens importados
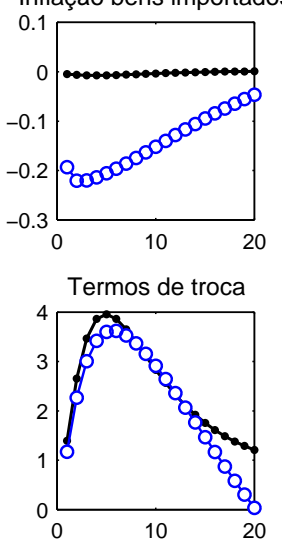

Exportações líquidas

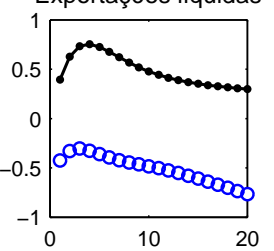


Tabela D.3: Decomposição de variância : Regime de bandas cambiais

\begin{tabular}{ccccccccc}
\hline \hline & $\varepsilon_{M}$ & $\varepsilon_{a}$ & $\varepsilon_{g}$ & $\varepsilon_{s}$ & $\varepsilon_{c p}$ & $Y^{*}$ & $\pi^{*}$ & $i^{*}$ \\
\hline 1 trim. & & & & & & & & \\
\hline $\mathrm{Y}$ & 3.03 & 9.76 & 71.03 & 9.56 & 2.67 & 3.32 & 0.20 & 0.42 \\
$\pi$ & 0.07 & 45.61 & 6.62 & 16.85 & 29.51 & 0.71 & 0.03 & 0.60 \\
$\mathrm{i}$ & 50.16 & 3.32 & 2.80 & 34.54 & 1.78 & 0.87 & 0.17 & 6.37 \\
$\mathrm{~s}$ & 0.05 & 34.66 & 5.10 & 13.21 & 46.03 & 0.44 & 0.00 & 0.51 \\
$\mathrm{e}$ & 21.54 & 4.37 & 4.29 & 56.56 & 6.99 & 0.04 & 0.01 & 6.20 \\
\hline 4 trim. & & & & & & & & \\
\hline $\mathrm{Y}$ & 0.88 & 47.22 & 30.54 & 16.03 & 2.12 & 2.11 & 0.23 & 0.87 \\
$\pi$ & 0.05 & 49.93 & 4.04 & 21.25 & 22.58 & 1.48 & 0.06 & 0.62 \\
$\mathrm{i}$ & 24.97 & 7.14 & 3.05 & 52.95 & 1.86 & 1.83 & 0.10 & 8.08 \\
$\mathrm{~s}$ & 0.02 & 57.68 & 2.09 & 25.43 & 12.67 & 1.30 & 0.00 & 0.80 \\
$\mathrm{e}$ & 13.20 & 3.80 & 3.45 & 65.61 & 7.93 & 0.40 & 0.09 & 5.51 \\
\hline 20 trim. & & & & & & & & \\
\hline $\mathrm{Y}$ & 0.33 & 76.46 & 11.57 & 7.76 & 2.14 & 1.12 & 0.22 & 0.40 \\
$\pi$ & 0.06 & 47.87 & 4.53 & 24.74 & 19.92 & 2.03 & 0.08 & 0.77 \\
$\mathrm{i}$ & 15.08 & 5.19 & 1.87 & 67.93 & 1.29 & 2.35 & 0.08 & 6.21 \\
$\mathrm{~s}$ & 0.05 & 59.54 & 1.50 & 23.11 & 5.82 & 9.49 & 0.01 & 0.49 \\
$\mathrm{e}$ & 10.00 & 22.73 & 2.81 & 52.87 & 6.62 & 0.58 & 0.13 & 4.25 \\
\hline
\end{tabular}


Tabela D.4: Decomposição de variância : Regime de metas para a inflação

\begin{tabular}{ccccccccc}
\hline \hline & $\varepsilon_{M}$ & $\varepsilon_{a}$ & $\varepsilon_{g}$ & $\varepsilon_{s}$ & $\varepsilon_{c p}$ & $Y^{*}$ & $\pi^{*}$ & $i^{*}$ \\
\hline 1 trim. & & & & & & & & \\
\hline $\mathrm{Y}$ & 15.20 & 0.71 & 53.85 & 26.34 & 1.71 & 0.38 & 0.00 & 1.81 \\
$\pi$ & 1.35 & 65.80 & 7.08 & 1.78 & 23.61 & 0.34 & 0.01 & 0.03 \\
$\mathrm{i}$ & 41.09 & 39.04 & 6.98 & 9.26 & 2.88 & 0.00 & 0.02 & 0.72 \\
$\mathrm{~s}$ & 0.54 & 25.81 & 4.25 & 1.93 & 67.11 & 0.31 & 0.01 & 0.04 \\
$\mathrm{e}$ & 7.80 & 18.18 & 1.30 & 59.94 & 6.86 & 2.17 & 0.30 & 3.46 \\
\hline 4 trim. & & & & & & & & \\
\hline $\mathrm{Y}$ & 11.19 & 38.71 & 29.52 & 17.01 & 2.44 & 0.19 & 0.01 & 0.94 \\
$\pi$ & 1.06 & 77.73 & 3.84 & 2.62 & 14.07 & 0.63 & 0.01 & 0.04 \\
$\mathrm{i}$ & 16.86 & 64.82 & 8.61 & 3.91 & 5.15 & 0.32 & 0.01 & 0.32 \\
$\mathrm{~S}$ & 0.72 & 56.65 & 1.95 & 5.63 & 33.83 & 1.09 & 0.02 & 0.10 \\
$\mathrm{e}$ & 5.12 & 32.34 & 0.67 & 50.22 & 6.00 & 2.98 & 0.49 & 2.18 \\
\hline 20 trim. & & & & & & & & \\
\hline $\mathrm{Y}$ & 7.48 & 54.04 & 15.83 & 13.87 & 7.43 & 0.77 & 0.01 & 0.57 \\
$\pi$ & 1.36 & 73.90 & 3.97 & 2.61 & 16.45 & 1.64 & 0.01 & 0.05 \\
$\mathrm{i}$ & 12.65 & 64.71 & 6.57 & 2.92 & 10.77 & 2.12 & 0.02 & 0.23 \\
$\mathrm{~S}$ & 0.83 & 55.48 & 0.74 & 18.65 & 12.36 & 11.45 & 0.10 & 0.39 \\
$\mathrm{e}$ & 2.20 & 74.52 & 0.16 & 16.95 & 2.08 & 2.97 & 0.57 & 0.56 \\
\hline
\end{tabular}


Figura D.10: Choques exógenos extraídos do modelo
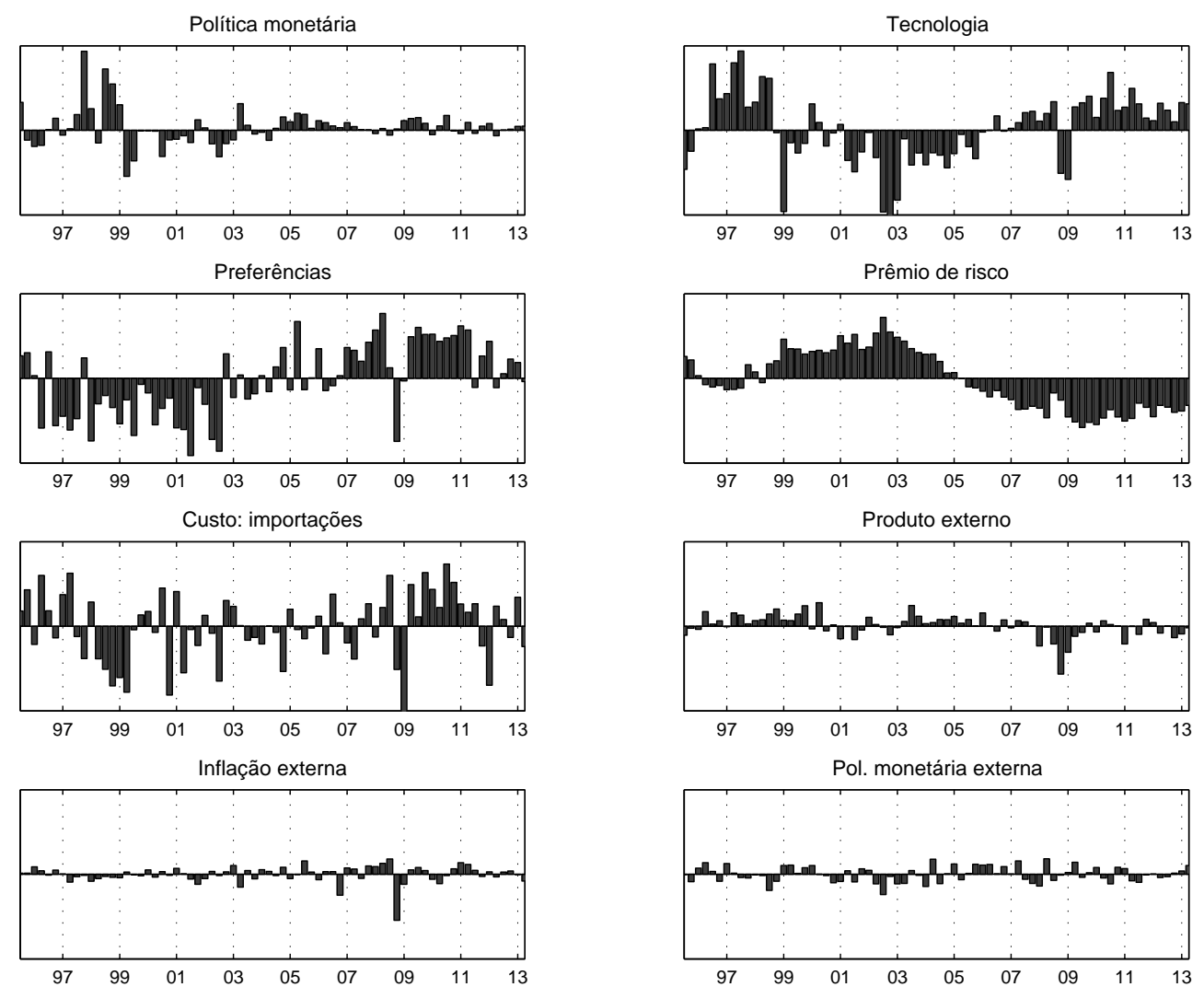
Figura D.11: Choques exógenos extraídos do modelo (Somente inovações)
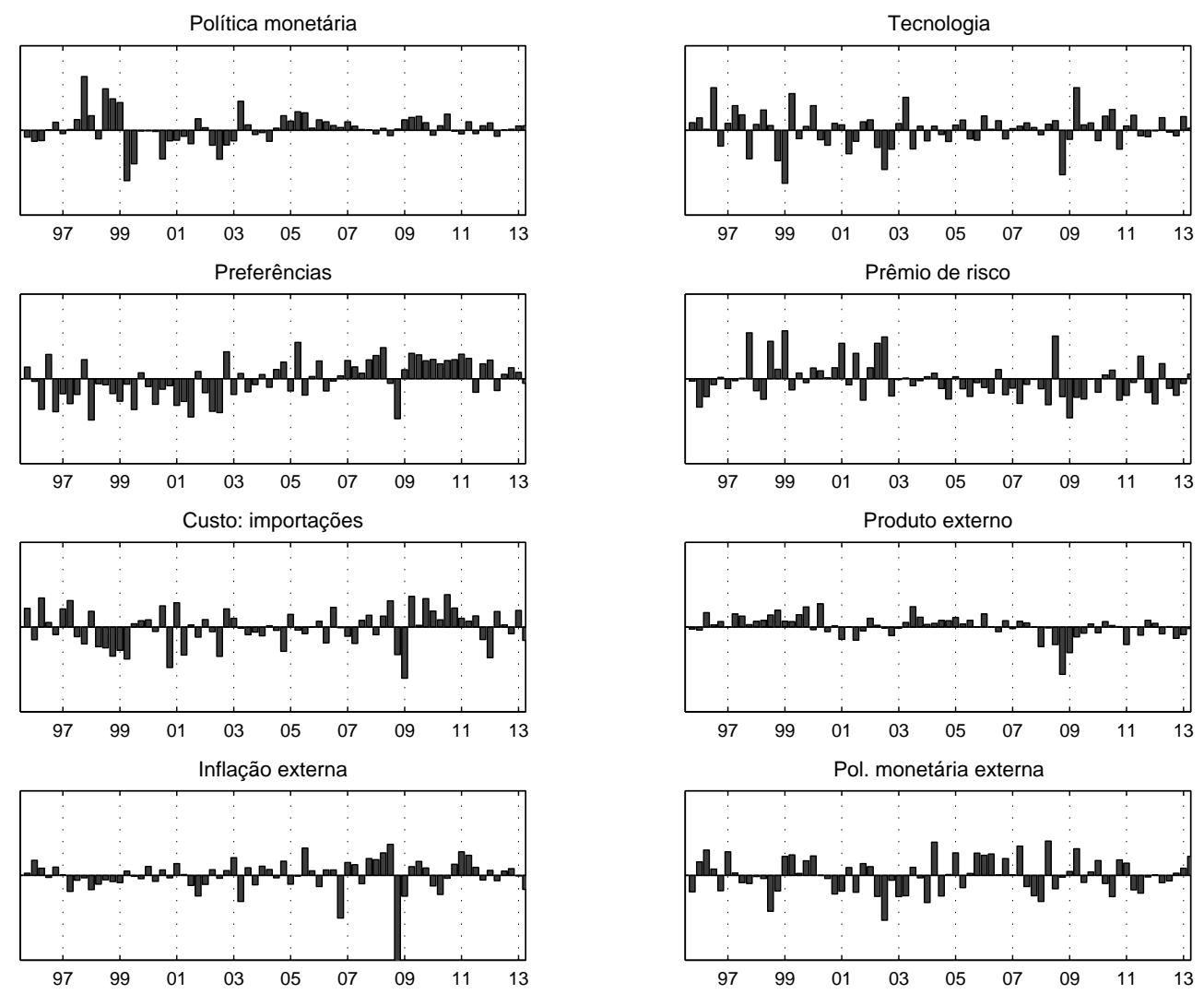
Figura D.12: Prêmio de risco: Choques exógenos e índice Embi + Brazil (JP Morgan)

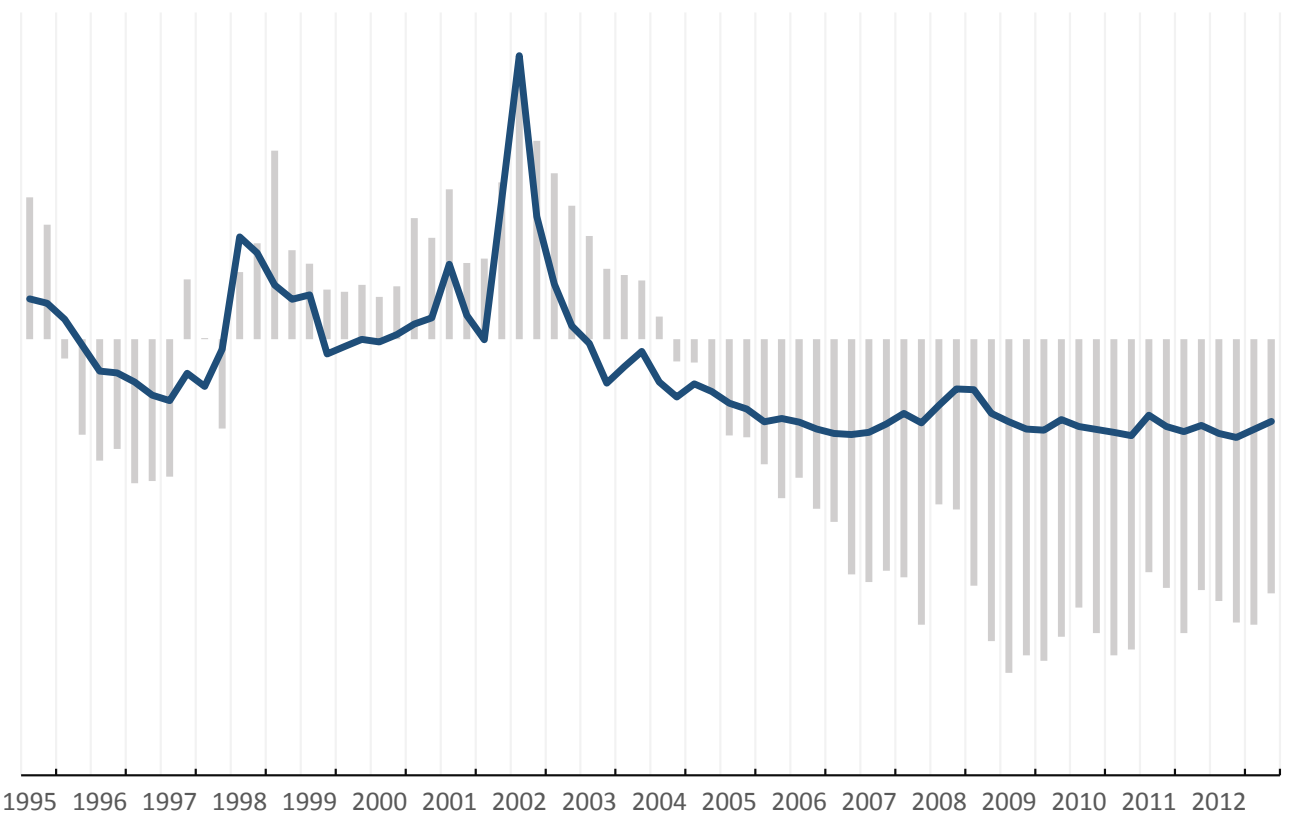

Choques exógenos (barras) | Índice Embi + Brazil (linha) 
Figura D.13: Contrafactual: Simulação dos efeitos da manutenção do regime de bandas cambiais.
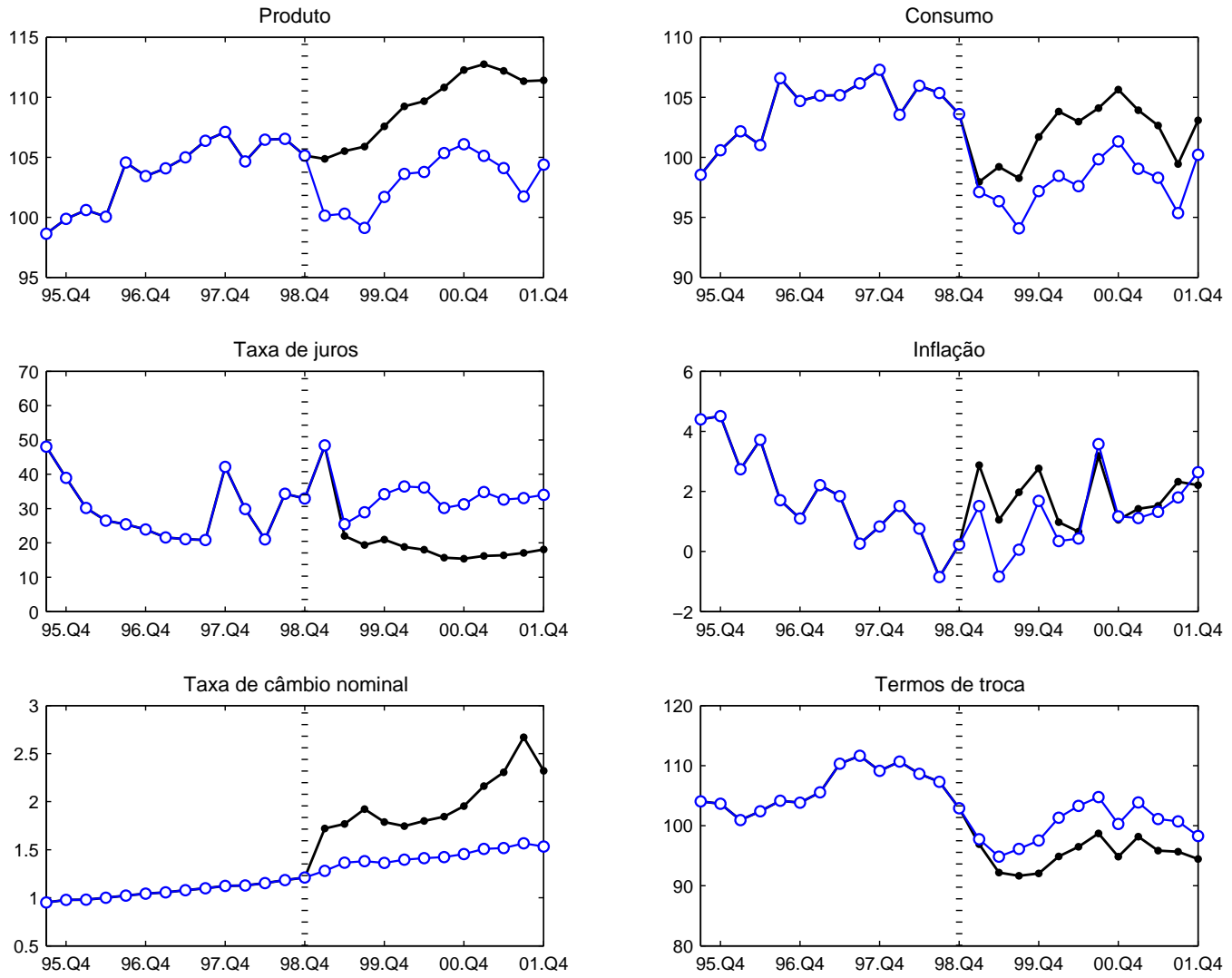

Série observada

Série simulada 
Figura D.14: Contrafactual: Simulação de uma desvalorização cambial mais acentuada no regime de bandas cambiais.
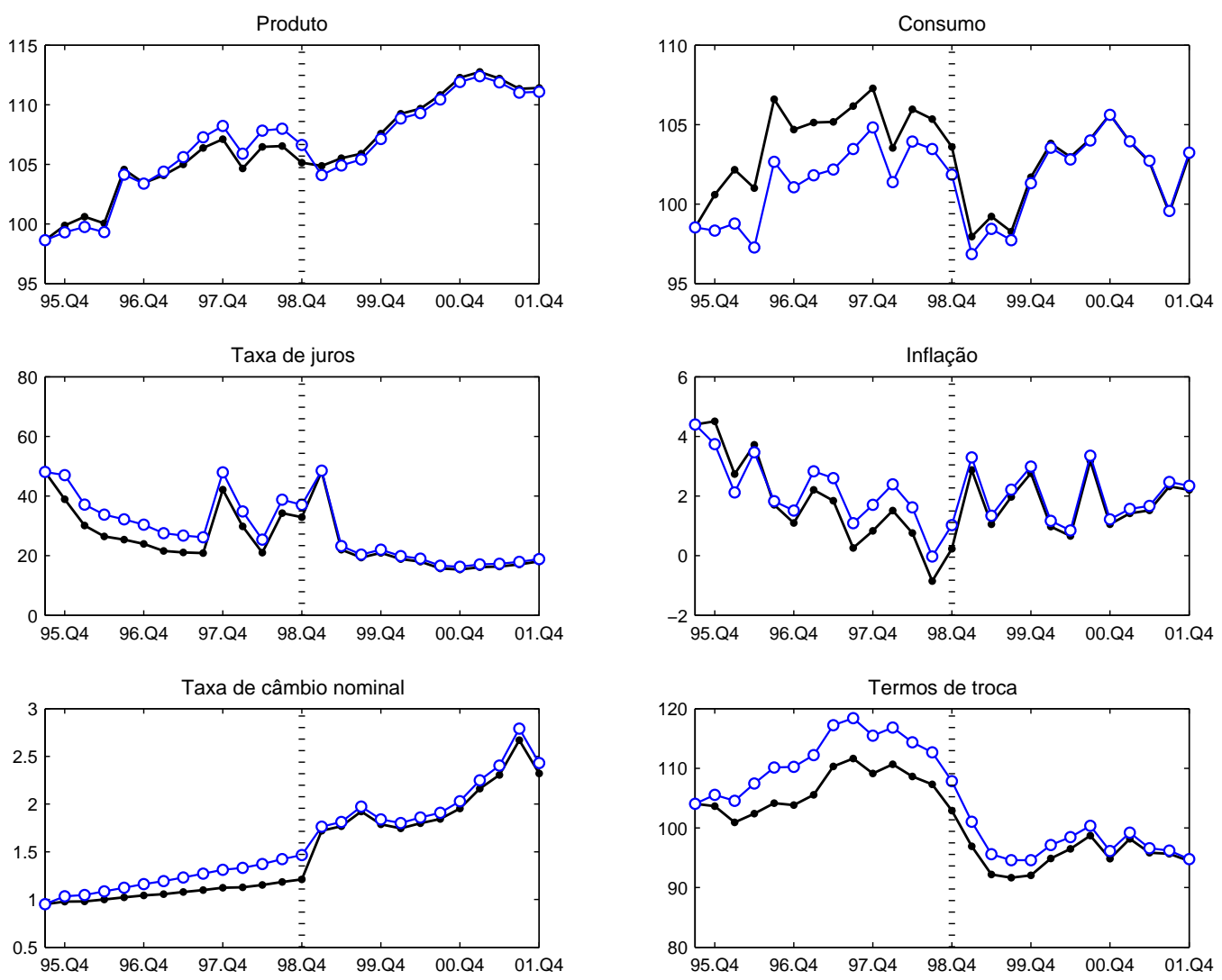
Figura D.15: Contrafactual: Simulação da antecipação do regime de metas para a inflação - Pré-crise da Ásia 1997 / Meta 8\% a.a.
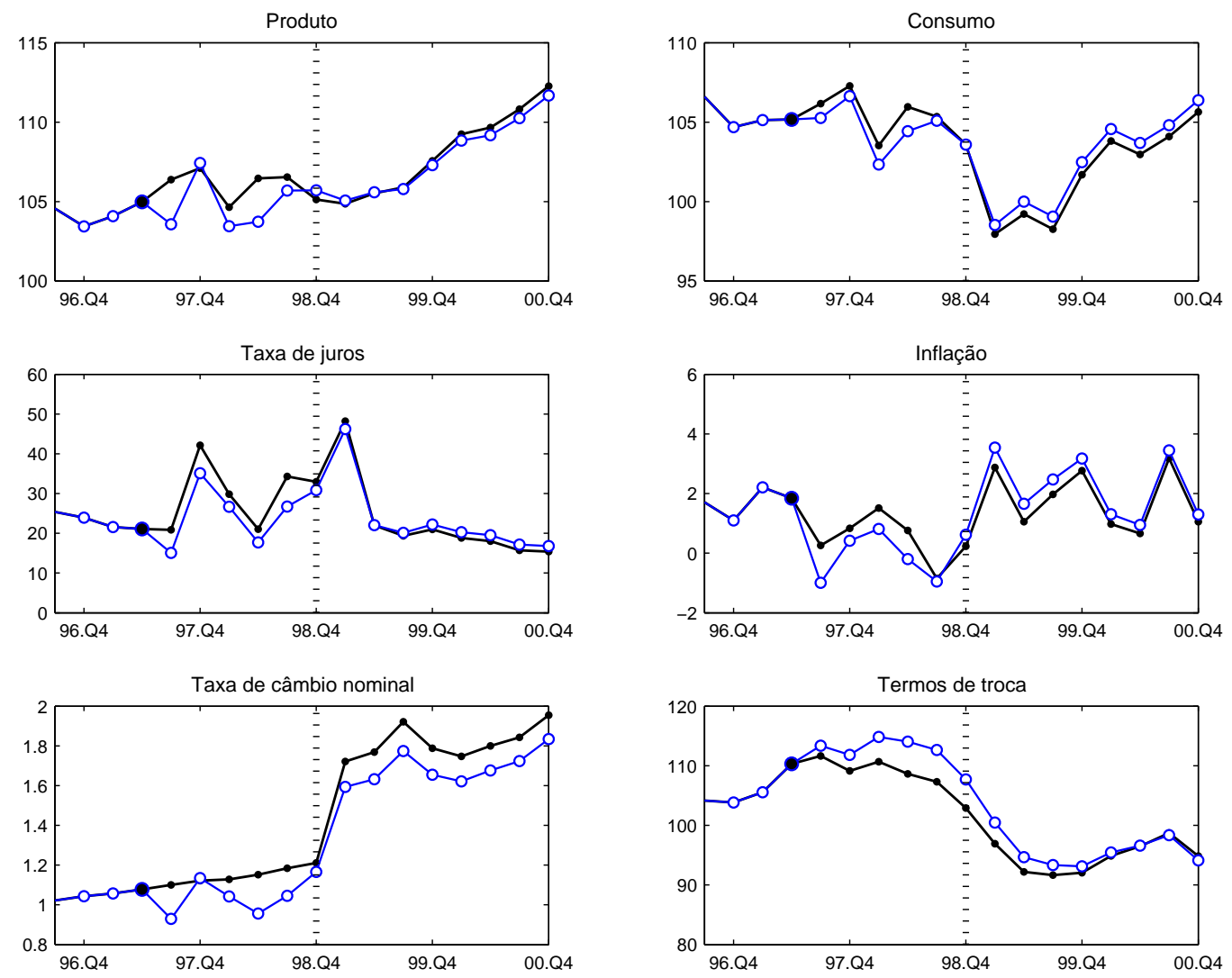
Figura D.16: Contrafactual: Simulação da antecipação do regime de metas para a inflação - Pré-crise da Rússia 1998 / Meta 8\% a.a.
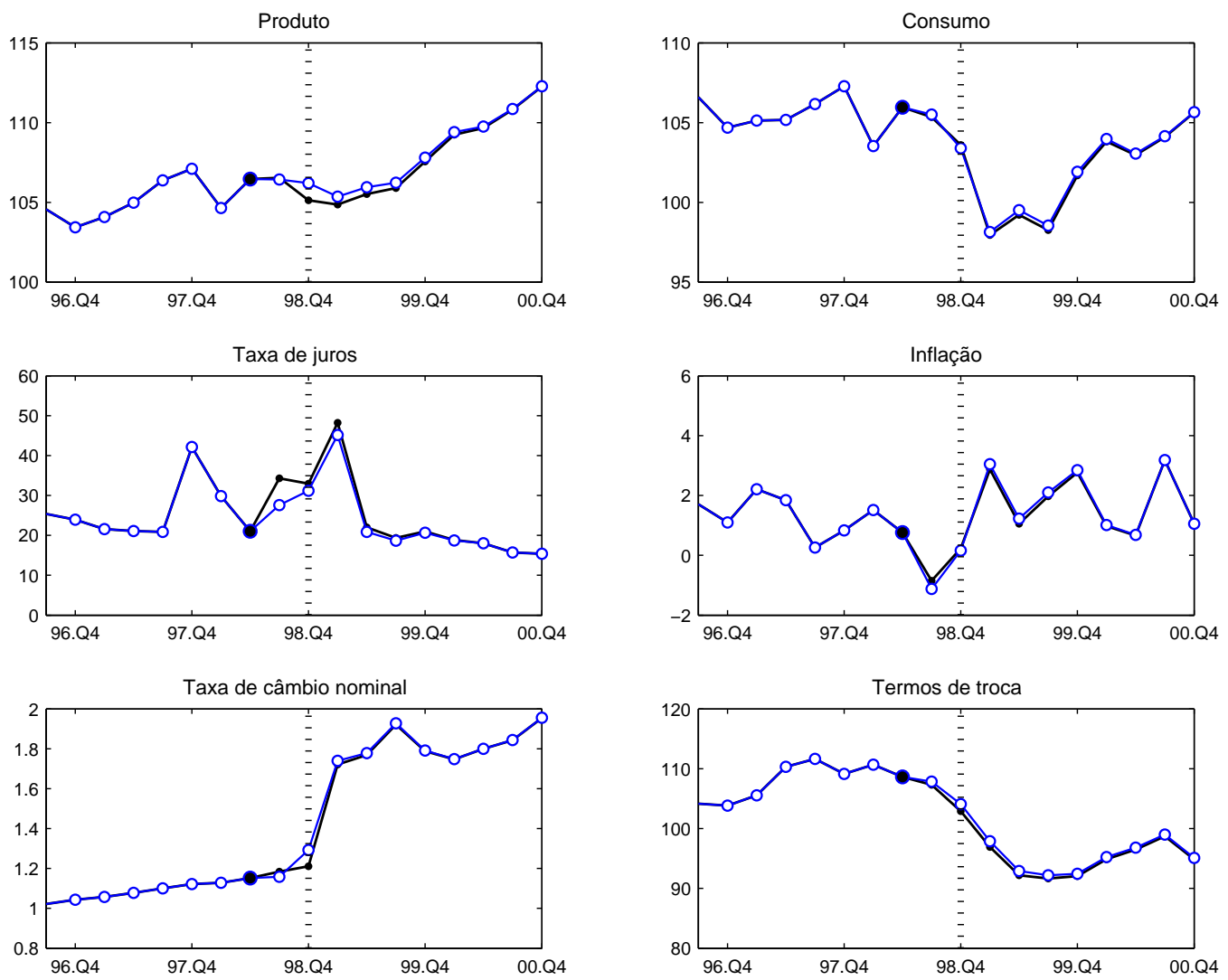
Figura D.17: Contrafactual: Simulação da antecipação do regime de metas para a inflação - Pré-crise da Rússia 1998 / Meta 5\% a.a.
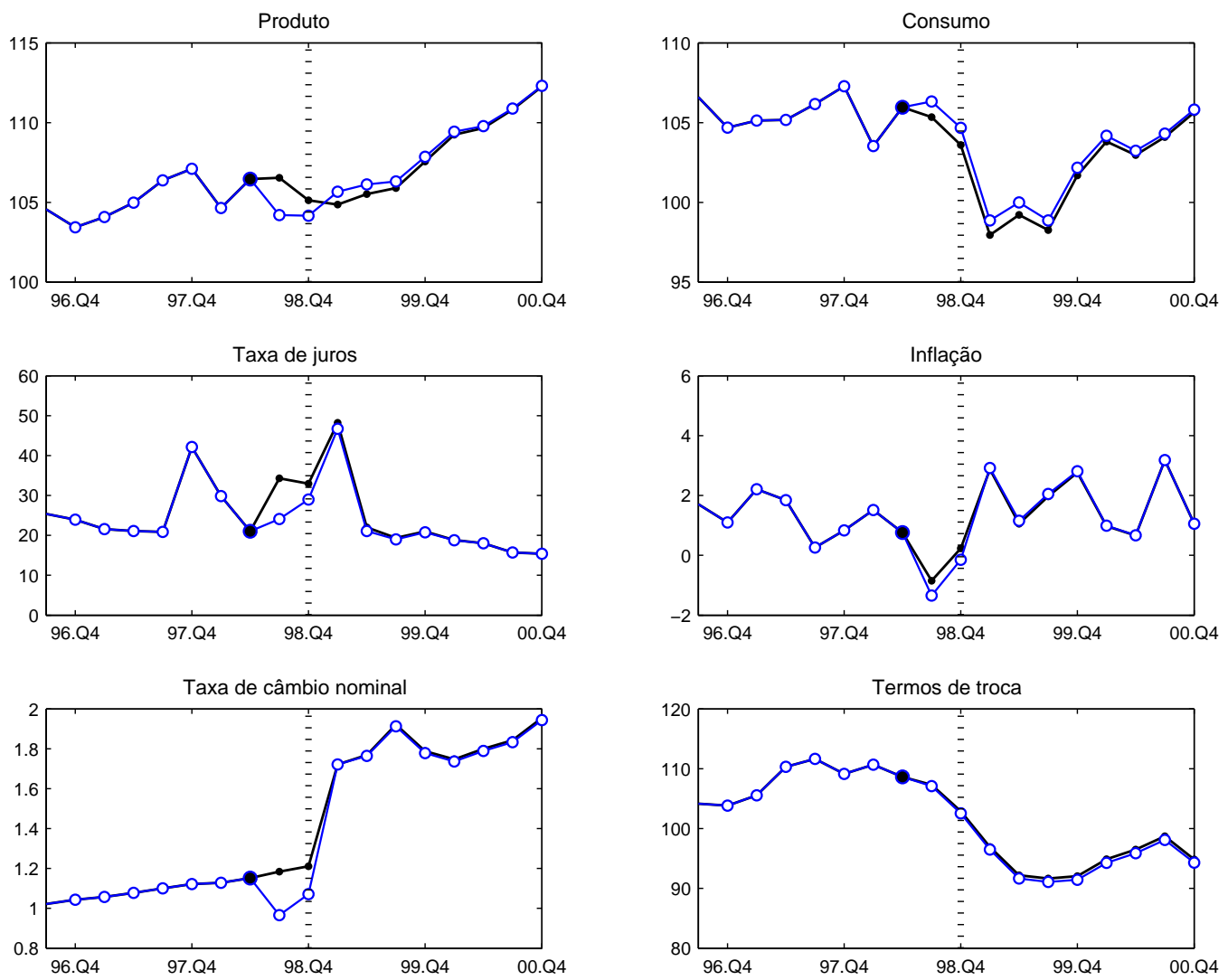
Figura D.18: Contrafactual: Simulação da antecipação do regime de metas para a inflação - Pré-crise da Rússia 1998 / Meta 10\% a.a.
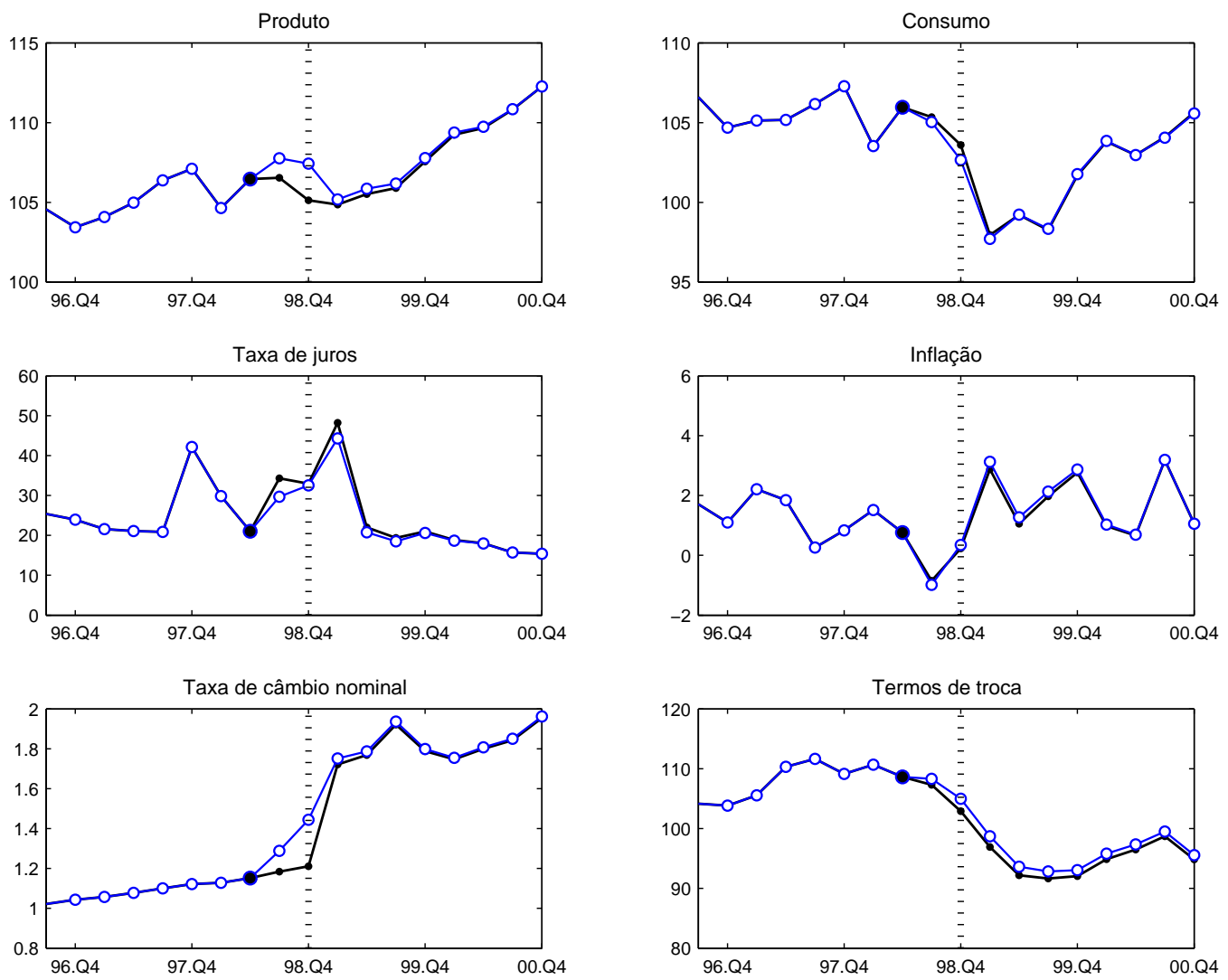
Figura D.19: Teste de quebra: Dados simulados
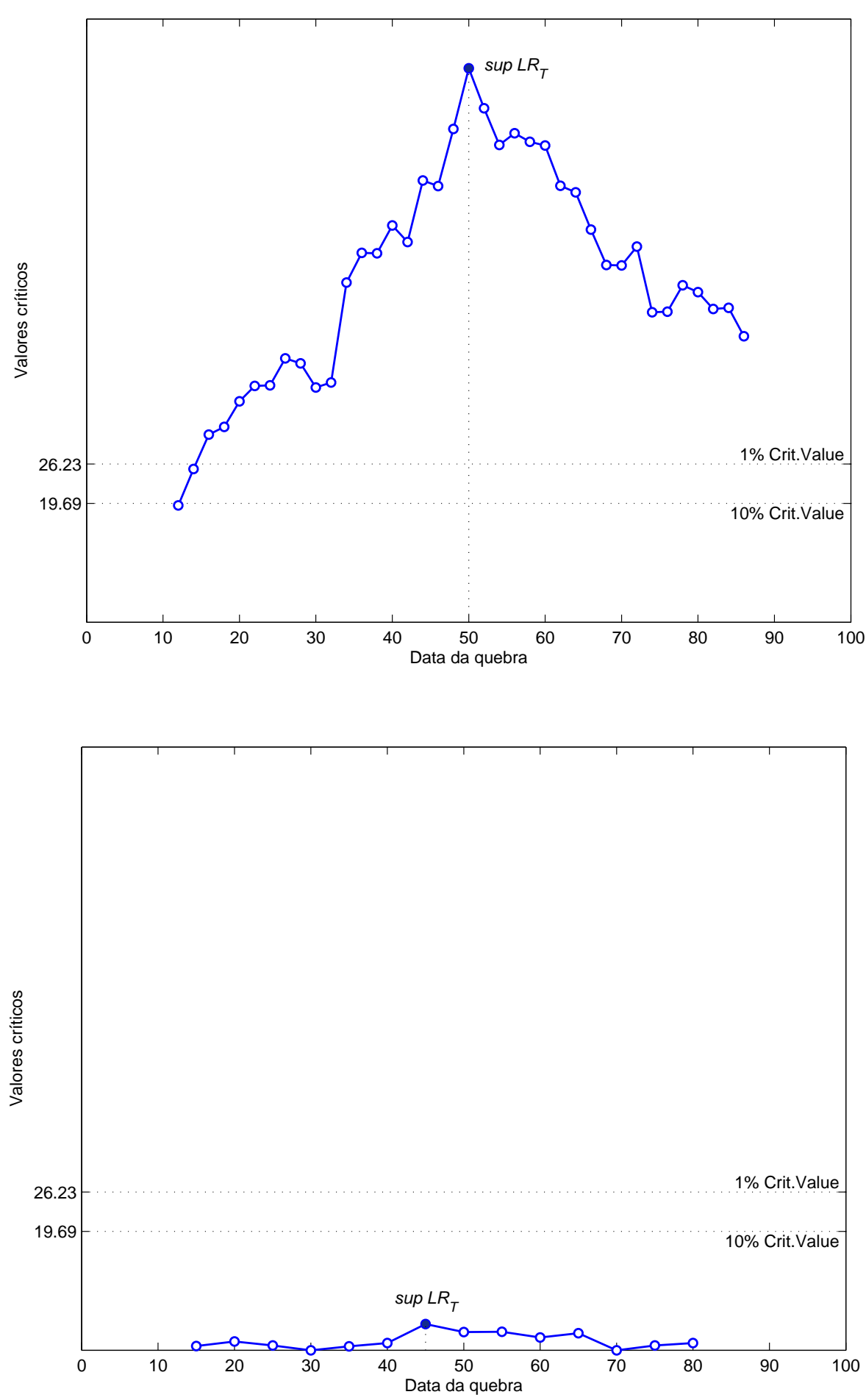
Figura D.20: Teste de quebra: Dados observados
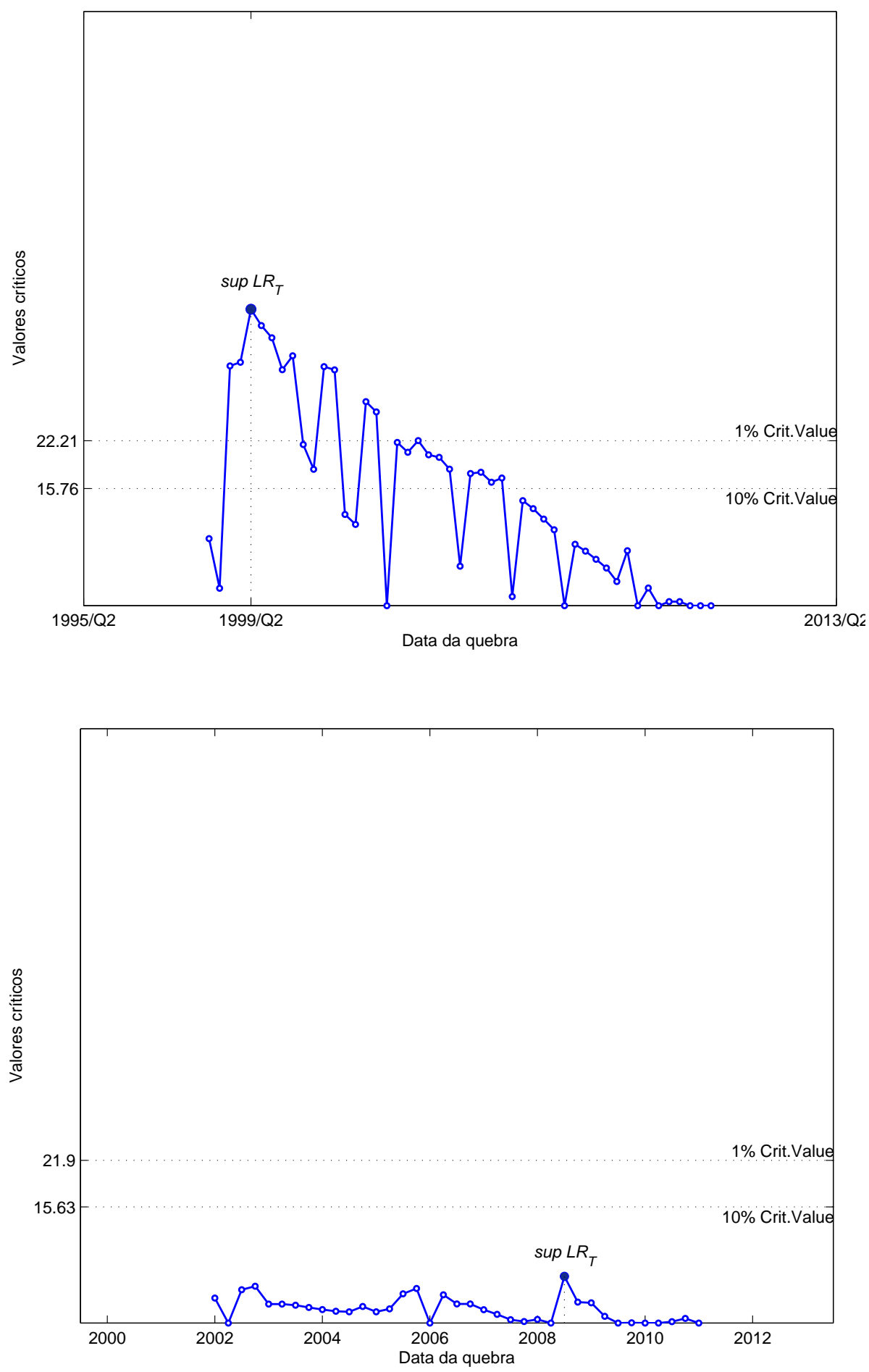
Figura D.21: Teste de quebra: Dados observados

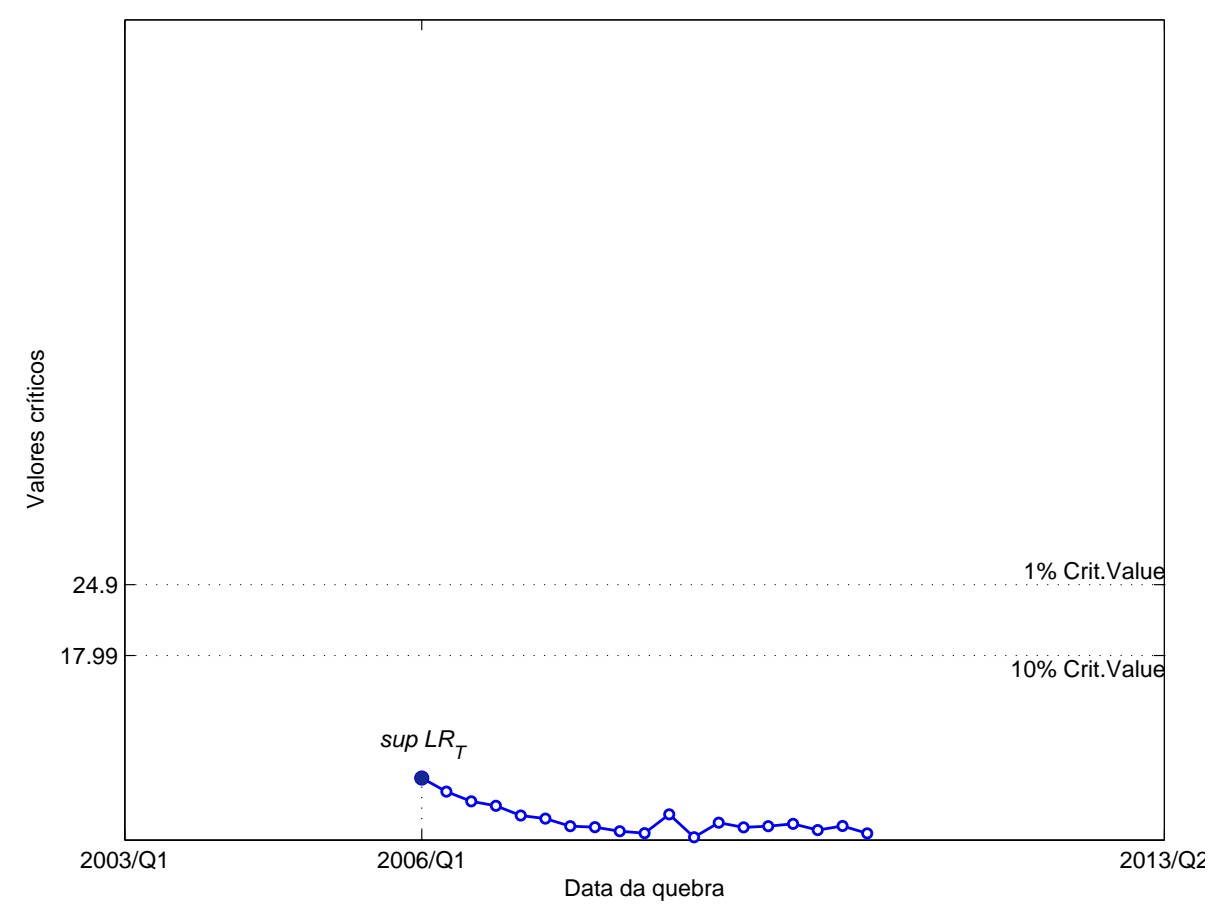

